University of Louisville

ThinkIR: The University of Louisville's Institutional Repository

$5-2021$

\title{
Chronic codeswitching: A phenomenological study examining Multiracial student sense of belonging in a predominantly White institution.
}

Nicholas Lamar Wright

University of Louisville

Follow this and additional works at: https://ir.library.louisville.edu/etd

Part of the Academic Advising Commons, African American Studies Commons, Bilingual, Multilingual, and Multicultural Education Commons, Educational Leadership Commons, Ethnic Studies Commons, Higher Education Administration Commons, Higher Education and Teaching Commons, and the Scholarship of Teaching and Learning Commons

\section{Recommended Citation}

Wright, Nicholas Lamar, "Chronic codeswitching: A phenomenological study examining Multiracial student sense of belonging in a predominantly White institution." (2021). Electronic Theses and Dissertations. Paper 3658.

https://doi.org/10.18297/etd/3658

This Doctoral Dissertation is brought to you for free and open access by ThinkIR: The University of Louisville's Institutional Repository. It has been accepted for inclusion in Electronic Theses and Dissertations by an authorized administrator of ThinkIR: The University of Louisville's Institutional Repository. This title appears here courtesy of the author, who has retained all other copyrights. For more information, please contact thinkir@louisville.edu. 


\title{
CHRONIC CODESWITCHING: A PHENOMENOLOGICAL STUDY EXAMINING MULTIRACIAL STUDENT SENSE OF BELONGING IN A PREDOMINATELY WHITE INSTITUTION
}

By

\author{
Nicholas Lamar Wright \\ B.S., University of Louisville, 2016 \\ M.Ed., University of Louisville, 2018
}

\begin{abstract}
A Dissertation
Submitted to the Faculty of the College of Education and Human Development of the University of Louisville in Partial Fulfillment of the Requirements for the Degree of
\end{abstract}

Doctor of Philosophy in Counseling and Personnel Services

\author{
Department of Counseling and Human Development \\ University of Louisville \\ Louisville, Kentucky
}

May 2021 

CHRONIC CODESWITCHING: A PHENOMENOLOGICAL STUDY EXAMINING MULTICULTURAL STUDENT SENSE OF BELONGING IN PREDOMINANTLY WHITE INSTITUTION

By

Nicholas Lamar Wright

B.S., University of Louisville, 2016

M.Ed., University of Louisville, 2018

A Dissertation Approved on

November 19, 2020

By the following Dissertation Committee

Dr. Susan Longerbeam, Dissertation Chair

Dr. Amy Hirschy, Committee member

Dr. Meera Alagaraja, Committee member

Dr. Ishwanzya Rivers, Committee member 


\section{DEDICATION}

I dedicate this dissertation to every multiracial student, especially those who did not have their racial demographic as an option growing up and was forced to select "other". Remember that you are more than an "other" and "other" does not define you. Always remember that regardless of how society may treat you, YOUR LIFE MATTERS. 


\section{ACKNOWLEDGEMENTS}

I would like to extend my most heartfelt gratitude to the people that have helped me along my journey. I could not have completed this dissertation without the love and support of the people I will acknowledge.

First, giving honor and glory to my Lord and Savior Jesus Christ. "Jesus looked at them and said to them, 'With man this is impossible, but with God all things are possible' (Matthew 19:26, NKJV). There was a time in my life, after my accident, I was told by doctors "not to return to college" and I was unsure if I could continue with my educational journey "BUT GOD” made a way.

I would like to extend gratitude to every multiracial participant in this study. This study would not have been possible if it was not for you all. Thank you for being vulnerable, transparent, and authentic with me regarding your experience as a multiracial individual.

I appreciate all the guidance and support my Dissertation Chair, Dr. Susan Longerbeam, has given me. Her careful assistance and encouragement allowed me to accomplish this dissertation and obtain my educational goals.

I would also like to thank members of the dissertation committee, Dr. Amy Hirschy, Dr. Meera Alagaraja, and Dr. Ishwanzya Rivers, who worked diligently with me on my dissertation. Their insight and feedback allowed me to be successful and continue to learn. Dr. Amy Hirschy, thank you for always challenging me to grow and become a better student. You challenged me in my writing specifically, which at times was extremely frustrating, but it was always incredibly beneficial. Dr. Meera Alagaraja, thank you for sharing your passion for research with me and sharing your experience as a marginalized individual in academia. Your knowledge of research ignited my passion for qualitative research and the experience you shared with me will allow me to overcome obstacles I will face in my career as a multiracial individual. Dr. Ishwanzya Rivers, thank you for being completely authentic with me at all times. Regardless of what time you came to campus, you were always completely REAL with me, which allowed me to become more authentic at this predominantly White institution.

I have been on this educational journey since preschool, for a total of 23 straight years. I appreciate everyone who has made an impact on my path and encouraged/challenged me to continue pursuing education. I have been at the University of Louisville for the past 8 years and I appreciate every student, staff, and faculty member that I was able to build a relationship with. You all assisted me on my journey and gave me purpose.

I feel the need to acknowledge my canine, HoneyBee, for always being by my side through this writing process. She has provided emotional support and has given me unimaginable companionship. My wife and I adopted her to give her a better life, but in reality, she is our blessing and has given us more than we could imagine. 
Some people are blessed with set of loving parents, I was blessed with two sets of loving parents. Thank you Lynus (Fly) Wright and Diane Wright for always being there for me since birth. You all have ALWAYS supported me. Thank you for the love you have given me and always assisting me in my development. Thank you, Steve Gribler and Victoria Gribler, for always treating me like family. You two have always supported me and treated me as a son, not just a Son-in-law.

Last, but not least, I would like to acknowledge my beautiful, loving, supportive wife that has been there for me every step of the way, especially during the coding process. Thank you for always being there for me and understanding. There were weeks on end that I would be writing sun up, to sun down, as if I was running out of time. Thank you for always being the genuine, loving person that you are and will continue to be.

There are other individuals that have assisted me in this journey towards obtaining my $\mathrm{Ph} . \mathrm{D}$. In this brief acknowledgement I am not able to acknowledge every person, but omission from this acknowledgement does not mean a lack of gratitude. 


\begin{abstract}
CHRONIC CODESWITCHING: A PHENOMENOLOGICAL STUDY EXAMINING MULTIRACIAL STUDENT SENSE OF BELONGING IN A PREDOMINATELY WHITE INSTITUTION
\end{abstract}

\author{
Nicholas Lamar Wright
}

November 19, 2020

Constantly feeling a lack of acceptance and getting the comment "You are too Black" or "You are too White" is a challenging, common occurrence for multiracial students, but especially those in predominantly White institutions. This is just one of the barriers that stand between multiracial students and forming a sense of belonging at a predominantly White institution. The majority of research examining sense of belonging focuses on either Black or White students, but neglect multiracial students and their experiences. This dissertation examines sense of belonging for multiracial (Black/White) students in a predominantly White institution, by interviewing 11 multiracial students at one predominantly White institution. Renn's (2004) Ecological Theory of Mixed-Race Identity Development and Maslow's (1954) Hierarchy of Needs are used as the theoretical framework for this study. Chronic codeswitching, multiracial bridge, multiracial students as pawns, and sense of belonging with close friends \& student organizations are emergent themes in this phenomenological qualitative study on multiracial students and their sense of belonging in a predominantly White institutions. 


\section{TABLE OF CONTENTS}

DEDICATION ................................................................

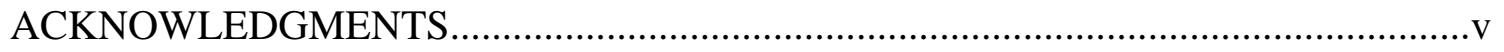

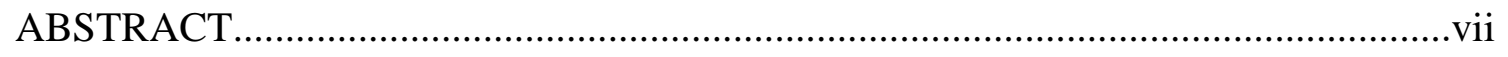

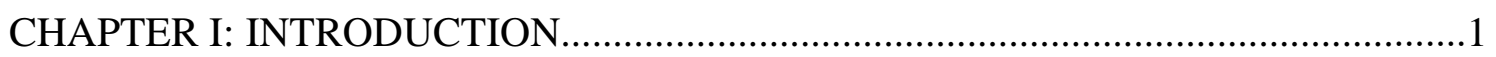

Defining Multiracial.................................................................................. 3

Problem Statement......................................................4

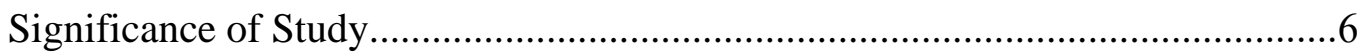

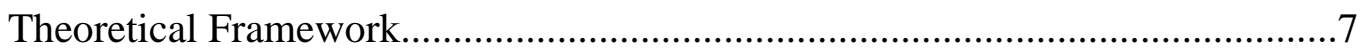

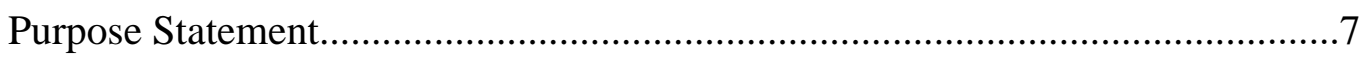

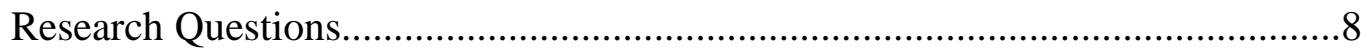

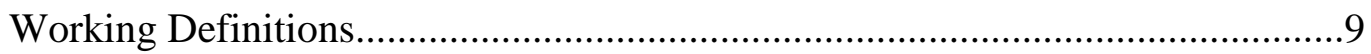

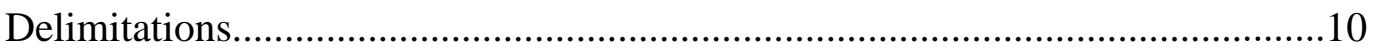

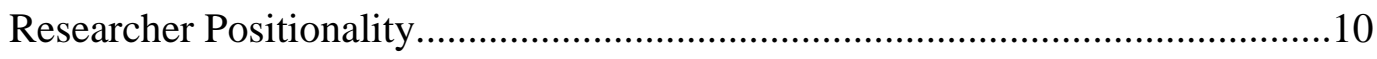

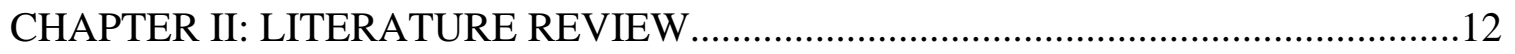

Theoretical Framework....................................................................... 12

Renn Ecological Theory of Mixed-Race Identity Development................12

Monoracial Identity......................................17 
Multiple Monoracial Identities

Multiracial Identity.

Extraracial Identity. .18

Situational Identity. 18

Maslow's Hierarchy of Needs.

Sense of Belonging in Higher Education. .22

Self-actualization in Higher Education .23

Multiracial Students

Slavery in the United States...........................................................25

Laws Targeting Multiracial Individuals.............................................26

Miscegenation...........................................26

Hypodescent (One Drop Rule).............................27

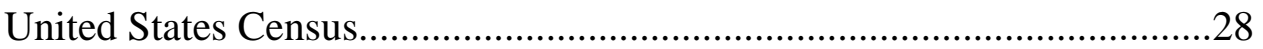

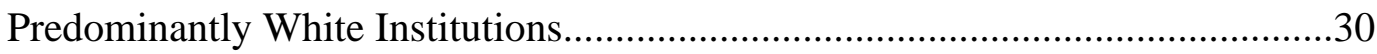

Marginalized Students in a Predominantly White Institution...................31

Microaggressions.......................................... 32

Coping with Discrimination.................................33

Multiracial Student Experience.................................34 
College Involvement......................................................40

Campus Resources...........................................................4

Multiracial Organizations and Cultural Centers...............42

Diversity Plans..................................................................43

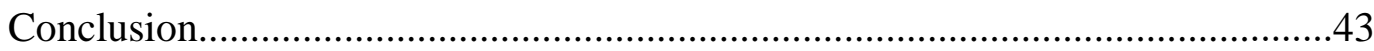

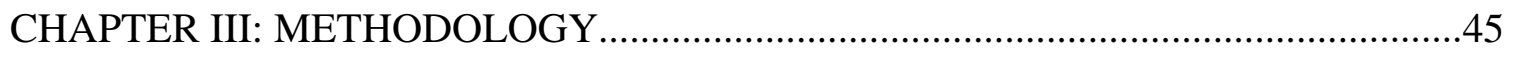

Qualitative Research.................................................46

Qualitative Approaches......................................................................46

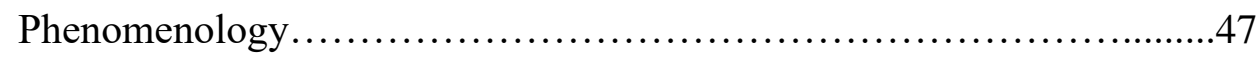

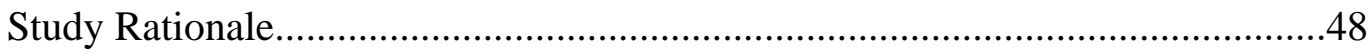

Research Questions...................................................49

Interpretive Framework and Philosophical Assumptions................................50

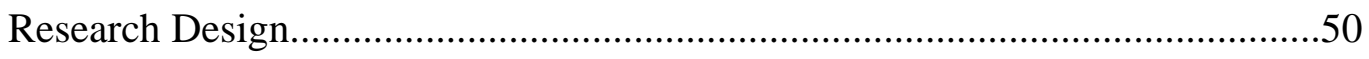

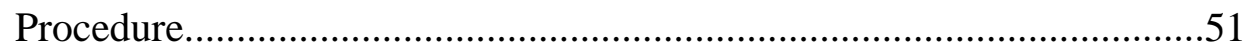

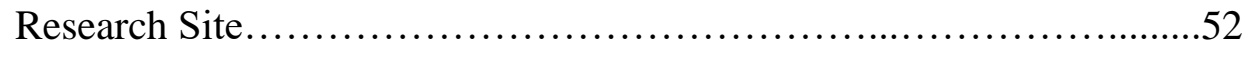




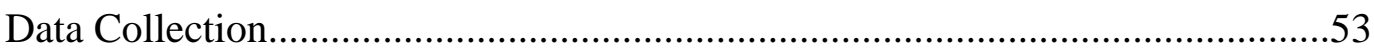

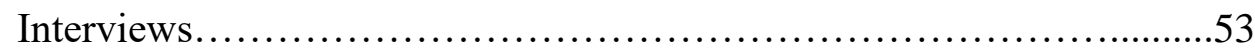

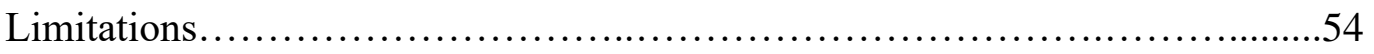

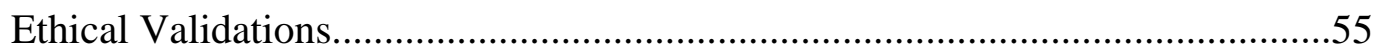

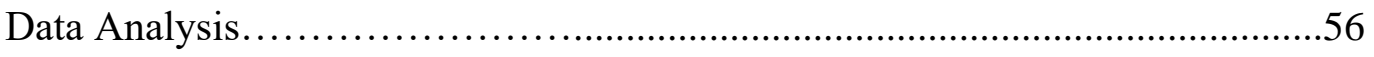

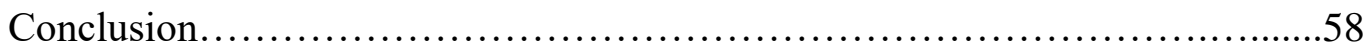

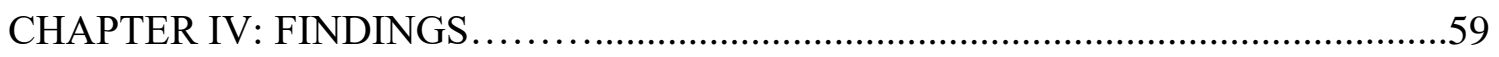

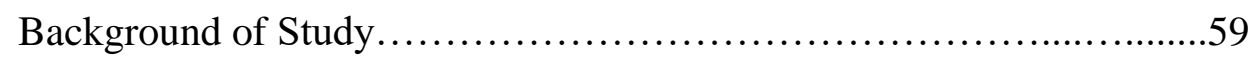

Theoretical Framework.........................................60

Participants...................................................... 60

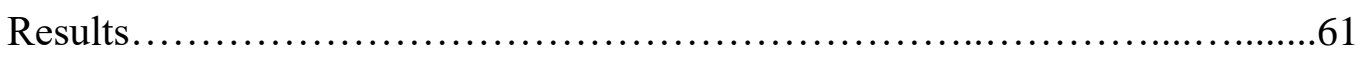

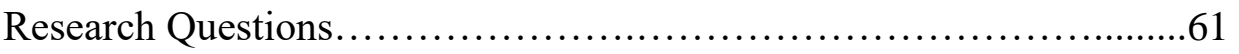

Central Research Question...................................62

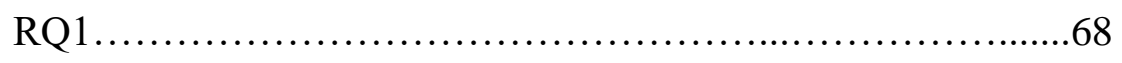

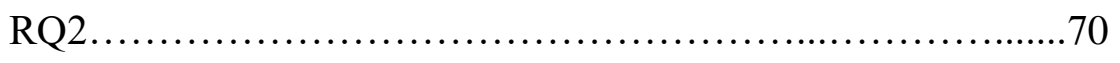

Comfortable............................................ 70

Uncomfortable............................................72 
Emergent Themes.............................................79

Chronic Codeswitching........................................79

Multiracial Bridge...........................................82

Multiracial Students Feel Like Pawns...........................83

Sense of Belonging w/ Close Friends \& Organizations.............85

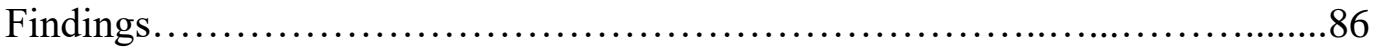

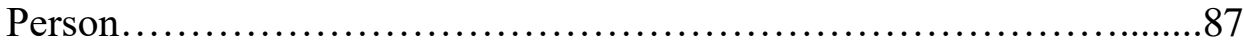

Process.......................................................88

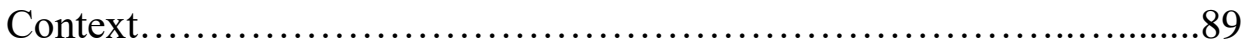

Microsystem.........................................89

Mesosystem..........................................90

Exosystem..........................................92

Macrosystem.............................................93

Time "Chronosystem"

Black Lives Matter (BLM) .............................94

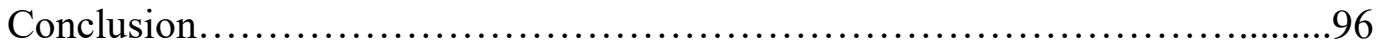

CHAPTER V: DISCUSSION ................................................ 98 
Summary of Study.

Implications for Practice.................................................. 99

Racial Diversity Education.........................................100

Racial Diversity Education-Employees......................101

Racial Diversity Education-Predominantly White Greek...........103

Multiracial Experience Courses.................................104

Multiracial Organizations........................................106

Recommendations for Future Research..................................107

Long-term Effects of Chronic Codeswitching........................108

Sense of Belonging for Multiracial Students Who Withdrew.............108

Additional Institution Types.....................................108

Various Multiracial Combinations.................................109

Conclusion...........................................................110

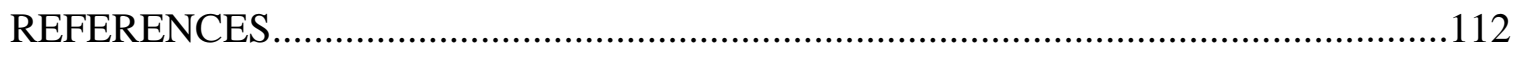

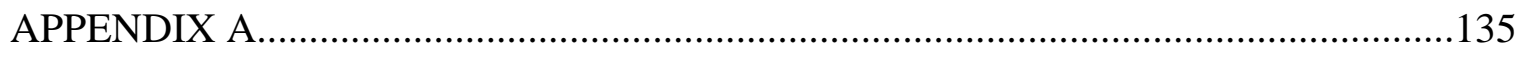

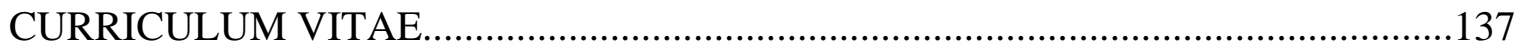




\section{CHAPTER I}

\section{INTRODUCTION}

Multiracial students are one of the fastest growing populations in the world and by the year 2050, 20\% of the population will identify as multiracial (Garrod et al., 2014; Jackson, 2010; Lee \& Bean, 2004; Shih \& Sanchez, 2009). As more emphasis is placed on higher education, as a high rate of return on investment to individual and society, college campuses will become occupied with the multiracial student population (Porter, 2002). With a higher number of multiracial students occupying college campuses, higher education staff and faculty must be prepared to work with multiracial individuals. Professionals in higher education spend time in student affairs preparation programs preparing to work with diverse populations, but more education is needed (Gayles \& Kelly, 2007). Education on diversity, equity, and inclusion is critical to best support the needs of multiracial students. Unfortunately, the majority of student affairs and higher education graduate preparation programs and professional trainings teach traditional approaches to teaching, advising, and program planning, based on research from White student populations, and neglect multiracial college students' unique needs and challenges (Stage \& Manning, 1992).

Multiracial students face distinct challenges, such as: rejection by own racial groups, interrogation by own racial groups, and assumptions about their racial identity by all racial groups (Kilson, 2001; Rockquemore \& Brunsma, 2002; Roth, 2005). Multiracial 
students encounter these issues all their lives, but especially when immersed in a new environment. Pursuing a baccalaureate degree is a sensitive time in students' lives, when foul treatment (microaggressions, isolation, exclusion) can mean the difference between persisting successfully and withdrawing from college (Solórzano et al., 2000).

Multiracial students' context influences their racial identity development (Harris \& Sim, 2002). Concerning multiracial individuals, Harris and Sim (2002) state "racial classifications can differ not only among nations and historical periods, but also in the day-to-day lives of individuals" (p. 615). Fluidity of race for multiracial students is practiced daily, depending on their interactions.

A student's environment has impact on their feeling of belongingness and development (Hoffman et al., 2003; Nora et al., 1996; Velásquez, 1999). Positive environments and communities can increase a feeling of belonging by providing social and academic support, while negative environments can hinder a feeling of belonging. Throughout their college experience, multiracial students must feel a sense of belonging to succeed on their educational journey. Sense of belonging is important for students, but especially for those of marginalized backgrounds such as multiracial students.

The topic of this study was multiracial student sense of belonging in a predominantly White institution (PWI). Although multiracial students are becoming a larger part of the college student population, only a few researchers have showed them attention (e.g., Ingram et al., 2014; King, 2008, 2011; Renn, 2000, 2004, 2008; Talbot, 2008). The central phenomenon in this study was sense of belonging that multiracial students feel in a predominantly White campus. This study dove deeper into the multiracial phenomenon by interviewing participants to gain information about their 
direct experiences and, unlike most multiracial college student research that focused on the broad multiracial category (Ingram et al., 2014; King, 2008, 2011; Renn, 2000, 2004, 2008; Talbot, 2008), focused specifically on multiracial students with one biological parent of African American descent (Black) and the other of European American descent (White) to understand their sense of belonging in a predominantly White institution. In this phenomenological study I interviewed eleven multiracial college students at one urban, mid-sized public research institution. The information I gained gave insight into sense of belonging multiracial students feel while enrolled in a predominantly White institution (PWI).

\section{Defining Multiracial}

The terms "biracial," "mixed," "mixed heritage," and "multiethnic" are just a few of the terms that have been used to describe people who identify as multiracial (King, 2011). Multiracial defines someone with biological parents of two or more different racial backgrounds. People who are multiracial do not always have a lighter skin complexion than People of Color, which is one of the reasons why they must self-identify with their multiracial identity for others to become aware (Campbell \& Eggerling-Boeck, 2006). Campbell and Eggerling-Boeck (2006) discuss that from an early age, multiracial individuals commonly feel forced to choose only one of their heritages they are made up of with which to racially identify. Multiracial individuals are constantly questioned about their ambiguous identities, due to not having all of their characteristics aligning with only one of the racial identities they hold. Multiracial people, but especially those of African American (Black) and European American (White) descent, experience both direct and indirect racism by hearing or overhearing people refer to them using the terms "Oreo," 
the "N" word, "Mixed-Breed," or "Mutt" (Jackson, 2007). Multiracial people encounter dilemmas when identifying their racial identity, such as in their home and family dynamics, physical environments, social encounters, and friendships (Brunsma, 2006). Examples of dilemmas for multiracial people are: "forced choice" in which they are pressured to choose only one of the races they are made up of to identify with (Standen, 1996), being around friends of only one of their races in search of legitimacy (Renn, 2000, 2004; Wallace, 2003), and constantly being forced to answer the infamous question "What are you?" (Kilson, 2001; Renn, 2004; Wallace, 2001, 2003). Kristen Renn (2000) found these dilemmas influence multiracial students to identify in one of five patterns: monoracial identity, multiple monoracial identities, multiracial identity, extraracial identity, and situational identity. Multiracial people can move through these identity patterns depending on their environmental influences (Renn, 2003). The pattern that multiracial people are in is their lens through which they navigate the world.

\section{Problem Statement}

This research focused on multiracial students' sense of belonging while attending a predominantly White institution. Ideally students feel a strong sense of belonging while enrolled in college, because belongingness is a basic human need (Maslow, 1954). Sense of belonging has impact and is a predictor of graduation and persistence rates, because sense of belonging impacts a student's self-value (Hausmann et al., 2007). Hausmann et al. (2007) researched the effects of sense of belonging on Black and White first-year students in a quantitative study and found "that sense of belonging is an important but often overlooked variable in studies of student persistence" (p. 835). Further analysis of 
research on multiracial students is needed to gauge the impact sense of belonging has on their success.

Evidence shows that sense of belonging has a direct impact on the intention to persist (Hausmann et al., 2007). Sense of belonging is a factor in persistence and students must persist to graduate. The most recent national 6-year graduation rates appear in Table 1. The race with the highest 6-year graduation rate is Asian, with $74 \%$, followed by White, with $64 \%$, followed by two or more races shortly behind with $57 \%$ (National Center for Education Statistics, 2018). Two or more races on the higher end of 6-year graduation rates piqued curiosity and supported reasoning for this study because there is research stating multiracial people experience social isolation, disapproval, lack of social recognition, and exclusion (Brown, 1995; Kerwin \& Ponterotto, 1995; Museus et al., 2016; Nakashima, 1996). 6-year graduation rate at 57\% could mean that the majority of multiracial people who selected two or more races were in the multiracial identity pattern and not in any other of the identity patterns that Renn (2004) discusses, but multiracial students' identity pattern was not recorded. Multiracial students in the multiracial identity pattern elect a "Multiracial" identity that comprises and values all of their racial backgrounds (Renn, 2004). Renn (2004) described the impact of peer influence on identity patterns and students that are in the multiracial identity pattern search and find a population of multiracial students to socialize and identify with. More research must be conducted in finding sense of belonging for multiracial students while in a predominantly White institution, specifically those with a Black/White multiracial identity,

Table 1. 


\begin{tabular}{|c|c|c|c|c|c|c|}
\hline \multicolumn{7}{|c|}{2018 6-Year Graduation Rate } \\
(first-time, full-time bachelor's degree-seeking students at 4-year postsecondary \\
\hline \\
\hline White & Black & Hispanic & Asian & Pacific & American & Two or \\
& & & Islander & Indian/Alaska & more \\
& & & & & Native & races \\
\hline $64 \%$ & $40 \%$ & $55 \%$ & $74 \%$ & $49 \%$ & $38 \%$ & $57 \%$ \\
\hline
\end{tabular}

Source: National Center for Education Statistics, 2018

\section{Significance of Study}

Multiracial students have different college experiences than their monoracial peers. At times, some multiracial students feel forced to identify with just one of the races they are made up of and feel "misperceived, misrepresented, miscategorized, and misunderstood" (Cortes, 2000, p. 10) by members of the college community. Multiracial identity is a process that develops throughout a multiracial person's life (Rockquemore \& Brunsma, 2002; Root, 1990, 2001). Context, "new people, new ideas, and new environments" (Root, 1990, p. 202), plays a role in multiracial identity development. Context having a large influence in multiracial students' identity development is why it is important for these students to have a sense of belonging at the predominantly White institution in which they are enrolled. By having a strong sense of belonging, multiracial students are more likely to persist and continue on towards graduation at their predominantly White institutions (Hausmann et al., 2007). Interviewing and listening to multiracial students gave insight to the complexities of their identity. The results prepare 
members of the campus community to work with multiracial students and build their sense of belonging (Kellogg \& Liddell, 2012).

\section{Theoretical Framework}

Renn Ecological Theory of Mixed-Race Identity Development (2004) and Maslow's Hierarchy of Needs (1954) were used as theoretical frameworks in this study. Renn Ecological Theory of Mixed-Race Identity Development (2004) focuses on ecological factors that influence multiracial student identity development and identity

patterns. The ecology portion of Renn's theory comes from Bronfenbrenner's (1993) model of human development that focuses on person, process, context, and time.

Maslow's Hierarchy of Needs (1954) is a motivational theory with five tierslower tiers needing satisfaction before higher ones. The needs from lowest to highest are physiological, safety, love and belongingness, esteem, and self-actualization. Every individual is on a journey towards fulfillment of one's potentialities, which is selfactualization. I discuss these theories further in Chapter 2.

\section{Purpose Statement}

Nationally, the college population is constantly increasing and by the year 2028 college enrollment is projected to increase to 17.0 million students (National Center for Education Statistics, 2020.). During the transition to college, many underrepresented students at predominantly White institutions, compared to their White peers, feel socially isolated, neglected, and alienated (Freeman, 2005; Harper, 2013; Jones et al., 2002). First-year multiracial students experience neglect due to: beginning a dynamic situation and losing their typical support systems, entering college without a strategy, and lacking 
preparation with the skills to work through the transition to college. The population of multiracial students is quickly growing and $20 \%$ of the population will identify as multiracial by 2050 (Garrod et al., 2014; Jackson, 2010; Lee \& Bean, 2004; Shih \& Sanchez, 2009). Multiracial students attending a predominantly White institution face even more challenges than their monoracial peers due to the additional barriers between multiracial students and success. Many challenges come from a sense of discrimination, while support comes from a sense of belonging. Sense of belonging must be investigated further to find what approaches best help multiracial students while in a predominantly White institution. The purpose of this qualitative study was to understand sense of belonging for multiracial students in a predominantly White institution.

\section{Research Questions}

Answers to the research question allowed me to gain information regarding multiracial students' sense of belonging in a predominantly White institution. My central research question was: How do multiracial students at a predominantly White institution describe their sense of belonging? Each multiracial student views their identities with a distinct lens. Multiracial students vary significantly. Some of these students identify as multiracial, while others hold other identities more salient and identify as monoracial or refuse to identify racially altogether (Renn, 2004).

Sub-questions followed the central research question to gain a deeper understanding of multiracial students and their experiences in a predominantly White institution. The following research questions provide further inquiry: In what ways do multiracial college students feel that they can be their completely authentic self while enrolled at a predominantly White institution? How do multiracial students feel 
comfortable or uncomfortable at a predominantly White institution? How salient is

multiracial students' race while at a predominantly White institution?

\section{Working Definitions}

Throughout this dissertation the following are working definitions to provide a better understanding.

- Authenticity- Involves being genuine, self-aware, and defined by one's self, rather than the expectations others have of one (Abes et al., 2019).

- Chronic Codeswitching-Constantly needing to adjust personality or appearance based on the racial identity of surrounding individuals.

- Multiracial- Although multiracial is a term used for several different backgrounds, for the purpose of this research the term is defined as concerning or containing members of two racial groups, African American (Black) and European American (White).

- Predominantly White Institution (PWI)- Higher education institutions in which European American (White) student enrollment makes up the majority of the student population (Brown II \& Dancy II, 2010).

- Sense of Belonging- "refers to students' perceived social support on campus, a feeling or sensation of connectedness, and the experience of mattering or feeling cared about, accepted, respected, valued by, and important to the campus community or others on campus such as faculty, staff, and peers" (Strayhorn, 2012, p. 4). 


\section{Delimitations}

In this study, I proactively set boundaries around my research for precision and the gaining of information pertaining to the specific population I am researching. There are a multitude of racial combinations in the world with which multiracial college students may identify. I examined the Black/White multiracial identity, when one biological parent is of African American (Black) descent and the other is of European American (White) descent. On the 2010 United States Census, there are 57 racial combinations and the most common combination (20.4\%) is Black/White (Saulny, 2011). Because the Black/White multiracial identity is the most common combination, it was important to get a better understanding of sense of belonging these students feel in a predominantly White institution.

\section{Researcher Positionality}

My researcher positionality informs this research. I am a multiracial firstgeneration college student who graduated from a predominantly White institution. Because of my past, I am aware of the challenges and discrimination that multiracial students encounter, specifically those with a Black/White multiracial combination, like myself. I faced challenges throughout life, but they were heightened when enrolled at the predominantly White institution. An example of a challenge is when I attempted to participate in student involvement and join an organization on campus. My first year at the predominantly White institution, I attempted to join Greek life. At first, I went to the organizations that a majority of my friends were in. These were the historically White fraternities. When attending social gatherings, my friends who were White were welcomed in, but I got stopped at the door and was automatically interrogated. These 
older, large, White members of the organizations asked me questions such as "what do you plan on doing here?", "You aren't planning any trouble are you?", and "If something goes wrong, you know you are easy to find right?”. Them treating me as if I was a problem discouraged me from joining any fraternal historically White organization. This was one of my first major experiences being a multiracial student in a predominantly White institution and I will always remember this challenge.

The purpose of this research was to understand sense of belonging that multiracial students have while in a predominantly White institution. Multiracial students possess diverse experiences and face challenges that should be better understood. In this study, I put aside personal views through the process of bracketing and gather participants' experiences so they could be better understood, to help faculty and staff support multiracial students and their success at predominantly White institutions.

In the literature review, Chapter 2, I discuss the current knowledge pertaining to multiracial students, the theoretical framework, and factors impacting multiracial students and their sense of belonging at a predominantly White institution. In Chapter 3, I share details about how the research was conducted. I discuss: methodology, research design, data collection, ethical considerations, limitations, and data analysis. In Chapter 4, I share the findings of this study by giving answers to the research questions and discussing the emergent themes. In Chapter 5, I give the implications for practice and recommendations for future research. 


\section{CHAPTER 2}

\section{LITERATURE REVIEW}

To understand the importance of my proposed research on multiracial students and their sense of belonging at a predominantly White institution, I reviewed the existing literature. There is limited literature on multiracial student sense of belonging at PWIs, so I conducted a complex literature review to not only access the current state of knowledge, but argue how this literature leads to the problem and the reasoning for this research (Machi \& McEvoy, 2016). I have broken the literature review into three concepts: theoretical framework, multiracial students, and predominantly White institutions. These topics address research questions by giving background knowledge of the multiracial student population and their experiences. The topics connected broaden the understanding of multiracial students and their sense of belonging in a predominantly White institution.

\section{Theoretical Framework}

\section{Renn Ecological Theory of Mixed-Race Identity Development}

Dr. Kristen Renn (2004) developed the Ecological Theory of Mixed-Race Identity Development. In this modernist society we currently live in, race is considered a "master status" because it overrides judgement and cannot be ignored, due to race being a physical characteristic in most people (Stephan, 1992, p. 51). Race is given much 
importance throughout U.S. society and higher education, but research into multiracial students was limited at the time of Renn's research. Dominant monoracial minority identity development models had been created by 1995 (Atkinson et al., 1979; Cross, 1995; Helms, 1995), but the only two models for multiracial student development were from Poston (1990) and Root (1990). Both of these models examined multiracial identity development using the early stages of minority identity development. Poston's (1990) model was missing the possibility of multiracial students having multiple healthy identities. Root (1990) claimed that multiracial students of African American (Black) and European American (White) race could not fully reject their White mainstream culture and completely immerse themselves in their African American culture. Both Poston (1990) and Root (1990) neglected to show the influence societal racism had on the identity development of multiracial individuals.

Renn's (2004) Ecological Theory of Mixed-Race Identity Development examines multiracial identity development through an ecological lens. To decide which ecological factors to study, Renn used Bronfenbrenner's Person, Process, Context, and Time (PPCT) model (Bronfenbrenner, 1993). The component of person described the multiracial individuals' heritage, physical features, and cultural background (Renn, 2004). Process is complex, ongoing reciprocal interactions involving the person and other people in society (Renn, 2004). Context is the settings that impact a multiracial person's identity development. Time or "chronosystem" relates to elements the individual usually cannot control. Time is historical, such as politicians elected, or personal, such as the death of a family member or physiological changes (Bronfenbrenner, 1993). The four systems that 
make up context are the microsystem, mesosystem, exosystem, and macrosystem (Bronfenbrenner, 1993) described next.

The microsystem is the setting closest to the individual impacted. In a higher education setting, microsystem means residential and social settings (Renn, 2004). Microsystem is not just the physical setting, but also the interactions with the people there (Bronfenbrenner, 1993). Microsystem includes the relationships and the impact these interactions have on the person and that the person has on those relationships. Bronfenbrenner (1993) describes these relationships as bi-directional influences. The next level defined by Bronfenbrenner (1993) and Renn (2004) is the mesosystem. Mesosystem occurs when microsystems interact with one another. On a college campus, an example of mesosystem is when academics impact social life or vice versa. The exosystem is the next level of context. Exosystem is described as two or more settings, with one involving the person and the other not involving the person, interacting and indirectly impacting the individual (Bronfenbrenner, 1993). An example of exosystem is when faculty committees engage with state and federal agencies to create policies that impact the student. These policies could be fueled by the political climate. New policies on "Free Speech" is an example of a policy fueled by political climate, that reserves space for racist, sexist, and homophobic speakers on college campuses to interact with students (AASCU, 2020). Macrosystem is the last setting in the context and this describes cultural milieu, laws, societal beliefs, and attitudes shared throughout society (Thomas, 1992). Examples of how the macrosystem impacts students is through social forces or cultural expectations. For example, attitudes shared throughout society are that Black individuals on a college campus are their due to athletics or affirmative action, which reinforces White 
entitlement and the rejection of Black intellect (Charles et al., 2009). Another example is if a belief in higher education is to focus on diversity and inclusion, institutions would have more resources for cultural centers for marginalized students. Beliefs, in turn, impact the students because they are or are not getting resources they would benefit from that would help them towards graduation. Viewing multiracial identity development using Bronfenbrenner's (1993) Person, Process, Context, Time (PPCT) model allows for a more holistic view of the identity development for these students.

The most impactful factors in identity development were the person's physical appearance, cultural knowledge, and peer knowledge (Renn, 2004). Physical appearance describes a person's physical features such as complexion, hair, nose, and eye color,. Societal assumptions are connected to physical appearance and can alter the way people treat multiracial individuals. Mistreatment influences the way a multiracial individual identifies because they are constantly asked the question "What [race] are you?" (Kilson, 2001; Renn, 2004; Wallace, 2001, 2013). Answering this repetitive question is taxing on a person. How they navigate the campus is also guided by their physical appearance. Their physical appearance can lead to them becoming involved in some organizations and avoiding others. Having a racial identity that is not easily recognizable by others impacts how a person navigates their environment and forces the person to negotiate their own racial identity (Root, 1990).

Cultural knowledge, or the lack of it, is another factor in racial identity development. Specifically, cultural knowledge refers to the racial identities that make up a person. Cultural knowledge is typically passed down from family or community members. This factor is important because it gives evidence to authenticity and 
legitimacy (Renn, 2000, 2004; Wallace, 2003). Renn (2004) stated that some students reported that speaking their native language, listening to certain music, or participating in events gives people somewhat of a "passport" and more access to a community of color. A person's physical appearance and cultural knowledge have a large role in multiracial student's identity development, but the factors in identity are not just internal.

Peer culture in college is a critical factor in multiracial students' identity development. Challenges and supports are huge impacts in determining how a multiracial student identifies racially. Major challenges that impact identity development amongst multiracial students are racism and discrimination (Renn, 2000). Racism and discrimination can come from both White and Black monoracial peers. Resistance by peers can make it difficult to feel comfortable and accepted. Support from peers increases confidence and comfort. Peer support can come from other multiracial students and student involvement activities (Renn, 2000, 2004; Wallace, 2003). Racial identity is strongly influenced by societal and historical context (Wijeyesinghe, 2001).

These ecological factors noted above were located in Kristen Renn's (2004) research using a grounded theory study involving fifty-six students from six different institutions in the eastern and midwestern United States in 2000 and 2004. In multiracial students, Renn (2004) found five patterns of identity from analyzing data collected through written responses, observations, focus groups, and archival sources. In the five identity patterns, some multiracial students chose to identify with one race, while others chose to identify with both, changed the race they identify with, or chose to not identify with a race altogether (Renn, 2004). These stages are non-linear and can be fluid (Renn, 2004). No pattern is deemed more developed than the other. 


\section{Monoracial Identity}

Some multiracial students identify with only one of the races of their racial background (Renn, 2004). This is known as the monoracial identity pattern. Typically,

multiracial individuals who are in monoracial identity pattern identify with the race with which they have more physical characteristics. By identifying thus, the student removes barriers such as interrogation about their race, and thus they are challenged less on how they identify compared to their monoracial peers (Brackett et al., 2006). Renn (2004) found that forty-eight percent $(48 \%)$ of people in her study identified with a monoracial identity pattern.

\section{Multiple Monoracial Identities}

Multiracial students sometimes hold multiple monoracial identities and will switch amongst them because they have cultural knowledge of both identities (Renn, 2004). Monoracial identity will change depending on the context. Many times, multiracial students choose to switch identities because White and Black social groups are often intolerant and discriminate against multiracial groups. The multiple monoracial identity pattern is similar to Root's (1990) second resolution of identifying with both racial groups depending on societal support. Renn (2004) found that forty-eight percent (48\%) of participants identified with multiple monoracial identities pattern.

\section{Multiracial Identity}

Some multiracial students choose to identify with the "Multiracial Group" (Renn, 2008). Multiracial identity means that the multiracial student does not identify with any one racial group, but with the multiracial category. Individuals in this pattern do not pick 
one isolated race they are comprised of but identify with a term that represents their background. This term could be multiracial, biracial, or mixed. (Renn, 2004). Over eighty-nine percent (89\%) of participants in Renn's (2004) study aligned with multiracial identity pattern.

\section{Extraracial Identity}

Certain multiracial students resist race in society and choose not to identify with a race, which is known as extraracial identity (Renn, 2008). Multiracial individuals in this pattern completely opt out of answering any racial classification. This is a form of resistance for multiracial students that consider race and racial categories “... socially constructed by the dominant, monoracial, White majority" (Renn, 2008, p.17). Twentyfive percent (25\%) of participants in Renn's (2004) study identified with extraracial identity pattern.

\section{Situational Identity}

The last pattern of situational identity means that individuals fluidly change which race they identify with based on the context of their situations (Renn, 2008). Situational identity pattern shows that multiracial identity is fluid. Racist environments can alter the frequency that a multiracial person switches race. People who are forced to switch racial identification frequently due to outside pressures have more stress and frustration, leading to worse mental health (Sanchez et al., 2009). Sixty-one percent $(61 \%)$ of participants in Renn's (2004) study identified in situational identity pattern.

These five categories total more than one-hundred percent (100\%) due to the fluidity in identity patterns for multiracial students and those in the extraracial pattern 
selecting more than one (Renn, 2008). Peer culture influences how multiracial students choose to identify and contributes to the pattern they are in. A weakness of Renn's (2004) model is that it only captured a snapshot of the pattern students were identifying in at the time (Renn, 2003). In this theory Renn (2000) discussed the importance of a space for multiracial students, "a group of like-others with whom to affiliate" (p. 415). Renn (2004) clearly shows how a multiracial student's environment impacts their development.

\section{Maslow's Hierarchy of Needs}

Abraham Maslow (1954), a behavioral scientist, had the desire to find what motivated people. He depicted a pyramid titled Hierarchy of Needs in Motivation and Personality (Maslow, 1954). The most basic needs are listed at the bottom and are prepotent: in order to progress up to next tier, the lower need must be met. Maslow (1943) initially said that it was mandatory to meet the lower needs before progressing, but clarified later, stating that it was not absolute and that he may have given "the false impression that a need must be satisfied one-hundred percent $(100 \%)$ before the next need emerges" (Maslow, 1987, p. 69). The urge to feel the need will grow stronger as time goes on and the need is unmet. Every individual has the desire to reach the highest level in the hierarchy. Unfortunately, progress will be disrupted throughout life that will force people to go down in levels to satisfy lower needs. People are unique and will not progress through the Hierarchy of Needs at the same rate. The needs from lowest to highest are: Physiological, Safety, Love and Belongingness, Esteem, and SelfActualization (1954).

The most basic, survival needs, are labeled physiological (Maslow, 1954). It is not possible for the human body to function if these needs go unmet. These needs are: air, 
water, food, shelter, and sleep (Maslow, 1954). Physiological needs are considered instinctive because the desire to do anything else is challenging if these go unmet. Every other need is secondary to the primary physiological need.

Safety is the second most basic need in Maslow's (1954) Hierarchy. When an individual's basic physiological needs are met, they began to seek safety and security in their personal, emotional, and financial realms. Protection is something that can give them freedom to comfortably pursue other elements of life and not have fear. Safety could be by means of shelter, employment, stability, and health.

The third tier on Maslow's (1954) Hierarchy of Needs is love and belongingness. This tier describes the feeling of belongingness and acceptance. Maslow (1954), when describing the love and belongingness need, stated that a person "will hunger for affectionate relations with people in general, namely, for a place in his group or family, and he will strive with great intensity to achieve this goal" (p. 43). Social groups, regardless how large or small these are, are ways for a person to feel a sense of belonging. These social groups provide people the opportunity to overcome "alienation, aloneness, strangeness, and loneliness" (Maslow, 1954, p. 44). Maslow (1954) mentions that people need to not only love, but need to be loved as well. Examples of ways people achieve belongingness is through friendships, intimacy, and family. This is the third tier in Maslow's (1954) Hierarchy of Needs, but the sense of belonging need at times can overcome more basic needs depending on societal pressures.

Once the previous tier of love and belongingness has been met, an individual will find importance in their esteem needs (Maslow, 1954). The esteem need builds from love and belongingness because when one feels accepted, positive feelings such as self-esteem 
and self-worth will follow. These feelings give the individual pride in themselves and their accomplishments. Maslow (1954) described two different types of esteem needs, esteem in self and reputation. Self-esteem is dignity, confidence, and achievement. Esteem in reputation means that a person is respected by others around them, receives recognition, prestige, and attention (Maslow, 1954). Esteem need connects with and is impacted by the lower three needs.

The lower, more basic four needs are known as deficiency needs, meaning that a person's mental health will be impacted if these are not met (Maslow, 1954). Selfactualization is the highest tier in Maslow's Hierarchy of Needs (1954) and is described as fully functioning and living a more enriched life (1962). From the five tiers in this model, self-actualization is the level that is known as a growth or being need (Maslow, 1954). Some characteristics of self-actualized people, as described by Maslow (1962), are: accepting of self, highly creative, concerned with the welfare of humanity, and having strong moral/ethical standards. Everyone has this goal to fulfill lower tiers and reach the top tier, but unfortunately disruptions and failure occur in life that delay advancement.

Maslow (1954) developed these tiers of motivational needs to explain what people are motivated by.

It is quite true that man lives by bread alone - when there is no bread. But what happens to man's desires when there is plenty of bread and when his belly is chronically filled? At once other (and "higher") needs emerge and these, rather than physiological hungers, dominate the organism. And when these in turn are satisfied, again new (and still "higher") needs emerge and so on. This is what we mean by saying that the basic human needs are organized into a hierarchy of relative prepotency (Maslow, 1943, p. 375). 
This quote shows how the basic needs are most important and must be met, but after they are met, individuals desire more. Most behavior is impacted by more than one of the tiers (Maslow, 1987). Maslow's Hierarchy of Needs (1954) is well known and is used across disciplines. For my study, I utilized a portion of this theory, specifically the third tier of love and belongingness and the fifth tier of self-actualization, as they relate to higher education.

\section{Sense of Belonging in Higher Education}

Sense of belonging is a sense of mattering and acceptance, which is related to academic achievement (Strayhorn, 2012). Belonging is a human need that all individuals have. Love and belongingness is the third tier in Maslow's Hierarchy of Needs, right after food and shelter (Maslow, 1954). It is important for everyone to feel a sense of love and belongingness to succeed. I argue that by having belongingness, the person has love. Students can feel a sense of belonging in a dyad, clique, or group, which is why colleges encourage involvement.

Sense of belonging relates to college students' perceived social support on campus, sensation of connectedness, and how they are valued by the campus community (Strayhorn, 2012). Positive interactions contribute to a sense of belonging, but rejection inhibits a sense of belonging. Students of Color historically have reported a lower sense of belonging than their White counterparts in advanced degrees (Winkle-Wagner et al., 2010) and in predominantly White institutions, due to a lack of "safe spaces" on campus (Strayhorn, 2012, p. 82). Multiracial students feel a lower sense of belonging due to not feeling accepted in the general campus population, or in a specific group. Lack of a sense of belonging can lead to lower academic performance, anxiety, and depression. 
If a person feels a sense of belonging they are more likely to experience higher academic outcomes and positive adjustments (Van Ryzin et al., 2009) but, if the sense of belonging need goes unmet, in severe cases, can lead to suicidal ideation (Baumeister \& Leary, 1995). Analyzing higher education through the lens with Maslow's Hierarchy of Needs (1954) allowed for factors that hinder or support belongingness for multiracial students at predominantly White institutions. Students' sense of belongingness has benefits to their academic success at a college institution and belongingness must be met to achieve the top tier of self-actualization.

\section{Self-actualization in Higher Education}

"The self-actualizing person is in the process of maximizing his or her full potential" (Jones \& Crandall, 1986, p. 63). Self-actualization has been defined in multiple ways, but this quote by Jones \& Crandall (1986) is a core definition. Acceptance, freedom of expression, and reaching personal capacity are all characteristics of the tenet of self-actualization (Maslow, 1962). A person who has reached self-actualization, the highest level in Maslow's Hierarchy of Needs (1954), navigates by the enjoyment in growth and not by fear. Maslow (1962) mentions that the ultimate goal of education should be self-actualization.

Davidson, Bromfield, and Beck (2007), conducted a quantitative study involving 137 men and 311 women, regarding self-actualization and college students' adjustment. The hypothesis of self-actualization is positively associated with academic efficacy and creative expression, and it is negatively associated with the mistrust of professors. Mistrust of instructors was defined as "negative perception of instructors as people who deliberately impose unreasonable requirements on students and enjoy their distress" 
(Davidson et al., 2007, p. 605). Students with high self-actualization scored high in academic efficacy and creative expression, and low in mistrust of instructors (2007). Davidson et al (2007) demonstrated the academic and personal benefits of reaching selfactualization, but also showed the importance of a belonging and trusting academic environment.

In order for the achievement of the highest tenet of Maslow's Hierarchy of Needs (1954), self-actualization, institutions assist students with their development. A small private liberal arts college in the Northeast made actions towards all students achieving self-actualization by providing People of Color, White People, and multiracial identity dialogues (Ford \& Malaney, 2012). Inter-/Intragroup dialogue created at Skidmore College was created to combat historical exclusion and promote belongingness of multiracial students and Students of Color within the predominantly White institution (Ford \& Malaney, 2012). Thirty-one Students of Color were involved in these dialogues, with seven identifying as multiracial. A multiracial student in Ford and Malaney (2012) study mentioned that as a result of becoming involved in the dialogues, they feel that they were one step closer towards self-actualization. In higher education we should want all students to achieve belongingness and self-actualization, specifically multiracial students.

\section{Multiracial Students}

The United States of America has a narrative of anti-Blackness. In order to accurately depict the topic of multiracial students, I must first start with the topic of slavery in the United States. Race is "ascribed, symbolically mediated as status or stigma, socially constructed, and consciously manipulated or performed" (Willie, 2003, p. 9). It is important that race and racial hierarchy are analyzed further in order to better 
understand multiracial students. After a brief review of slavery, I will analyze laws targeting multiracial individuals. These will not only be legal laws, but social laws. Lastly, I will analyze the United States Census and how it has changed throughout time.

\section{Slavery in the United States}

Race was created to form hierarchy, with White people at the top (Haney Lopez, 1996; Omi \& Winant, 1986; Waters, 1990). In fact, prior to the sixteenth century, the Oxford English Dictionary described the term Black as "Indicating disgrace, censure, liability to punishment, etc.” (Jordan, 1974, p. 6). Black was described in this negative way and White implied opposition. Negative views continued and partly resulted in the enslavement of Black people in what is now the United States from 1619 to 1865 (Bales, 2007).

The enslavement of African people is a tragic time in history that must not be forgotten. Allen Carden (2014) writes “The American past has no darker stain, no more glaring hypocrisy, no greater heart-rending challenge than the story of generations of men, women, and children trapped in a demeaning and brutal system of racially based slavery" (p. ix). 1619 to 1865 was a horrendous time in history for People of Color. Slavery in the United States was a product of U.S. law and was enforced throughout the courts (Alpert, 1970). This was a racial law that existed throughout the United States of America.

"The land of the free where the blacks enslaved, three-fifths of a man I believe's the phrase" (Mill, Jay-Z, \& Ross, 2018). Jay-Z sung these lyrics in 2018 and they refer to the lyrics of Francis Scott Key in the Star-Spangled Banner (1814). The lyrics of the song 
by Francis Scott Key (1814) continue "No refuge could save the hireling and slave from the terror of flight, or the gloom of the grave." The United States National Anthem highlights the maltreatment of slaves, by glorifying White people and reemphasizing oppression. The constitution is another national document in the United States that has a history of oppression, and shows that Black people were not considered as part of the future. In the United States constitution, the bolded words "All Men Are Created Equal" appear, yet there was slavery, which was evidence that everyone did not feel these words were true (Maier, 1999). Conflicting information between the constitution and the events that were occurring highlighted the idea that White people viewed Black people and People of Color as lesser than them. In fact, many people still to this day align with the 1861 Texas Declaration of Secession that states "We hold as undeniable truths that the governments of the various states, and the confederacy [the United States] itself, were established exclusively by the White race, for themselves, and their posterity." (Texas. Convention, 1861, p. 1).

\section{Laws Targeting Multiracial Individuals}

\section{Miscegenation}

The first Black captives were forced into Virginia in 1619 and quickly after, the anti-miscegenation statute was created in 1661 (Shah \& Adolphe, 2019). Antimiscegenation statute made marriage between White and Black races prohibited and unlawful. The miscegenation statute ignited and conveyed the conflict White people had with multiracial individuals. The idea of interracial relationships and the violent conflict continued in 1955 when a Black fourteen-year-old named Emmett Till was viciously murdered by White males after he was accused of whistling at a White woman 
(Whitfield, 1991). The pure thought of a Black man interacting with a White woman ignited enough rage to get him brutally murdered. The accusations the White woman made that day she later admitted were false, but the oppression against Black people and the opposition to interracial marriage continued (Pérez-Peña, 2017).

Miscegenation, the law founded in racism, was against interracial marriage, was pure discrimination, and was actively enforced for over three hundred years until the 1967 supreme court case of Loving v. Virginia (Lombardo, 1988). Overturning miscegenation law was an impactful move towards equal rights due to the foul acts supporting the law. The first act in support of anti-miscegenation was the Racial Integrity Act of 1924 which stated "racial mixing was scientifically unsound and would pollute America with mixed-blood offspring" (1988 p. 423). Support for the miscegenation law clearly displays White supremacy and the discrimination of Black people. Propaganda at the time boldly had the goal of preserving the racially pure White civilization in America (1988). Powell and Plecker were forces in support of keeping miscegenation and although they are gone, their bigotry, racism, and oppression continue (Feagin, 2013).

\section{Hypodescent (One Drop Rule)}

The racial identity of multiracial people in America has been limited due to the one-drop rule, which automatically categorized anyone with African descent as Black (Roth, 2005). The one drop rule required for anyone that visually had any trace of African ancestry be considered Black. Hypodescent had legal status during the Jim Crow era, and although does not anymore, is still used to discriminate against people of mixed race (Hollinger, 2005). Hypodescent was a legal notion in Virginia (1662) that expressed how to treat mixed-race people (Hickman, 1997). People of African American ethnicity 
have origins of three different continents: Africa, North America, and South America. African American people can look completely different, but the one drop rule categorized them altogether, which in turn unified them to fight against slavery and segregation (Hickman, 1997). The hypodescent rule was founded on greed and oppression but led to African Americans uniting. As the multiracial population continued to increase, attention was brought to a new racial category on the 2000 United States Census.

\section{United States Census}

Loving v. Virginia in 1967 overturned miscegenation, but this was not the end of problems targeting interracial marriage and multiracial people. The United States had a fixation on the single race category and this was reemphasized in the United States Census. The United States Census occurs once each decade to count inhabitants and gain additional information relating to population (Wright, 1966). The census began in 1790 and called only for a few details. These details were people's color, sex, and age (1966). These inquiries of the United States Census continued each decade with additional questions for participants. Since 1967, interracial couples have been getting legally married and legally having children. Race is a salient identity for most people but was something interracial parents had to negotiate for their children in every census until the year 2000 (Holloway et al., 2009).

Until the year 2000, the United States Census only allowed one option for the racial classification category. The five racial classifications allowed were: White, African American/Black, Asian American, Latino/a, and Native American (Literte, 2010). Only allowing five racial classifications was challenging for people with a multiracial identity because the multiracial option was not listed and they were unable to check multiple 
boxes (Wright, 1966). Limited racial classification options meant that one could check Black or check White, but not both. Limitation on the United States Census was a prime example of ignoring multiracial people. Interracial married couples and multiracial people were outraged with the absence of multiracial and advocated for the inclusion of their racial category (Morning, 2005). Frustration was heard, and the 2000 United States Census allowed for the selection of multiple racial categories, which revealed an emerging population of multiracial individuals (Jones \& Bullock, 2013). Revisions of the census allowed for gathering data and understanding the racial combinations of the reported multiple races (Jones \& Bullock, 2013). Gaining specific reported multiple races allows for the trajectory of where racial categories were heading. In fact, as seen in figure 1 below, the White (European American) and Black (African American) combination is the largest multiple race category selected (Jones \& Bullock, 2013). Harris and Sim (2000) suggest that measurement of the multiracial category cannot be accurately captured due to race and racial identity being fluid concepts, especially in multiracial individuals. Information from the most recent United States Census indicates that multiracial is the fastest growing racial population and $20 \%$ of Americans will identify as multiracial by the year 2050 (Jackson, 2010; Jones \& Bullock, 2013; Lee \& Bean, 2004).

Figure 1. 


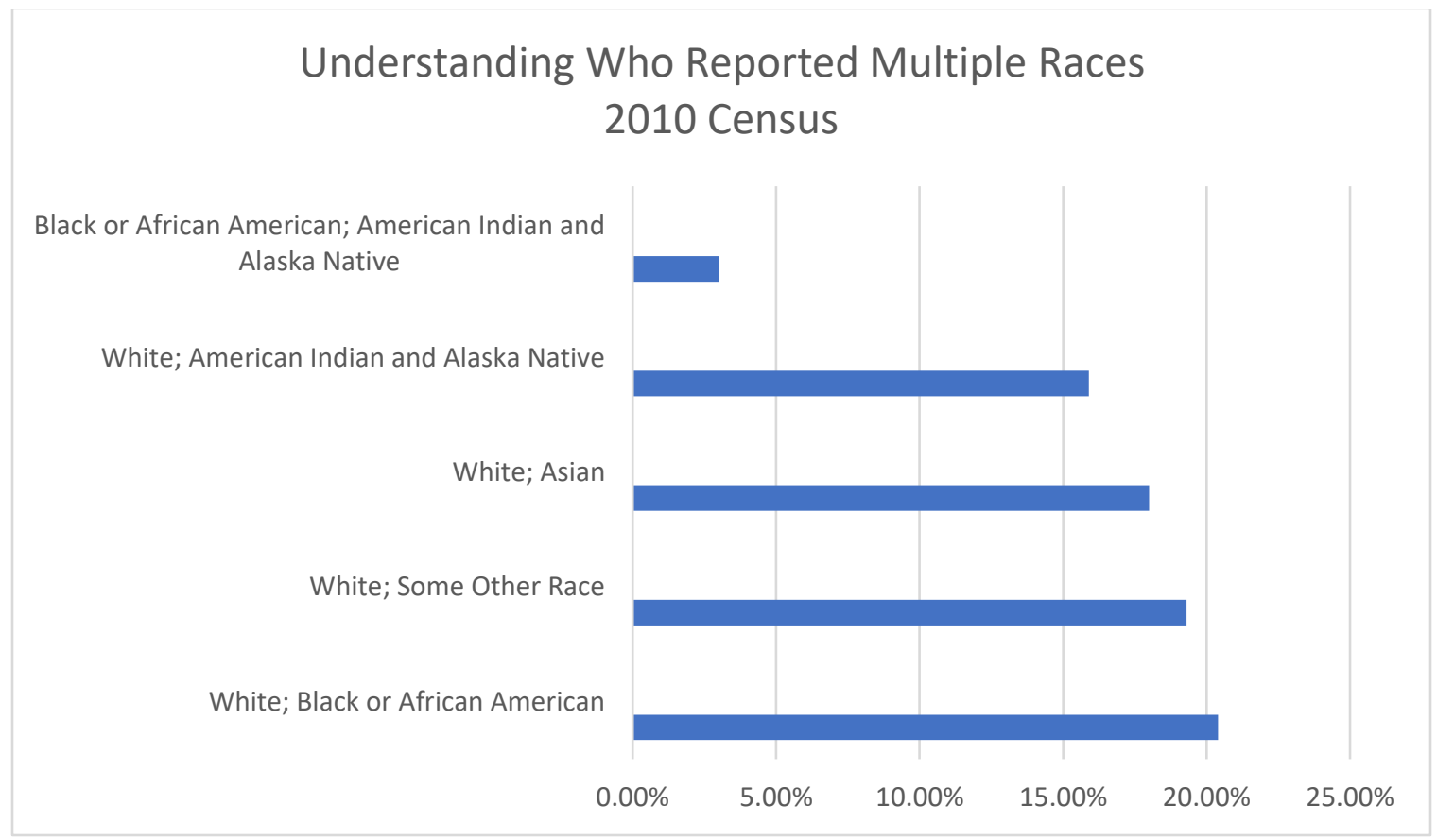

Source: Jones \& Bullock, 2013

\section{Predominantly White Institutions}

Higher education in the United States is modeled from the English universities of Cambridge and Oxford that focused on social and academic aspects of life (Thelin \& Gasman, 2011). Higher education enrollment has ebbed and flowed throughout America's history. In fact, from 1700 to 1900 less than five percent (5\%) of Americans attended college (Thelin \& Gasman, 2011). These institutions were all considered predominantly White institutions because they served majority, if not all, White students. James Axtell (1974) discussed that college and universities were a "wishful" and "optimistic" attempt to grasp the English undergraduate education, in order to create responsible leaders through the "collegiate way" (1974). Although specific population serving institutions began as early as 1850 , predominantly White institutions are still the 
most abundant. In this section I will discuss marginalized students at these predominantly White institutions and the impact that sense of belonging has on students.

\section{Marginalized Students in a Predominantly White Institution}

Higher education is more diverse than ever and marginalized student enrollment has dramatically increased in the last twenty years (Espinosa et al., 2019). In fact, the majority of African American students, roughly seventy-two percent (72\%) in the United States, attend predominantly White institutions (Hubbard, 2006). Although more Black students are attending higher education, Black students have among the lowest persistence rates and highest dropout rates (Espinosa et al., 2019). Institutions must show initiatives to support and retain them. Institutions develop initiatives partly through student involvement, faculty interaction, peer support, and self-accountability (Palmer et al., 2012).

Marginalized students face multiple issues that their White counterparts do not. Cuyjet (1998) found that African American students overwhelmingly reported more negative perceptions of campus and felt marginalized. In fact, marginalized students report experiencing discrimination at one or more points throughout their college tenure (Hughes, 2002). Discrimination discourages their sense of belonging within the institution (Carter, 2007; Hurtado, 2007; Hurtado \& Carter, 1997). Oppression and discrimination can be particularly challenging for these students due to their decision to attend a predominantly White institution. Many White students reported their reason for attending a predominantly White institution was because of the passion and tradition of the institution, but marginalized students often looked for schools which provided the 
most financial aid (Hughes, 2002). Marginalized students' reasons for attending a college makes retaining them at a predominantly White institution even more challenging.

\section{Microaggressions}

Minoritized students constantly battle discrimination and prejudice in higher education (Ancis et al., 2000; Feagin et al., 1996; Harper \& Hurtado, 1992; Hurtado, 2007; Lewis et al., 2000; Solórzano et al., 2000). Microaggressions are common oppressive remarks that multiracial students experience. Microaggressions are intentional or unintentional subtle statements that convey hurtful remarks to People of Color (Nadal et al., 2011). These often occur amongst people that interact with multiracial individuals. A common location for the occurrence of microaggressions is in the higher education setting.

Nadal et al. (2011) found six types of common microaggressions in a mixed method study with a total of 271 multiracial participants. In this study, Nadel et al. (2011) asked questions of what microaggressions exist for multiracial people and how they experienced them. Six domains were found regarding microaggressions: isolation, objectification, mistaken identity, denial of reality, pathologizing identity, and microaggressions based on racial stereotype (Nadal et al., 2011). Six domains of microaggressions shows that multiracial individuals get the oppression and microaggressions of the racial identity they have physical characteristics of, in addition to what they already receive as multiracial people. These microaggressions can have an everlasting impact on individuals, especially during a critical point in their lives, when in college. 


\section{Coping with Discrimination}

Discrimination and racial prejudice can be major stressors for minoritized students in higher education, but coping responses can help mediate stress (Lazarus, 1990). Coping can be a beneficial tool in any student's arsenal, but especially for minoritized students. Coping is described as "a process whereby an individual attempts to manage, through cognitive or behavioral efforts, external and internal demands that are assessed as exceeding one's resources" (Utsey et al., 2000, p. 79). When a person is faced with a situation they cannot handle, they first appraise the situation to see if a threat presents itself. After primary appraisal, they look to see if they have the proper resources to help with this challenge (Lazarus \& Folkman, 1984; Outlaw, 1993).

Minoritized students, when faced with discrimination or racial prejudice, may choose one of three different coping responses: avoidant, problem focused, or emotion focused (Billings \& Moos, 1984; Lazarus \& Folkman, 1984; Lian et al., 2007). Students using avoidant coping typically leave the area when faced with racial discrimination. This could mean the immediate area or the institution as a whole if it is repetitive. Avoidant coping has longevity and the person will try to avoid that area or that person in the future. Negative consequences to this strategy in People of Color is that the person seems intimidated easily and this leads to more stress, lower satisfaction long-term, and not seeking help from faculty and staff (Carter, 2007; Sanders Thompson, 2006; Truong \& Museus, 2012). Problem focused coping is almost the opposite of avoidant, because this strategy encourages the person to confront the individual spewing the derogatory remarks by trying to enlighten them. This strategy has negative consequences because the person can be deemed as combative and angry, which reinforces certain racial stereotypes 
(Carter, 2007; Sanders Thompson, 2006; Truong \& Museus, 2012). Emotion focused coping is a combination of the two; the person flees the area to seek help from resources or people for support. This coping strategy relies on others for support and can be challenging if not enough support is given.

\section{Multiracial Student Experience}

Multiracial people are constantly limited due to not having physical characteristics that reside with one race and face discrimination (Ancis et al., 2000; Harper \& Hurtado, 2007; Ingram et al., 2014; Museus et al., 2015). Those who have a biological parent of African American (Black) descent are automatically considered Black through the one-drop rule. (Roth, 2005). Previously I discussed oppression and racism impacting Black people and due to the one-drop rule, discrimination impacts multiracial people as well, in addition to other oppressive remarks already impacting them. Discrimination is not absent for multiracial people; in fact, at times it is heightened due to their racial ambiguity. Early on, the Portuguese term mulatto was used to describe multiracial individuals composed of both Black and White races (Daniel, 2010). This term evolved from the word mule and is used towards these multiracial individuals as a way to degrade them. This is blatant racism, but this is not the only discrimination these individuals receive. Multiracial students are common targets for microaggressions. These can come as curious questions towards their ambiguous identities such as "What are you?’. Answering questions such as this one constantly can be taxing on multiracial students.

At predominantly White institutions, discrimination shapes how multiracial students understand their race and identity (Kellogg \& Liddell, 2012). Kellogg and 
Liddell (2012) conducted a qualitative study, which included 14 multiracial undergraduate students from two separate institutions in the Midwest, regarding critical incidents of discrimination impacting multiracial individuals. Most critical incidents were influenced by peers. Four categories describe Kellogg and Liddell's (2012) findings: confronting race and racism (encountering racism; seeing the importance of race), responding to external definitions (racial ambiguity; checking one box), defending legitimacy (academic and racial legitimacy), and affirming racial identity (possessing racial and cultural knowledge). Many participants admitted experience in multiple critical incident categories. Unfortunately, this study only had two students who identified as having one biological parent of African American (Black) descent and the other of European American (White) decent. This is a limitation that my study addressed, due to multiracial students having unique experiences, especially depending on their racial make-up.

Multiracial students experience discrimination at predominantly White institutions from monoracial individuals. Multiracial students experience "not being fully part of a monoracial group, nor being completely recognized as a separate category" (Brackett et al., 2006, p. 443), which escalates racial issues for multiracial students. Museus et al. (2015) interviewed 22 multiracial participants across seven campuses on the East Coast to find the coping strategies that multiracial students used when confronted with racial discrimination. They found four themes on how multiracial students cope with discrimination: "educating others", "utilizing support networks", “embracing fluidity”, and "avoiding confrontation” (Museus, Lamb Sariñana, \& Ryan, 2015). Educating others was described as teaching others about their racial backgrounds 
and raising awareness of multiracial people and issues. Utilizing support networks meant reaching out to mentors and resources they had previously constructed. Embracing fluidity was used to find common ground with people of other racial backgrounds. Avoiding confrontation implied minimizing the experiences that discrimination had on them. At times these themes were used in combination to allow the multiracial student to cope with the discrimination they faced. This study did not analyze the different coping strategies that various multiracial combinations use when faced with prejudice and discrimination. For my study, I examined how multiracial students of European (White) descent and African American (Black) descent cope with prejudice and discrimination and make sense of their experiences. Museus et al. (2015) end by highlighting the importance for safe spaces for multiracial college students on campus and discuss that if college educators fail to welcome places for open dialogues, that they are doing a disservice to multiracial people and depriving them of the coping mechanism of spreading awareness.

Contributing Factors of Multiracial Success. Having a multiracial identity increases cultural diversity and empathy for these individuals (Shih \& Sanchez, 2009). This leads to an increase in resilience which is needed to combat the many obstacles facing multiracial students. Social groups are another obstacle for multiracial students because they often feel pressured to associate with only one of their racial identities (Ingram et al., 2014). Several universities have created identity-based organizations which are designed to support students of marginalized groups. In fact, there is an increasing number of multiracial programs, services, and student organizations on college campuses across the United States (Wong \& Buckner, 2008). A majority of these groups 
are for marginalized monoracial populations to give them a secure place to meet and have racial pride. Solely having these groups is damaging to multiracial students because it forces them to make an uncomfortable choice (Ingram et al., 2014). By identifying with one of these groups, it would mean losing a part of their identity and most of the time just one of these organizations does not meet all their needs (Ingram et al., 2014). Multiracial students desire a multiracial center or space so they can feel comfortable and welcomed. Some campuses already have these (e.g., Yale University, University of Vermont, Harvard University), but many do not.

Ingram et al. (2014) focused on the interactions multiracial students have with the majority of campus and used the information gained to develop ways that college campuses could be more welcoming and inclusive. This research was conducted online through a survey at a predominantly White institution. Approximately 1,500 students received the survey and 201 completed the survey (Ingram et al., 2014). The findings provide several recommendations on the behalf of multiracial students such as, the need for more supportive services, recognition that multiracial students' beliefs vary, and the need to increase awareness of these students. What was enlightening in this study was that the general population of the college made multiple suggestions about their desire to obtain more knowledge about multiracial students. Ingram et al. (2014) stated:

Nearly three-quarters of respondents "agreed" or "strongly agreed" that opportunities for open dialogue and cross-cultural communication, hosting guest speakers on multiracial topics, and raising awareness of multiracial issues among mono-racial student organization/groups would help create a welcoming environment for biracial students on university campuses (p. 303). 
A majority of the general population continued to show support for multiracial students by inquiring about courses and professional development opportunities on multiracial students and their identity.

Multiracial Student Identity. Students' mesosystem is how the student is identified by others and how they identify personally, which has an impact on their interactions (Ingram et al., 2014). A student's physical appearance has an impact on whether a student is accepted or not into a social group. This is difficult for multiracial students because their physical appearance may not align with how they identify. These students vary and some find comfort with just one race, while others choose to embrace their multiracial identity. Embracing a multiracial identity can prove difficult when others force them to choose one race or make assumptions based on their presumed identity (Abiola, 2017; Harris, 2017b).

"Others" forcing them to choose a race are not only by European American (White) people, but also African American (Black) people. Colorism is "the tendency to perceive or behave toward members of a racial category based on the lightness or darkness of their skin tone" (Maddox \& Gray, 2002, p. 250) and is common among multiracial and African American (Black) people. Abiola (2017) discussed the finding of "light skin vs. dark skin rivalry" amongst Black women. Abiola (2017) found that women commonly reinforce negative stereotypes about their darker or lighter skinned counterparts.

Many obstacles face multiracial students, especially at a predominantly White institution, which is why it is important for multiracial students to be equipped with coping mechanisms to combat these obstacles. Multiracial students encounter different 
obstacles depending on their physical appearance. Multiracial students attending predominantly White institutions face prejudice and discrimination in the forms of microaggression and blatant racism (Ancis et al., 2000; Harper \& Hurtado, 2007; Museus et al., 2015). All marginalized students encounter barriers such as these, but the research that is missing is the belonging multiracial students at a predominantly White institution have and what encourages a feeling of belonging. This is the literature that my study contributed.

\section{Sense of Belonging Importance}

The six-year graduation rate for public institutions in the United States is approximately fifty percent (50\%) to fifty-six percent (56\%) (Crosling et al., 2008; Mortenson, 2005). The third tier in Maslow's (1954) Hierarchy of Needs, love and belongingness, is identified as a critical factor for student retention and graduation rates (O'Keeffe, 2013). In order to properly create this sense of belonging, the college must be welcoming, caring, and supportive (O'Keeffe, 2013). If the institution is not welcoming, caring, and supportive, failure to create a sense of belonging could ensue, which encourages emotional withdrawal and withdrawal from college. Tinto (1975) constructed a model on reasons students "drop out" of college. The reason for this "drop out" was a combination of insufficient social integration, informal peer group association or activities, and insufficient academic environment (poor grade performance). The biggest impact on student sense of belonging is the interactions they have with individual entities in the community (Tinto, 1993). Partly informed by Tinto, institutions have created involvement opportunities to help form a sense of belonging within students. These involvement opportunities within the college are in the form of social communication, 
friendship support, faculty support, and collective affiliation, all which promote social integration (Tinto, 1975).

\section{College Involvement}

The influence of student involvement on retention research and practice is known as "The Age of Involvement" (Study Group on the Conditions of Excellence in Higher Education, 1984). Student involvement has been defined as "the amount of physical and psychological energy that the student devotes to the academic experience" (Astin, 1984,

p. 518). There are multiple forms of involvement and most of them require the student to have more interactions with other members of the campus community. The effectiveness of student involvement depends on how much a student invests in the opportunity. Student involvement encourages the faculty members to focus less on what they do, and more on what the students do (Astin, 1984). Institutions have created various organizations and involvement opportunities for students to get involved on campus.

Hurtado and Carter (1997) found that student involvement contributes to sense of belonging in higher education. In a longitudinal quantitative study, Hurtado and Carter (1997) examined Latino students to find what contributed to their sense of belonging. Involvement in informal activities, such as frequent discussion with peers outside of class, or in formal activities, such as participation in student organizations, contributed to the sense of belonging they felt while at the institution. A finding I would like to highlight of Hurtado and Carter's (1997) is that students who felt racial-ethnic tension on campus had a lower sense of belonging, but involvement in racial-ethnic student organizations helped mediate this. Environment has a major impact on sense of 
belonging. My study focused on the multiracial student population, but similarities may be discovered because both groups are Students of Color.

\section{Campus Resources}

Administrators in higher education promote cultural centers, which are tools to increase the student experience and social integration for students of that particular race. Cultural centers are just one example, a physical facility. Other resources in Astin's (1984) resource theory are human resources and fiscal resources (Astin, 1984). Human resource officers are the individuals who aid in higher education. Examples of human resource officers are counselors, academic advisors, and professors. Human resources are spread across campus with some in formal roles and others as informal mentors. Fiscal resources give opportunities for purchasing advantageous opportunities in the form of financial aid and endowments. Physical facilities provide campus resources such as laboratories and libraries, but especially resource centers. Predominantly White institutions provide support serving resource centers catered towards minoritized individuals. Cultural Centers especially, provide safe havens on campus for marginalized students (Jones et al., 2002). These facilities provide social, academic, and recreational events (Princes, 1994). Patton (2004) found that Cultural Centers have a positive impact on marginalized students' experiences by being a welcoming space that is social, educational, and culturally relevant. Cultural Centers specific to minoritized groups are partly how institutions address racial problems, but funding for these physical facilities is lacking (Jones et al., 2002; Patton, 2004). The lack of funding is the reason these cultural centers are not more abundant. 
Multiracial Organizations and Cultural Centers. Having only monoracial organizations and cultural centers contributes to the denial of the existence of multiracial individuals (Harris, 2017b). This happens not only for students, but for employees as well. Harris (2017a), after gaining narratives from twenty-four multiracial campus professionals, found that they experience denial of multiracial reality, assumption of monoracial identity, and not being monoracial enough. This is similar to what many multiracial students feel. Many institutions lack support catered specifically towards multiracial individuals. Multiracial individuals seek places where they can share experiences with other multiracial people, while educating the general population about the multiracial college experience. Many multiracial students report monoracial support groups not receiving them positively (Jones \& Jones, 2010). To counter marginality and promote productivity, understanding, and motivation in multiracial students, institutions can create and support multiracial organizations and cultural centers that advocate for multiracial students and their unique needs (Gasser, 2002). These cultural centers would provide a forum for people to register their concerns and hear different opinions while respecting others' voices (Gasser, 2002).

Multiracial organizations and cultural centers can be challenging and have unique issues due to the various experiences of multiracial individuals. The term multiracial is inclusive to all people who are made up of more than one race. This can create challenges with naming the organizations. The organizations' names are important because it is connected to validation of existence for multiracial students (Root, 1992). This name of the organization is what encourages some to join and others to stay away. Students inside the organization could be so diverse that they do not have common interests, which could 
prove challenging. This could limit the involvement that members of the organization are seeking (Ozaki \& Johnston, 2008).

\section{Diversity Plans}

Williams (2013) claims having a more diverse learning environment is supported by more reasons than moral responsibilities; it leads to academic and social excellence for all. Diverse learning environments contribute to increased creativity, problem solving, and critical thinking (Gurin et al., 2004; Hurtado, 2007). Connections have encouraged all institutions, but especially predominantly White institutions, to develop strategic diversity plans. Diversity plans have priority in "creating a multicultural and inclusive campus climate for the entire institutional community" (Williams, 2013, p. 18). Inclusive environment means that everyone feels welcome and has a sense of belonging. Diversity plans are not just the work of the chief diversity officer, but the work of every stake holder involved. A deliberate diversity plan that holds everyone accountable ensures that everyone feels that they belong, including multiracial students. Having an efficient diversity plan will limit prejudice and discrimination by promoting understanding in diverse learning environments (Williams, 2013). A holistic diversity plan not only promotes understanding, but also promotes sense of belonging in all students.

\section{Conclusion}

Multiracial students and sense of belonging at a predominantly White institution can be understood and increased. Increasing enrollment and belonging will require everyone who is involved in higher education to continuously gain knowledge about multiracial students. Multiracial students in a predominantly White campus can have 
difficulty finding a sense of belonging. Sense of belonging is important throughout their tenure and is crucial for success. Belongingness is a motivator to participate in certain activities, and pursue certain goals. If unmet, lack of belonging can lead to anxiety, depression, uncertainty, or even suicide (Baumeister \& Leary, 1995). For multiracial students, sense of belonging is difficult to find due to other students assuming their race, questioning their identity, and discriminating against them. By understanding this phenomenon, we can assist this fast-growing population towards success. 


\section{CHAPTER 3}

\section{METHODOLOGY}

The central phenomenon I studied was multiracial students' experiences with sense of belonging in a predominantly White institution. The qualitative approach I chose was phenomenology. Justification for choosing this approach was because of the elements it holds on grasping the multiracial college experience and how the participants have directly experienced the phenomenon. A phenomenological approach "describes the common meaning for several individuals of their lived experiences of a phenomenon" (Creswell \& Poth, 2018, p. 75). I attempted to grasp what it means to be a multiracial student in a predominantly White institution and how this affects belongingness. Love and belongingness are complex, deep human emotions that define our lived experiences. I understand that by gathering individual experiences from study participants who identified as multiracial, I gathered the universal essence of sense of belonging multiracial students had in a predominantly White institution.

I understand that there are different types of phenomenological studies. The type I used was transcendental. By adopting a transcendental study, information gained is perceived as new. This allowed me to focus on the experiences of the participants and not on myself. I viewed this information as raw data, at the same time limiting my own preconceived notions. My positionality or stance comes from being a multiracial, firstgeneration college student who graduated from a predominantly White institution. 
Because of my past, I am aware of the challenges and discrimination that multiracial students encounter. I faced challenges throughout my life, but they were heightened when enrolled at the predominantly White institution. The rational for this research was to understand sense of belonging that multiracial students have while in a predominantly White institution. Multiracial students possess diverse experiences and face challenges that must be understood. In this study, I put aside personal views and gathered participants' experiences so they could potentially be better understood as multiracial students at a predominantly White institution.

\section{Qualitative Research}

In the past, much of the world viewed quantitative research as the conventional way to gain knowledge and was elevated, especially for social and natural sciences (Lincoln \& Guba, 1985). Qualitative research is a way to provide understanding (Bogdan \& Biklen, 1982; Lincoln \& Guba, 1985). The ultimate goal for qualitative research is to understand the experiences of participants and discover the richness of how it impacted them (Manning, 1992). Denzin and Lincoln (2011) note, “...qualitative researchers study things in their natural settings, attempting to make sense of, or interpret, phenomena in terms of the meanings people bring to them" (p. 3). In this study I examined sense of belonging multiracial students had while enrolled in a predominantly White institution; I hoped to gain a better understanding than I currently have, which is why qualitative research was appropriate.

\section{Qualitative Approaches}

In qualitative research five different approaches are commonly used: narrative, grounded theory, ethnography, case studies, and phenomenology (Creswell \& Poth, 
2018). These different approaches all have various purposes, research questions, data analysis, and standards of validation. The five different approaches are different, yet valuable to finding the answers in qualitative research. For my research I utilized the phenomenological approach.

\section{Phenomenology}

The qualitative approach I explored was phenomenology. Phenomenology "describes the common meaning for several individuals of their lived experiences" (Creswell \& Poth, 2018, p. 75). In this approach, the researcher seeks to explore what participants have in common in order to better understand the universal experience of the phenomenon. Moustakas (1994) describes this approach as a human experience that is described as what exactly it is and how it was experienced. Phenomenology is widely used in sociology (Borgatta \& Borgatta, 1992; Swingewood, 1991), health sciences (Nieswiadomy, 1993; Oiler, 1986), and psychology (Giorgi, 1985; Polkinghorne, 1989; Wertz, 2005). Data is collected via interviewing. Creswell and Poth (2018) recommend between three and fifteen participants. In phenomenology, the researcher discusses their personal experiences with the phenomenon in a process called bracketing, which acknowledges the researchers' past experiences, but does not allow it to cloud their judgement (Giorgi, 2009). The two types of phenomenology are hermeneutical and transcendental. Van Manen (1990) describes hermeneutical phenomenology as research on lived experiences and the text of life. Transcendental focuses on the description of experiences of several persons and encourages the researcher to bracket out their experiences with the phenomenon so everything is perceived as new (Moustakas, 1994). As a result of the study, the phenomenon captured must be explained in detail. A major 
challenge in phenomenology is that the researchers own knowledge and experiences with the phenomenon must be suspended to seek new knowledge.

Multiple multiracial individuals experience this phenomenon of being in a predominantly White institution and I had to hear from several of them to understand what they experienced. Multiracial students of the African American (Black) and European American (White) combination are the most common multiracial students (20.4\%), yet their sense of belonging on predominantly White institutions has not been explored. This is why phenomenology is an appropriate approach for this study (Saulny, 2011).

Phenomenology is an appropriate approach because of the features it holds. I sought to understand the concept of sense of belonging multiracial students feel while in a predominantly White institution. More specifically, I used transcendental phenomenology so all information gained was considered new to me. Moustakas (1994) describes transcendental as "...everything is perceived freshly, as if for the first time" (p. 34). This cannot be completely achieved, but I disclosed my own experience with this topic to separate personal experiences from the information I gained from the participants. This method of bracketing out my experiences in the researcher positionality allowed transparency and deep analysis of the information gained. I gave textural descriptions (what the participants experienced) and structural descriptions (how they experienced them) to provide a rich description of my study.

\section{Study Rationale}


Multiracial students in predominantly White institutions hold unique experiences that needed examination for better understanding. These experiences were best examined through the qualitative research approach of phenomenology. Phenomenology was the best approach for this study because I studied multiracial students' lived experiences in a predominantly White institution and I sought to grasp the essence of them (Moustakas, 1994; Van Manen, 2014).

\section{Research Questions}

In this phenomenological study I attempted to understand the essence of how multiracial (Black/White) students felt in a predominantly White institution. Maslow's (1954) Hierarchy of Needs and Renn's (2004) Ecological Theory of Mixed-Race Identity Development influenced my research questions by focusing on sense of belonging and factors that influence multiracial identity. The factors I examined that impacted belonging and multiracial identity were: support systems, critical incidents (Kellogg \& Liddell, 2012), comfort, and authenticity. I gained information for these through one ninetyminute interview with each participant.

- Central Research Question: How do multiracial students at a predominantly White institution describe their sense of belonging?

○ RQ1: In what ways do multiracial college students feel that they can be their completely authentic self while enrolled at a predominantly White institution?

○ RQ2: How do multiracial students feel comfortable or uncomfortable at a predominantly White institution? 
○ RQ3: How salient is multiracial students' race while at a predominantly White institution?

\section{Interpretive Framework and Philosophical Assumptions}

As a researcher I understand that we all conduct research with prior philosophical assumptions and interpretive frameworks. I possess epistemological assumptions and I come from a transformative framework. The epistemological assumption encourages the researcher to get as close as possible to the phenomenon and the participants (Creswell \& Poth, 2018). This assumption allowed me to gain insight to participant experiences. The transformative framework allowed me to have an action agenda, in hopes of discovering something so I can make change (Creswell \& Poth, 2018). This framework assisted with the removal of barriers experienced by multiracial students, by giving me the opportunity to advocate for them throughout higher education. Transformative framework allowed me to work with the participants by gaining their insights to remove barriers. Using epistemological beliefs and transformative framework together helped me understand that there are multiple ways of knowing and experiencing this phenomenon of multiracial students and their sense of belonging in a predominantly White institution (Creswell \& Poth, 2018).

\section{Research Design}

This qualitative study was a phenomenological study in order to gain the essence of the phenomenon of multiracial students in a predominantly White institution and their sense of belonging. I employed semi-structured interviews with each participant in order to ask clarifying questions. The interviews lasted approximately 90 minutes in length and 
only included myself and the participant. The participant received a consent form at the beginning of our meeting and was informed of the protocol, risks, and the reasoning for this study.

\section{Procedure}

I chose to research a predominantly White institution that many students, faculty, and staff at this university claim as the most diverse school in the state. Upon entering the doctoral program in Counseling and Personnel Services with a specialization in College Student Personnel in Fall of 2018, I contacted individuals regarding my central research question. I used resources and connections on campus to learn of faculty and staff who had connections to students who might identify as multiracial, with one biological parent of African American (Black) descent and the other of European American (White) descent. I reached out to those faculty and staff members to find if they were willing to assist me with recruitment efforts.

I used purposeful sampling to reach targeted demographics in participants, to align with the phenomenon I attempted to understand. Multiracial students are difficult to identify, due to ambiguous visual characteristics. Someone who knew the participants on an in-depth level had to recommend the participant or the participant needed to disclose their racial demographics to the researcher. For this reason, purposeful sampling was deemed best to recruit the population in this study.

Institutional Review Board (IRB) approval was sought to recruit participants. After IRB approval, I sent emails to faculty and staff members of specific departments. Flyers were also posted around popular campus locations, such as the Student Activities 
Center (SAC), libraries, and the Student Recreational Center (SRC), in order to gain participants who may not be affiliated with any resources I contacted on campus. This study was completely voluntary for the participants and no financial incentives were given.

\section{Research Site}

The predominantly White institution that participants were enrolled in is a research institution located in the east central region of the United States. The Carnegie classification is a public, 4-year, large, primarily residential institution that offers both undergraduate and graduate programs. The mission statement included several occurrences of diversity, inclusion, and community. The reported ethnic diversity of undergraduate students was approximately $75 \%$ White and 10\% Black. The ethnic diversity of faculty reflected the undergraduate student ethnic diversity numbers.

\section{Participants}

Participants in this study were chosen purposefully to fit specific criteria. Criteria is as follows: (a) college student; (b) enrolled at the University; (c) multiracial (Black/White). Once I located participants, I employed snowball sampling and asked existing participants to identify anyone who they may know who would fit the criteria (Ritchie, Lewis, \& Elam, 2003). I understood that this may limit the diversity in experiences across participants, but I wanted to make sure I captured the specific

phenomenon. Polkinghorne (1989), recommends that five to twenty-five participants who have all experienced the particular phenomenon. Creswell \& Poth (2018) recommend: "participants in the study need to be carefully chosen to be individuals who have all 
experienced the phenomena in question..." (p. 81). I chose eleven participants that had experienced the multiracial student phenomenon in a predominantly White institution.

\section{Data Collection}

Interviews were used in this research design. This data source is deemed valuable because of the data collected from the in-depth interviews. To support ethics in this study, I completed the "Research Ethics and Compliance Training" in the CITI Program website (Research Ethics and Compliance Training, n.d.). Participants were informed that their information is kept confidential, a foreseen risk is emotional distress from sharing experiences of the past, and that this is a completely voluntary interview. All interviews were recorded. These participants were free to leave at any time, refuse to answer any question, and transcripts were sent to them after they were transcribed to ensure accuracy.

\section{Interviews}

During interviews, participants provided their experiences directly to the researcher verbally. All interviews were conducted individually, online to ensure information was communicated clearly. These interviews were held in a private, virtual room, which allowed for the sharing of raw data and experiences within an intimate setting. Participants were encouraged to choose pseudonyms to protect their identities. Pseudonyms mask names and reduce identifiable information to protect the participants (Creswell \& Poth, 2018). These students varied in major, gender, and year in school.

Participants were informed of the data collection protocol when the interview started. I avoided sending them the protocol in advance because of the desire for raw answers. I informed participants that their data was confidential and used only for 
academic purposes. As an ethical consideration, I sent all participants the transcripts to ensure accuracy. Participants were informed that by participating they are disclosing experiences that they had as multiracial students and how it affected their sense of belonging in a predominantly White institution.

\section{Limitation}

I only asked them a few questions, none which pertained to any identities outside of their race, which did not allow for other accounted influences, though they may have discussed them. Multiracial students can have a wide variety of racial identities. Even isolating the make-up to multiracial (Black/White) has its limitations because some participants had biological African American mothers and European American fathers, while others had biological European American mothers and African American fathers. Some participants lived in a two-parent household, while others lived with one parent. In fact, some participants may have been adopted and not have lived with either of their biological parents.

Isolating my study to one university posed limitations as well. Predominantly White institutions across the United States are not all the same. Some institutions are smaller in enrollment, while some are much larger. The demographic makeup of institutions varies. All predominantly White institutions will have a majority of White students, but the percentage varies.

I captured their experiences during one interview. This is not a longitudinal study because I did not plan on following these participants for a long period of time. I asked them to reflect on experiences that they had during their recent past, which is a limitation 
as well. Recollecting memories is complex and never remains exactly the same, but is restructured depending on the questions asked (Jedlowski, 2001). Although results of this study are not generalizable as the sense of belonging for the complete population of multiracial (Black/White) students at predominantly White institutions, I believe this research adds useful knowledge for student affairs practitioners and professionals.

\section{Ethical Validations}

I took every precaution available to ensure that the data collected was ethical and valid. I know that after research there are two lingering questions, "Did we[I] get it right?" (Stake, 1995, p. 107) and "Did[Will] we[I] publish a 'wrong' or inaccurate account?" (Thomas, 1993, p. 39). These questions were in mind throughout my research and reminded me to always seek validity. By taking these precautions before doing the research, I was able to answer these questions.

Creswell and Poth (2018) describe validation as an attempt to access accuracy. To access the accuracy in this study, I clarified researcher bias by disclosing my biases and experiences that I brought to this research so the audience understood my position (Hammersley \& Atkinson, 1995; Merriam \& Tisdell, 2015). I have illuminated this experience in researcher positionality and I will continue to do so. The rigor of my study was strengthened through data saturation. I knew I had reached data saturation when participants were sharing similar data and were no longer providing new information to add in my understanding of multiracial students in a predominantly White institution (Creswell \& Poth, 2018). I also applied member checking to ensure that the information captured throughout the interviews was accurate (Miles \& Huberman, 1994). Member checking built rapport with participants while also seeking credibility. Along with 
member checking, I provided rich, thick descriptions of the participants, research site, and overall study (Erlandson, Harris, Skipper, \& Allen, 1993; Lincoln \& Guba, 1986; Merriam \& Tisdell, 2015). By describing research in detail, I gave readers the ability to gauge if other sites have shared characteristics. Debriefing of the data and research process occurred with other doctoral students, in addition to my dissertation committee, to examine the process and the product to assess accuracy (Creswell \& Miller, 2000; Ely et al., 1991; Erlandson et al., 1993; Glesne, 2016; Lincoln \& Guba, 1986; Merriam \& Tisdell, 2015). The dissertation committee did this by asking challenging questions to ensure that I was always honest. They did this throughout the research process, specifically at the proposal and dissertation defense. By using these methods, I ensured that data is both ethical and valid.

\section{Data Analysis}

The first step in analyzing data was in properly storing, organizing, and managing the data collected. I stored the data in digital files and organized them by date interviewed, pseudonym, and transcript/interview number. I stored this information on a secured password protected computer in a locked room. Storing it in this way not only protected the participants' information, but also allowed me to access the database for analysis (Bazeley, 2013).

After collecting data and properly organizing it, recordings were transcribed manually by listening to the recordings repeatedly and typing the participants' exact words. I listened to the recordings while reading the transcripts to make sure nothing was left out and everything was accurate. Doing this encouraged active reading and encouraged me to look closely at the data (Agar, 1980; Creswell \& Poth, 2018). I then 
read the transcripts line by line several times to immerse myself in this data. Reading through all the transcripts allowed me to gain an idea of the data I had collected. I participated in memoing in order to write ideas, analytical meanings, and emergent ideas (Miles et al., 2014). Memoing allowed me to uncover information that allowed for a stronger explanation of the context in my study, while bracketing my experience as a researcher (Janesick, 2011). I understood that during interviews, participants'salient identities not related to race emerged. Although this is not the focus of my research, I included this in my data analysis. This led to a deeper, richer, holistic description of the study and the participants.

The next step in data analysis is coding, which simplifies large pieces of data into smaller, similar text that describes the data it is explaining. Creswell and Poth (2018) emphasize that coding is a major part in qualitative research. Creswell and Poth (2018), suggest twenty-five to thirty codes or categories developed, in order to not make the list too complex. I assigned a label to each code that described the data. From these codes I examined the criteria and combined similar codes into broader categories defined as themes. I counted the codes in each theme to find how frequently the code appeared throughout the data (Huberman \& Miles, 1994). The frequency of the codes did not necessarily describe the magnitude of the impact, but it did quantify the occurrence. These codes were condensed to form four themes that represent the data and developed a description of the phenomenon.

Codes are described in two cycles of coding. First cycle of coding is by In vivo codes, which are the participants' exact words (Creswell \& Poth, 2018). In vivo coding allowed for transparency, by illuminating the words of the participants and giving their 
perspective (Saldana, 2016). In the second cycle of coding, I remained open minded and used pattern coding by looking for patterns that were present in the first cycle of coding. This method allowed me to condense the codes into meta themes that I believed were significant (Saldana, 2016). I placed labels on the themes that the data presented.

\section{Conclusion}

In this phenomenological study I collected data through purposeful and snowball sampling of eleven multiracial students at a large, predominantly White, public research institution located in the east central region of the United States. Participants were informed of the risks and I conducted interviews with each participant lasting approximately ninety minutes each. Interviews were transcribed manually by listening to the recordings repeatedly and typing the participants' exact words. I employed member checking to ensure credibility. I coded and recoded the collected data for dependability using In vivo coding and pattern coding. I provided a rich thick description of my site, participants, and interviews to allow the audience to infer transferability. I present four themes as the result of my study. 


\section{CHAPTER 4}

\section{FINDINGS}

In this chapter, I discuss the findings of this study on multiracial students and their sense of belonging in a predominantly White institution. I give a summary of the study, a background of the participants, research questions central to this study, and the findings deduced from this study. These findings were found after interviewing multiracial participants, audio recording the interviews, utilizing in vivo coding as the first cycle of coding, and following up with pattern coding to locate themes as the findings.

\section{Background of Study}

In this study, I examined sense of belonging multiracial students experience while enrolled in a predominantly White institution. Currently, there is a lack of research that focuses on multiracial college students and their experience while enrolled in these institutions. This study was necessary to highlight the multiracial college student experience. Past studies have examined the experience and sense of belonging of White students and Black students at predominantly White institutions, but none have focused on the unique experience that multiracial students have. The lack of research on this particular topic motivated me to highlight these multiracial participants' experiences at this university. The goal for this study was to give a much-needed voice to multiracial students and assist them with being a part of the conversation surrounding sense of 
belonging. Multiracial students' experiences vary from their White and Black peers. I was able to gain insight on the phenomenon of multiracial students in a predominantly White institution by asking questions about their multiracial identity and listening to their experiences.

\section{Theoretical Framework}

The theoretical framework used in this study is Renn's (2004) Ecological Theory of Mixed-Race Identity Development and Maslow's (1954) Hierarchy of Needs. Renn's Ecological Theory of Mixed-Race Identity Development allowed me to identify ecological factors that influence the multiracial students' identity development. Maslow's Hierarchy of Needs theory is a motivational theory that has five tiers that need satisfaction in order for an individual to reach fulfillment of their potentialities. By partnering these two theories and using them as the framework, I was able to examine which of Maslow's five tiers were and were not being met at this predominantly White institution. Renn examines multiracial identity development through ecological factors (Renn, 2004) and Maslow's third tier of Love and Belongingness, is a factor that impacts this development.

\section{Participants}

In this phenomenological study, I interviewed 11 multiracial undergraduate participants at one predominantly White institution. Of the 11 participants, 3 were sophomores, 2 were juniors, and 6 were seniors. 4 participants identified as male and 7 identified as female. 4 of the participants identified their maternal racial identity was Black and their paternal racial identity was White, while 7 elected that their parents' 
racial identities were vice versa. Nearly half (5) of the participants identified that they were first generation college students. Each multiracial participant had a unique declared/interested major. 2 participants had transferred from another university.

TABLE 2.

\begin{tabular}{|c|c|c|c|c|c|c|}
\hline Participant & Gender & $\begin{array}{c}\text { Maternal } \\
\text { Racial } \\
\text { Identity }\end{array}$ & $\begin{array}{c}\text { Paternal } \\
\text { Racial } \\
\text { Identity }\end{array}$ & $\begin{array}{c}\text { Declared } \\
\text { Major }\end{array}$ & $\begin{array}{c}1^{\text {st }} \\
\text { Generation } \\
\text { College } \\
\text { Student }\end{array}$ & $\begin{array}{c}\text { Class } \\
\text { Status }\end{array}$ \\
\hline Leroy & Male & Black & White & Neuroscience & No & Junior \\
\hline Sage & Male & Black & White & $\begin{array}{c}\text { Art \& } \\
\text { Psychology }\end{array}$ & No & Sophomore \\
\hline Halle Berry & Female & Black & White & Biology & No & Senior \\
\hline Tom & Male & White & Black & $\begin{array}{c}\text { Sports } \\
\text { Administration }\end{array}$ & No & Senior \\
\hline Bay & Female & White & Black & Communication & Yes & Junior \\
\hline Paige & Female & White & Black & Chemistry & No & Senior \\
\hline Taty & Female & White & Black & Interior Design & Yes & Senior \\
\hline Jay & Female & White & Black & Communication & Yes & Senior \\
\hline Jamaal & Male & White & Black & Finance & No & Sophomore \\
\hline Beyonce & Female & White & Black & Pan-African & Yes & Senior \\
\hline Nichole & Female & White & Black & Biology & Yes & Sophomore \\
\hline
\end{tabular}

\section{Results}

Results from this study are broken into two sections. The first section includes the findings as they answer each research question, starting with the central research question, and present emerging themes. The second section includes the findings integrating Maslow's Hierarchy of Needs theory with Renn's Ecological Theory of Mixed-Race Identity Development.

\section{Research Questions}


- Central Research Question: How do multiracial students at a predominantly

White institution describe their sense of belonging?

- RQ1: In what ways do multiracial college students feel that they can be their completely authentic self at all times while at a predominantly White institution?

○ RQ2: How do multiracial students feel comfortable or uncomfortable at a predominantly White institution?

- RQ3: How salient is multiracial students' race while at a predominantly White institution?

\section{Central Research Question: How do Multiracial Students at a Predominantly White Institution Describe their Sense of Belonging?}

The majority of multiracial students in this study did feel connected to the university they were enrolled in. Multiracial students who felt connected at this university did so primarily through close friends and students in the campus community. When asked about their feeling of connectedness to the institution, one participant stated:

I would say that I feel connected to the community and the university through other people. Getting involved with the community, getting involved with anyone on campus and meeting new people is really the biggest chance you are ever going to get to step out and get used to the atmosphere. Specifically, the (Predominantly White Institution's) diversity allows me to go out on campus, whichever part of campus I am at, and I can see different colored people. I really can see different colored people (Nichole).

Multiracial participants in this study felt a sense of belonging at the university through social integration and through the interactions that they had with other students in the 
campus community. Multiracial participants' experiences align with Tinto (1993) when he discusses interactions having the biggest impact on sense of belonging.

Most multiracial students who felt a sense of belonging and connectedness did so through involvement in predominantly Black organizations and campus resources (e.g., Cultural Center, Student Activities Center, Writing Center). Multiple students stated that their minority scholarship program, National Pan-Hellenic Council (NPHC) Greek organization, diversity mentoring program, and the cultural center allowed them to become involved with other People of Color at the university. When asked a question regarding, to what extent the participant felt that they belong at the predominantly White institution they were enrolled in, the first participant stated:

The cultural center was where you needed to go, regardless if you were a minority. They could hook you up. Within the day they would send emails, get emails back to you, include you in those emails, and that's where I felt like included. Where I can talk to someone and rely on someone, in the cultural center cuz I always felt like if I needed something done within the hour they would be like "okay I got you, I will include you in the email" (Leroy).

Cultural centers are designed to be welcoming spaces for marginalized students (Patton, 2004). According to multiracial students in this study, the cultural center at this institution has a positive impact on sense of belonging for marginalized students. This physical facility is beneficial at this university and is providing a social haven for multiracial students (Jones et al., 2002).

Some multiracial students did not feel connected to the university and struggled to establish connectedness, especially during their incoming semester. This first semester is a transitional time and it can be difficult for multiracial students attending predominantly White institutions to get acquainted. Typically, these students feel better adjusted in 
diverse groups, due to multiracial students having increased cultural diversity and empathy (Shih \& Sanchez, 2009). When asked about a place or group on campus where they easily found a sense of belonging, one participant stated:

Well honestly, I didn't feel like I belonged anywhere on campus until my second semester and I took an art history class. My first semester I took a lot of social based classes because that was like part of a living learning community I chose, so I took a sociology class that was all about race, you know, a couple of honors classes that were race intensive. But, you know, I feel like I walked into this art history class and there were People of Color, like queer people, straight people, people of different religions and like, you know when you can walk into a room and just feel like it's not all singular. There was a lot of different things going on and people mixing. Everyone got a seat at the table and everyone was encouraged to participate (Sage).

Being in groups with diverse individuals allowed the multiracial student to not feel pressured to identify with just one identity (Ingram et al., 2014). This diversity of identity includes race, sexuality, gender, ability, religion, and socioeconomic status. Ingram and colleagues (2014) found multiracial students feel more comfortable interacting and being friends with diverse individuals, while enrolled in a predominantly White institution. Ingram and colleagues' (2014) findings relate to Sage feeling more comfortable in a class full of diverse individuals

Some multiracial students felt that the university did not make a strong enough effort and that the university treated them as a "pawn" to meet a diversity quota. When asked what ways do you feel connected to the predominantly White institution you are enrolled in, Jamaal said that they did not feel connected. When I asked a follow up question as to why they felt that way, they said, “The institution itself, I don't think it makes a big enough effort to try to connect with me. Organizations that are predominantly African American do. Not the university as a whole, but there are people 
there that do" (Jamaal). Many multiracial students discussed that they felt like a "pawn" at the institution. They felt that they are needed, but not appreciated. When I asked, to what extent do you trust or mistrust professors, administrators, or campus resources (e.g., Cultural Center, Student Activities Center, Writing Center) at the predominantly White institution, Halle Berry stated:

The only thing I think bothers me is like I mentioned earlier, being a Black person, I feel like I'm a pawn. I'm not important to an advisor necessarily or to someone higher up. The diversity chairs and stuff like that I feel like I would be used strategically for their gain in some way and not really cared about as much as a student if that makes sense. I feel like if I was performing well, they wouldn't be happy about it necessarily for me, but they would be like another Black girl who is going to look good on us (Halle Berry).

Halle Berry felt that her success, as a person of color, would be used primarily to better the university's image. Currently, African American students at predominantly White institutions have among the lowest persistence rates and highest dropout (Espinosa et al., 2019). Successful marginalized students, such as Halle Berry, increase the institutions' reputation of caring for diverse individuals. This increase in reputation encourages other marginalized students to attend the university, which increases enrollment. Some multiracial students feel like pawns and feel that the institution does not genuinely care about their success. Treating students as pawns contradicts the student affairs professions' goal of caring and developing the whole student (Baxter Magolda, 2009).

Multiracial students described their connection to campus through connection to people on campus, college fandom through athletics, and organizations. Multiracial students felt connected in a variety of places and groups on campus such as: National Pan-Hellenic Council (NPHC) Greek organizations, Interfraternity Council (IFC) 
fraternities, National Panhellenic Conference (NPC) sororities, diversity scholarship program, diversity mentoring programs, cultural center, housing and residence life, athletic teams, and academic departments. Hurtado and Carter (1997) found that minoritized students who were involved on campus had an increased sense of belonging, compared to peers who were not involved. Hurtado and Carter (1997) also found that students involved in racial-ethnic student organizations had a relatively higher sense of belonging, especially when racial tension was reported on campus. Student involvement contributing to multiracial students' sense of belonging confirms Hurtado and Carter's (1997) findings. Multiracial students made connections that helped with their sense of belonging with primarily minority faculty and staff on campus including: Cultural center employees, minority mentors, Black advisors, and Black professors. Predominantly White institutions develop these initiatives that multiracial participants took advantage of, such as student involvement, faculty interaction, and peer support as a way to support and retain marginalized students (Palmer et al., 2012).

A little over half of the students disclosed that they felt a sense of belonging at the university due to involvement on campus, finding a home within their academic department, and relationships with faculty and friends of color. Taty disclosed that her NPHC sorority makes her feel comfortable, connected, and welcomed on campus. When asked what about her sorority makes her feel comfortable, her response was "My sisters in (NPHC Sorority), we can talk about things like our hair and our bonnets. Just the little things in our lifestyles that separate us from White women that my White friends wouldn't understand. That is what makes me feel connected to them (Taty)". Taty expressed that she felt connected through the similarities they shared. Leroy mentioned 
that his professors of color are the ones that help him feel a sense of belonging. When asked about trusting or mistrusting professors he disclosed "I've noticed a lot of the teachers I take are foreign or either a minority in general. My freshman year actually had a lot of White teachers and they did not care at all (Leroy)." He then went on to discuss professors that made him feel like he belonged:

I had a physics teacher, it's a class of 120 students, I'm walking across the street and he's like "Hey (Leroy) I'm like "you know my name" I was like can I talk to you? I know it's not your office hours today, but I have a question on the homework assignment that I'm pretty sure is gonna be on the quiz. He's like "Let's go to my office" and this is outside of his office hours. Every teacher that I had that was not White has done that for me or has been able to sit on the phone outside of office hours and talk to me. He was the only teacher I know he would, he told his students to call my cell phone. Like, I will sit up and give you an hour of my time to make sure you understand what's going on in the class (Leroy).

Marginalized professors showing care and interacting with the multiracial student increases their sense of belonging. Strayhorn (2012) mentions the importance of faculty in his definition of sense of belonging, "...experience of mattering or feeling cared about, accepted, respected, valued by, and important to the campus community or others on campus such as faculty, staff, and peers" (p. 4). Faculty members demonstrating care and acknowledging multiracial students made them feel valued and accepted.

For the few multiracial students who feel like they do not belong, lack of belonging is due to adverse experiences at the university. One example of this is the racist remarks they received from their peers, specifically the predominantly White Greek fraternities. When asked, to what extent do you feel like you belong, Halle Berry recalled an experience she had that stayed with her:

A lot of White people in Greek life here are very oblivious on how to talk to Black people. That's another story, I've gone to frat parties with my friends 
where we are three black girls walking in. This is a true story, someone said "oh my god, I hope we don't get shot" (Halle Berry).

This experience not only stayed with Halle Berry, but it discouraged her sense of belonging at the university and influenced her to say “So, I wouldn't say like I feel like I belong necessarily" (Halle Berry).

\section{RQ1: In What Ways do Multiracial College Students feel that they can be their}

\section{Completely Authentic Self at all times while at a Predominantly White Institution?}

I gave participants the opportunity to form their own definition of what the term authenticity meant. Multiracial students at this university defined authenticity as being their "real, true, genuine self". One could argue that no one can, but nearly all of the multiracial students at the institution I interviewed do not feel like they can be their completely authentic self at all times. Multiracial students generally felt comfortable being completely authentic around close intimate friends. Halle Berry mentioned that she could not be her completely authentic self at all times, but she affirmed:

The only people that I am authentic around are my two best friends who are also, who are more lighter skin people who grew up in all white areas. We are kind of the only people that get our struggle of like, I don't really know as much as these other Black people do about the Black struggle and the Black culture, but at the same time I grew up in an all-White area so I face that feeling of being ostracized and that White discrimination (Halle Berry).

Halle Berry mentioned not knowing as much as other Black people, meaning that she does not have the same cultural knowledge as them (Renn, 2000). Cultural knowledge can dictate how a multiracial person navigates space on a college campus (Renn, 2004). This participant does not have the same cultural knowledge as other Black people, but 
just as in Renn's (2000) findings, she is still authentic in her private space. Halle Berry is completely authentic around her close intimate friends who are racially identical to her. These students have a shared experience and understand the discrimination that each other encounters. Multiracial students being authentic with close intimate friends allows them to have increased confidence and comfort (Renn, 2000, 2004; Wallace, 2003). Being authentic with close intimate friends confirms Renn's (2000, 2004) and Wallace's (2003) notion of space, whether it be public in social groups, or private with intimate friends.

Multiracial students in this study admitted that they were not their authentic self at all times due to constantly code switching in search of acceptance. Chronic codeswitching is an emergent theme in this study that I will discuss in more depth in the emergent themes section. Students feel obligated to have a "toned down" identity and feel "Too Black" around White peers and "Too White" around Black peers. Tom who said he feels completely authentic around intimate friends, stated that many people do not understand him and that "It has its own uphill battles and a lot of people just don't get it. There are times that you are told that you are too White around your Black friends and you are too Black around your White friends. That's happened" (Tom). This quote from Tom confirms Renn's (2000) findings regarding discrimination coming from both White and Black monoracial peers. Discrimination negatively impacts student development (Nadal et al., 2014).

\section{RQ2: How do Multiracial Students feel Comfortable or Uncomfortable at a Predominantly White Institution?}


Comfortable. Multiracial participants do feel physically comfortable at this predominantly White institution and have no physical safety concerns. Multiracial students primarily trust professors and advisors. Overall, multiracial students felt that faculty/staff of color are more helpful, caring, and authentic compared to White professors and staff who judged and were not always helpful. When asked what makes you feel comfortable at this predominantly White institution, Jamaal discussed faculty and staff of color. Jamaal reported:

They weren't afraid to be like "we are Black" or "we are People of Color" because we are and that's part of it, we have to take it with every stride. I think acknowledging it definitely is a big part of it because it is. I know like most people, if you're not African American or if you are not a Person of Color you can't quite understand that, but with them they do. They acknowledge my existence. Not like it is a problem, but we are People of Color and we are going to work with that and be successful either way (Jamaal).

In this study, faculty/staff of color simply acknowledging multiracial students overwhelmingly increased their sense of belonging. Acknowledgement from faculty/staff of color made multiracial students feel that they mattered and were supported, which correlated to sense of belonging (Strayhorn, 2012). Faculty support promotes social integration for college students, which increases their educational and institutional commitment (Tinto, 1975).

Seeing and being with other People of Color often made multiracial students overwhelmingly feel comfortable. Multiracial students discuss the comradery and the feeling of family when they were with other People of Color. Halle Berry expressed:

I feel like the people I was able to meet that freshmen year on those nights in the library, seeing them being in (Diversity) scholar society or BSU, (NPHC Fraternities), being an (NPHC Sorority), seeing that taste of Black culture, Black 
life, connecting with other Black people. For some reason I feel like I'm your sister or your cousin and they really took me under their wing (Halle Berry).

Having support systems such as these increased students' comfort. Multiracial students also feel more comfortable at this university when diversity talks among the university, White people, and other multiracial students are taking place. Sage feels that people are trying to understand him more and disclosed, "There are a lot of people at (Predominantly White institution) who weren't supposed to be involved in social justice before, who are now. Who are taking those race-based courses". Sage felt more comfortable when peers were actively learning about race and social justice. The university is providing opportunities for conversations around diversity. These diversity talks can be beneficial, if facilitated well. Multiracial students usually felt belongingness with other multiracial people and felt comfort in having someone that shares their struggles. Jay disclosed:

It was different and also the connections I made with, especially the girls, that made me feel like I belonged. We would tell our stories about our same struggles and things like that. My exes' roommate's girlfriend, she is also mixed/biracial, so we also connected on that level, her mom is White and her dad is Black so we connected like that. Then I met a bunch of other people and they kind of dealt with the same things. Once we started talking about it, we realized that that was not okay. It kind of comes with the college territory, you get educated and understand that you don't have to go through this and that you shouldn't be going through this. That was very very nice. That is where I felt like I belonged, and it helped me unlock this whole other half of me that I didn't realize I had or that I didn't embrace to the fullest (Jay).

Shared struggles allowed multiracial students to connect and find support with one another. Many times, monoracial individuals do not always understand and do not receive multiracial students positively (Jones \& Jones, 2010). In this study, multiracial students found comfort in knowing that multiracial friends would understand their struggle. 
Uncomfortable. Racism on campus was a large reason that, at times, multiracial students felt uncomfortable at the predominantly White institution. Racism in student areas occurred in the general campus population, but more abundantly in predominantly White Greek life. For racism within the general campus population, Nichole mentioned an experience she had in her residence hall. Nichole revealed:

One time I was walking down the hall close to my room. As I was passing the doors there was some loud music playing. It was a few doors down, but you could hear the loud music playing. I was passing the room because I was taking my laundry up to my room. What you don't want to hear passing those rooms, especially when you know who lives in those rooms, because you walk by those people every day. You don't want to hear someone taking advantage of your culture. They were listening to rap music and I don't remember what the song is, but I don't want to hear you say "nigger" I don't want to hear you say that. I know that you are White. I don't want to hear that in the hallway. It wasn't like I was right at your door; I am walking down the hallway and these are not the things I want to hear. To them it was a joke, I did speak to my RA who was also Black. I don't want to say completely, she might have been mixed, and she brought it up to management (Nichole).

This experience was extremely challenging for this multiracial student because the residence hall is where she spent a majority of her time. When one's living space degrades belonging it is difficult for a student to find comfort, due to constantly being reminded of the racist interaction. Racism on campus occurred within the general campus population, but according to multiracial students in this study, racism occurred more frequently within the predominantly White Greek life.

The multiracial participant Paige discussed that White faculty and staff gave judgement as soon as she met them. These judgements came from monoracial individuals who made assumption on her presumed identity. Harris (2017b) found that multiracial individuals commonly experience microaggressions from monoracial individuals, 
specifically through the assumption of a monoracial identity and characteristics. Paige

discussed a recent experience of judgement that she had with a White staff member:

Yeah, with my academic advisor. She called my name and I stood up, and my name is a very White name, and she was very surprised. When I sat down and I told her my major, she tried to hide it, but I know she stopped for a second and tried to play it off. With my major being chemistry, I don't think she was expecting that at all. It is just those little sudden movements that I come to notice that people are surprised (Paige).

In this situation, Paige experienced a microaggression from her academic advisor. This microaggression was unintentional and subtle, yet it was hurtful to this multiracial student. Racial microaggressions are a form of racism that can have a macro impact on marginalized students' motivation and social integration (Reynolds et al., 2010).

A majority of participants disclosed a racist incident that occurred with members of predominantly White Greek life. A question regarding discomfort was asked to Leroy and he mentioned a story regarding predominantly White Greek life. Leroy announced:

Whenever I see a lot of the White Greeks on Greek row, that kinda makes me uncomfortable. Because I kinda get like dirty looks because I don't really wear my letters that much, but when I do it kinda breaks their necks and they're like "O". And a lot of the retreats that I'm required to go on because I'm high up in my organization and in NPHC, they say a lot of racist stuff sometimes and they ask a lot of questionable questions like that make you think like they are very uneducated. That kind of makes me uncomfortable (Leroy).

Predominantly White Greek life members said racist things that made Leroy uncomfortable. Museus and colleagues (2015) found this discrimination challenging to cope with, due to the multiracial student being obligated to interact with these students and not being able to avoid the confrontation. Leroy shared: 
We were actually explaining to them how our organizations work on recruiting and they were kinda asking like ignorant questions on like "What do yall do to them, yall probably do some stupid stuff, and umm I don't think we can get in because we are White or whatever" and I'm looking to my right and I'm like, my ace is right there (Who is White). I'm like 'No, he's got the same letters on as me" (Leroy).

Students in predominantly White Greek life making uneducated assumptions on Historically Black Greek life makes this multiracial student feel uncomfortable.

The racist comments from predominantly White Greek life is so prevalent that some multiracial students are fearful of what the predominantly White Greek life members might say to them. Sage shared:

You'll walk by a group of fraternity dudes, not my fraternity, but you walk by guys from a certain type of fraternity because fraternities recruit certain types of dudes. And they are all wearing, I don't want to say uniform, but basically a uniform like short khaki shorts and the boat shoes. You walk past these dudes with your friends of color and unconsciously you put your head down, because you don't want to make eye contact with these people. Just because insecurities of people of color. Just because these people might say something racist about you, what if they do? You don't want to put yourself in that situation where you have to defend and attack. Not as much for me because like I said, I can pass for White, but that internal privilege like I can and should say something where my friends of color don't feel as comfortable. It's easier just to avoid those situations altogether, that's as accurately as I can describe discomfort (Sage).

These past racist comments from predominantly White Greek life members made the multiracial participants in this study uncomfortable and made them avoid situations where they might encounter predominantly White Greek life.

Another common source of discomfort for multiracial students was "Onlyness", being the only Person of Color in class (Harper et al., (2011). Harper and colleagues (2011) described "Onlyness" as "the psychoemotional burden of having to strategically 
navigate a racially politicized space occupied by few peers, role models, and guardians from one's same racial or ethnic group" (p. 190). Being the only Person of Color in the academic setting not only made the student feel uncomfortable, but also made them feel excluded. Beyoncé disclosed that she felt at home in her academic department (PanAfrican Studies), but felt uncomfortable in other courses due to being the only Person of Color and the only female. Beyoncé shared her experience saying:

I always feel uncomfortable in classes when, well I start off feeling uncomfortable in classes when I am the only woman, only Black person, and especially the only Black woman. It started off as uncomfortable and then it got to be like "Okay, here we go again" because I knew either my experience was going to not be acknowledged or it was going to be downplayed... (Beyonce).

In these uncomfortable situations multiracial students were forced to navigate their experiences. They feel "the psychoemotional burden of having to strategically navigate a racially politicized space occupied by few peers" (Harper et al., 2011, p. 190). This was challenging to navigate because their coping strategies were limited due to not being able to avoid the confrontation or utilize support networks (Museus, Lamb Sariñana, \& Ryan, 2015).

Multiracial students navigated feelings of discomfort by using an array of techniques. Some multiracial students used it as an opportunity to educate others, utilized close friends or other peers of color, ignored the feelings of discomfort, or used positive self-talk to get through the situation. Leroy navigated discomfort as opportunities to educate peers. Leroy announced:

So, navigating it it's just one step at a time and it's all about educating is how I see it. You educate because people they seem ignorant, but some people genuinely don't know because they are not taught to not say that. Or their parents have said it or are like "I say it all the time and my Black friends don't think it's a 
problem." So, fighting and navigating uncomfortable circumstances I seem like I give people the benefit of the doubt and I take it as an opportunity to educate versus some people would like pop off (Leroy).

Educating others is a coping strategy that teaches others about racial backgrounds and raises awareness (Museus, Lamb Sariñana, \& Ryan, 2015). Another coping strategy that multiracial students in this study used was positive self-talk. When asked how to navigate discomfort, Jamaal discussed:

I kind of had to deal with that my whole life so I am kind of used to it. I kind of just sit there. I usually try to take it like there is a reason that I am in that room and I a different color, but it really doesn't matter. I know my worth and I know that I am most likely going to be more successful than all these people. That's how I usually do it (Jamaal).

The strategy of positive self-talk is what this multiracial student was using. Positive selftalk relates to Maslow's (1954) fourth tier of esteem needs. By using positive self-talk, this student is giving pride to themselves and their accomplishments. Positive self-talk is a coping strategy that was not previously identified in the research, as a strategy that multiracial students in this study used to cope with discrimination.

\section{RQ3: How Salient is Multiracial Students' Race while at a Predominantly White}

\section{Institution?}

Only one multiracial participant felt that their race was not important at the university, while the rest of the participants admitted that race was "important", "huge", or "extremely important". Participants discussed that being multiracial meant that they are "The Best of Both Worlds" and that they are a "Multiracial Bridge". When asked what being multiracial meant for Paige, she shared: 
I think I have the best of both worlds; I really do. I get to see both sides in a different lens than other people. I grew up in a house that both sides of my family were different than one another. It gave me that opportunity to not see just, okay one side of the family is going to do this and the other is going to do this. It allowed me to see what are similarities, what are differences and it allowed me to bring that to campus and to other people. I think that brought a more well-rounded person out of me. I was able to see differences at a very young age, but also similarities (Paige).

Paige explained that growing up, she had exposure with both the Black and White sides of her family. Using this exposure, she was able to compare, contrast, and become a more well-rounded person with characteristics from both worlds. Being "The Best of Both Worlds" was a recurring sentiment that most participants shared. Another recurring statement and an emergent theme was multiracial participants feeling like a "Multiracial Bridge". When asked what being multiracial meant to her, Jay asserted:

Honestly, it means I have multiple sides to myself. It is something that I used to hate, and I just wished that I was just one or the other. Not that I bring, I don't think that I bring more to the table, but I bring a different perspective to the table. I am able to connect these two races that a majority of the time have issues. I can explain both sides in a way that I feel like each perspective side would understand. I think that it makes me unique and it was something that I was insecure about and didn't like but now I embrace it, I love it (Jay).

Jay discussed how she could connect friends from the two races and explain issues in a way that people from each race were more receptive. Quillian and Redd (2009) found that multiracial adolescents bridge friendships among peers that are typically racially segregated. Instead of adolescents, this study focused on college students who were more mature and knowledgeable about racial issues concerning both sides. Multiracial students in this study acknowledged that by being a part of both sides, they can explain issues to each perspective side in a way that they would understand. 
When describing what being multiracial at their current institution meant,

participants admitted that it was a challenge/struggle and includes discrimination against

race. Many participants used the words: challenge, struggle, difficult, and uneasy to

describe being multiracial at a predominantly White institution. Paige mentioned:

It's hard. It's like you are trying to find your place, but I feel like we have one of the hardest times trying to find that place because you are either too African American or you are too Caucasian. You put on a persona and it's not how they envision you are. You are trying to figure out where you want to go while other people are also trying to tell you where you should go too (Paige).

Due to multiracial students' racial ambiguity, they are challenged to respond to external definitions (Kellogg and Liddell, 2012). With difficulty finding a place, multiracial students face discrimination. Halle Berry discussed her experience

To me, being multiracial means, I still have seen a lot of discrimination, I have still been ostracized, I've still been the Black girl. At the same time, I have privilege to work towards a better future and to change things. I really think that is important in every part of my life. Going to Med school and starting a new generation where I can be the Black girl that goes to talk at high schools that I didn't have, being the Black girl who works in campus housing. Even though I'm light skinned, I can still connect with Black students and White students and make them feel comfortable in their space. I would say I have two sides of the coin. Sometimes I don't really know where I fit but at the same time it is kind of my place to make this a better place (Halle Berry).

Facing discrimination motivates Halle Berry to be the "Multiracial Bridge".

\section{Emergent Themes}

Four emergent themes were found after two cycles of coding. The four themes are chronic codeswitching, multiracial bridge, multiracial students as pawns, and sense of belonging with close friends \& student organizations. 


\section{Chronic Codeswitching}

All multiracial participants in this study constantly felt that they needed to adjust their personality or appearance based on the racial identity of the people they were around. Maria Root (1996) first discovered this adjustment in multiracial students and used the term "border crossing", describing it as "The active and habitual situational manipulation of race between foreground and background..." (p. xx). In this study, I am using the term chronic codeswitching because it occurred frequently in participants. Chronic codeswitching occurred amongst participants consistently in a variety of groups. Chronic codeswitching is primarily a behavioral (and or cognitive) adjustment that can be visible (adjusting words they use, or as one participant describes, having more or less swagger) in order to optimize the comfort of others in exchange for acceptance.

Negotiating authenticity and self-expression on a daily basis can spiral into a continual stream of negative effects on wellbeing. Chronic codeswitching contributed to multiracial students not being able to be their completely authentic self at all times while at the university. Halle Berry explained:

I would say no, definitely not. I'm constantly code switching, I'm constantly having to change who I am based on who I am around. That goes for when I'm around White people or Black people. Like I said, I really struggle with that, from growing up in an all-White area and being one of those people of color girls that, you know I have my White voice and then I have my Black voice. It's just kind of frustrating to me because when I'm around White people, I have to talk in a certain way that this person is receptive too. Talking about my White coworkers, you won't necessarily see me being very relaxed. I always work really hard to articulate myself very well. That could also be because it's a job. Even when I have White people in my class, I feel like I have to put on a veil to get them to be receptive to my personality in a way. On the other flip side of the coin, I feel like sometimes with Black people I code switch to where I can be more in that African American way but at the same time I feel like I can be judged because I'm still kind of like that White girl of the group. On one hand I feel like I'm the Black person around all the White people who has to work harder to articulate themselves and then around the Black people I feel like I'm too proper, I feel like 
I have no swagger. I have to navigate that a little bit on words to use, what words not to use because I'm still being a little bit judged (Halle Berry).

Halle Berry participated in chronic codeswitching by constantly altering herself based on which friend group she was around. She, like many multiracial students in this study, had a fear of judgement. To avoid this judgement, students felt that they must put on a veil to get others to be more receptive. People constantly judged the multiracial student, which pressured the student into chronic codeswitching as a way to navigate. Paige described chronic codeswitching as wearing masks:

I think it is just coming back to where I was talking about acceptance and how everyone paints this picture in there head about how you should act or what you are going to bring. I just always felt like I need to where one mask for some people, another mask for other people, and another mask for others. Of course, I am getting better with that. I know that's bad, but I felt like when I first set foot on campus they have that welcome week and you are trying to figure out where you belong, but you also want people to take you in as well. That's where I felt like it really began, was with how am I going to fit in campus, but also how am I going to get these people to bring me into their group. I think that's really where it started (Paige).

Changing of masks happened abundantly in search of acceptance. In chronic codeswitching there is no choice; and the exchange occurs because there is a lack of freedoms for multiracial students to feel comfortable. This first occurred during her first week on campus when she was trying to find where she belonged. Chronic codeswitching made it extremely difficult for multiracial students to be their authentic selves. When asked if she can be her authentic self, Bay stated:

No, but I also feel like that's kind of the way I am in everyday life. Not really knowing how to present myself to other people. I have heard everything from, "you're being too White" to "you're not Black enough". It really depends on who you are presenting yourself in front of. I kind of base how I alter my perception to them (Bay). 
Bay frequently altered her appearance and perception based on the people she was around. Chronic codeswitching appeared throughout the transcripts and data analysis. Multiracial students constantly receive the remarks that they were "Too Black" in some situations and "Too White" in others. Root (1996) describes people who make comments such as these as border patrols, or people who are determined to deny entrance to anyone outside of their racial group. Hearing remarks such as these discourage authenticity and encourage the multiracial student into chronic codeswitching, as a way to negotiate their identity. Hearing this repeatedly forces the multiracial students into chronic codeswitching, in search of acceptance.

\section{Multiracial Bridge}

Multiracial bridge was another recurring theme in this study. Quillian and Redd (2009) found a social relationship bridge amongst multiracial adolescents and their monoracial friend groups. These researchers described this bridge as the multiracial adolescents uniting friendship networks that were typically racially segregated (Quillian and Redd, 2009). In this study, I am describing this theme as the multiracial bridge. Multiracial students at this predominantly White institution felt that they can communicate with White peers about Black issues and ideologies in a way that they are more receptive and can communicate with Black peers about White issues and ideologies in a way that they are more receptive. Taty was involved in a NPHC sorority on campus and was involved in a NPHC pageant. Taty won the pageant, and she shared her experience:

Something that I think helped me win that pageant is that in my interview they asked me, "why could you bring such a positive outlook on life on whatever the 
outcome may be as Mrs. (NPHC Pageant)" and I told them "Since I am biracial, since I am Black and White I am able to converse with my Black community in a way that they will understand, when it comes to me talking about my White culture, and they would understand me better than it coming from someone who is White. I can go back and talk to my White community and inform them about my Black community in a different way". I told them "it's kind of like the best of both worlds" (Taty).

Taty discussed that by being multiracial, she can discuss racial issues in a way that both

Black and White peers can better understand. Beyonce reiterated this by saying:

Having access to different spaces, seeing things from multiple perspectives and being able to bring them together. Being able to use my voice in spaces where others may not feel like they will be heard and fight for them and advocate for them. It's being able to educate others who just genuinely don't know or have never been exposed to certain information or certain experiences that people have, different perspectives that people are not getting. Being an ally for multiple groups of marginalized communities and marginalized populations and finding a way to not bear the burden of all of it, but to be that voice and make sure that I am going to use my platform in whatever way I can so it can be addressed or at least so you aren't able to say that you don't know (Beyonce).

Beyonce discussed using her voice in spaces to advocate for people who may not have access to the space. Not only could these students advocate for multiple racial groups in a way that others are more receptive, but their multiracial identity granted them access to these various spaces through, what Root (1996) described as, border crossing. Nearly all of the multiracial participants in this study brought up experiences being the multiracial bridge while enrolled at the university. Many multiracial students identify with Tom when he said "I feel like I can bridge the gap between the issues. I can kind of see both sides and clearly state where something is wrong" (Tom). Tom wants to bridge this gap for better understanding among groups. Multiracial students at this university provided a multiracial bridge to racial issues.

Multiracial Students feel like Pawns 
Many multiracial students brought up the recurring feeling that as multiracial students, they were just pawns at the predominantly White institution. They mentioned that this made them feel that they did not actually belong at the university and that they did not matter. Halle Berry shared her experience as a Pre-Medical student:

Here is a real story, I was going to an advisor here and I will admit, I had some hiccups here at first with my grades. I have always been so worried about getting into med school. All the people at med school are telling me 3.8 is the median GPA I needed to shoot for. I was more like on the 3.2 or $3.3 \mathrm{GPA}$. I go to my advisor and she just gives me this look like "you'll be fine, you'll get in". It just kind of, I don't know exactly what she meant by that but I kind of knew that they were looking for People of Color and women of color. That was a moment that I was like I don't necessarily belong here, but they need me here as like some pawn. I felt like she didn't really feel like she cared about my security or my actual learning. How my progress was, my development was just kind of like a check off the box (Halle Berry).

University employees often treat multiracial students like a check off the box. This makes them feel similar to Halle Berry, as if they do not genuinely belong. Ancis and colleagues (2000) found that students of color had a more negative experience with campus, staff, and faculty, than their White peers. More specifically, students of color disclosed that faculty and staff did not take their academic ability earnestly (Fries-Britt \& Turner, 2001). University employees not genuinely caring for the multiracial students makes them feel like pawns. This feeling of being pawns, deters their sense of belonging. Being a pawn or another statistic worries multiracial students at this institution. They understand how easy it is for them to be "just another statistic" (Leroy). Leroy discussed his experience working with a non-White professor and not wanting to be a statistic: ...she's from Bosnia and no other chemistry teacher was as good as her because she understood the struggle of being in America or being like an outcast and I know how hard she had to work and I could relate to that because I'm at a predominantly White institution where you know you can just be another statistic 
that just drops out and then they are just going to give your scholarship to someone else (Leroy).

Leroy mentioned that they would just give his scholarship to someone else, as if he was disposable. Experiences such as these make multiracial students not feel like they belong. Multiracial students recognize, many times by White faculty and staff members, they are not viewed as a whole student. Multiracial students, such as Jamaal, also repeatedly mentioned that professionals of color increasingly made them more comfortable and made them feel that they belonged. When asked what about them made him feel this way, Jamaal mentioned their transparency and that "They acknowledge my existence" (Jamaal). By having their existence acknowledged, multiracial students' sense of belonging at their university increases but, unfortunately this does not always happen with all professionals at the institution.

\section{Sense of Belonging with Close Friends \& Organizations}

Nearly all the multiracial participants in this study admitted that the university was more than just a place to earn a degree, it was a hub for diverse individuals to gather. Their true sense of belonging was felt with the close friends they met at the institution and the organizations that are made available at the university. Renn (2000) used the notion of space to analyze belonging. Whether it be private or public, space has meaning. Private space is described as being with trusted others, while public space is the shared space with common social groups (Renn, 2000). In this study, close friends related to private space and student organizations related to public space. Beyonce shared how she found her sense of belonging in the public space, through student organizations:

I feel like I didn't necessarily belong with getting here, but I created my space while I am here. While not only in the classroom and academic circles, but 
through my involvement on campus. I made sure that I was joining organizations, or getting leadership roles, or using my voice in different roles to use my voice and say... Okay, you said predominantly White institution. From what I gathered about this university; I would say that it is more historically White. It was for White students, with the purpose of excluding Black students initially. For me, it's like you may not of wanted me here but here I am. I am going to make sure I am heard. I am going to make sure I am in spaces that I can create ways for our voices to be heard. You might not want me at this table but Hi, here I am (Beyonce).

Although Beyonce did not feel that she initially belonged at the university, she shaped her own space where she felt comfortable. She, like many multiracial students, found a sense of belonging through involvement on campus. When asked about what helps with sense of belonging at the institution, Nichole discussed her best friend and asserted:

For me, it helped having her around because she knew who I was. Having people around who really see you for who you are is a life changer in those "make it or break it moments" when you aren't sure if you can do it all by yourself. I have always been introverted and stayed to myself. I have always been the person to stay to myself and have been on the outside, or just different, or just weird. She has really, she is $100 \%$ Black. Just having her around, and I think it is important because she is Black, having her around has really helped me because she knew me for who I was (Nichole).

Nichole disclosed that she found belonging in private space with a close friend with commonalities. Multiracial students appreciated forming close bonds with People of Color. For nearly all the multiracial participants, the university is the most diverse place they have ever been. This allows for multiracial students to find connectedness with other People of Color, which is different from their nearly all White areas that they grew up. In these areas, multiracial students faced discrimination at a young age. Jay discussed her experiences with her predominantly White past:

Somehow at the age of 6,7 , or 8 , way too young, I knew that they were never allowed to date or marry a Black boy. I even got comments saying because I was mixed my entire family was a sin and that we were all going to hell. Crazy things, 
like I myself was a sin and this was at 6 or 7 . Obviously I didn't ever feel like I was good enough for them. (Jay).

Racist experiences such as this shape multiracial students' perceptions of their own identity and how they navigate space (Museus et al., 2016). Having experiences such as this was common throughout the multiracial participants, which makes it understandable for students to find sense of belonging with their best friends of color and minority organizations.

\section{Findings}

The findings of this research on multiracial students' sense of belonging in a predominantly White institution was analyzed through the theoretical framework of Renn's Ecological Theory of Mixed-Race Identity Development, while integrating Maslow’s Hierarchy of Needs theory. Kristen Renn used Bronfenbrenner's Person, Process, Context, and Time (PPCT) model. Maslow's third tier of Love and Belongingness and fifth tier of Self-Actualization, clearly fits in the context portion of Renn's theory of multiracial identity development. By analyzing the findings in this way, the multiracial student experience at the university is better understood.

\section{Person}

Physical features for participants in this study varied. Focusing on complexion, some participants had darker complexion, while others had a much lighter complexion. The multiracial individuals with a lighter complexion recognized their privilege and admitted that it allowed them to gain access to certain predominantly White environments. A majority of multiracial students in this study were coming from nearly 
all White backgrounds. Growing up, their peers were predominantly White, which made them distinctly stick out. These participants' seemingly ambiguous identities forced them to not feel accepted. Jay stated:

The problem was I was always trying to change myself to fit into this mode to be accepted by either side. It never worked. I never felt really accepted by either. Obviously when I was younger, I wanted to be a White girl because that's where all my friends were and those were the people looking down on me (Jay).

Multiracial students in this study felt like their physical characteristics limited who they could have interactions with. Physical appearance impacts whether a student is accepted or not into a social group and is how others identify them initially, regardless of how they identify personally (Ingram et al., 2014).

Another factor is cultural background. Approximately half of the multiracial participants in this study came from cultural backgrounds with the maternal parent being White and the paternal parent being Black and the other half's parents' racial identities were vice versa. In this study, Maternal and paternal racial identity did not have an impact on these multiracial student's identity development, but the racial identity of the people they were around did. These students grew up in nearly all White high schools. All the students in this study recalled multiple instances of racial discrimination from peers growing up.

\section{Process}

Process describes the complex, ongoing reciprocal interactions involving the person and other people in society. Multiracial students in this study were constantly bombarded with discrimination from both sides. Multiracial individuals consistently 
received the remark that they were "Too Black" or "Too White", which made it difficult to feel accepted. Hearing this discrimination regularly, as the multiracial student is developing, deterred their sense of belonging. At the predominantly White institution, all multiracial students could recall a time that they encountered discrimination, and although it wasn't as abundant as in the past, it was impactful. Multiracial students were accustomed to being the only Person of Color growing up, which allowed for repeated interactions with diverse individuals at the university to be positively impactful. Reciprocal interactions with close diverse friends increased the feeling of inclusion and sense of belonging for multiracial individuals.

\section{Context}

Context is the setting that directly impacted the multiracial individual's identity development. Context is best represented by the microsystem, mesosystem, exosystem, and macrosystem. These are the environments that multiracial students are in that impact them. Below I have described each system in context for multiracial students in this university. Maslow's Hierarchy of Needs' third tier of Love and Belongingness is found throughout, but predominantly in the Mesosystem and the Exosystem. Maslow's top tier of Self-Actualization is found in the Microsystem.

\section{Microsystem}

For multiracial students in this university, the microsystem is themselves. The microsystem stuck out to me, because this is where multiracial identity development was truly taking place. Multiracial students at this institution were intrigued by their multiracial identity and all multiracial participants mentioned that my interview with 
them was the first time they were able to truly discuss their multiracial identity.

Multiracial students desired to learn more about their multiracial identity development, yet their multiracial identity was never discussed in great detail at the university. Sage mentioned his experience with trying to personally learn more about his multiracial identity:

...we had a day where we talked about mixed race people in class. You're taking a race- based class, and you're a mixed-race person, you're obviously going to want more than that because my Black and White experience are going to be way different. You know as a biracial person, our Black and our White experiences are going to be so much different collectively than just Black or White people. That's something I just kind of struggled with and I wanted to understand that more (Sage).

This constant internal struggle is what multiracial students at this predominantly White institution feel because they are constantly overlooked.

The experiences that multiracial students have at their university shape them in their multiracial identity, which influences their internal mindset. Maslow identified a character of self-actualization as concerned with the welfare of humanity (Maslow, 1954). Nearly half of the multiracial students I interviewed, by Maslow's description of the characteristics, have met this top tier in the hierarchy of needs and are advocating for equity. Many participants in this study were similar to Halle Berry and stated their multiracial identity, “...means I should constantly be working to change things for the better for People of Color" (Halle Berry). Self-actualization is the internal mindset that many multiracial participants in this study expressed.

\section{Mesosystem}


Multiracial students' mesosystem at this university was their best friends of color. Multiracial students in this institution have a difficult time being their authentic selves and chronically codeswitch. The one area that all multiracial students felt they could be their completely authentic self is with their best friends of color, while in a closed space. This is where sense of belonging was formed at this this university for these students. In these intimate environments, students were able to share struggles and experiences, without fear of judgement. The mesosystem is where multiracial students in this university feel that they can be their truly authentic self. Paige describes her mesosystem, being with her best friend as:

She is kind of just that person. I felt like with her, she knew where I was coming from because she is darker skinned tone, she is in my sorority, she knows about (Diversity Mentor Program), she knows that we are (Diversity) scholars, so I felt like with her I can talk about the problems and she would know exactly where I am coming from. I felt like I never have to sugarcoat things because she usually feels the same way too (Paige).

Most multiracial students say they can be their completely authentic self around their best friends and describe authenticity as not having to wear a huge mask. Paige, like most multiracial students, says that in the general campus population “...I feel like I always have a mask on...” (Paige). Multiracial students' best friends are typically People of Color and these individuals are part of the mesosystem for multiracial students in this institution and increase their sense of belonging.

Another part of the mesosystem for multiracial students at this university was the involvement opportunities. There is a plethora of involvement opportunities for students at this institution, but the ones that multiracial students felt are most beneficial are the diverse organizations. Sage is involved in an organization such as this and he said, "I got 
that sense of comradery and brotherhood again with these guys who were mixed races like me" (Sage). Multiracial participants shared that this feeling of comradery and family is common amongst multiracial students who are involved in diverse organizations at this university, and this increased their sense of belonging. Being in diverse organizations is important to multiracial students, because many times in classes at this predominantly White institution, they are the only student of color. Many students identify with Jamaal and his experience in business school:

I am in the business school and there is very few African American or People of Color in there. I guess any person of color can identify with this, but when you walk into a room and you notice that you are the only person there or one of the few. It's not like I feel like people are looking at me or anything, but you walk into that room and I would catch your eye and not anyone else. I am definitely out of, you know what I mean (Jamaal)?

This feeling of being out of place in the academic environment amplified the importance of being involved in organizations with diverse individuals in order to form a sense of belonging. In these environments, multiracial students do not have to validate their existence or race.

\section{Exosystem}

The exosystem is another system where sense of belonging is impacted greatly. The exosystem is external relationships that do not directly involve the multiracial student but impact the student. The exosystem for multiracial students in this university was the institutions' diversity focus. At this current time, the university is focused on race and how they can be more inclusive and welcoming, due to the recent events surrounding racial injustice that I will discuss in detail below. This predominantly White institution 
hung Black Lives Matter (BLM) banners, hosted racial diversity talks, created more racebased diversity scholarships, and placed emphasis on race. The institutions' diversity focus was the exosystem for multiracial students in this university. Sage describes racial injustice and the institution as:

Everybody who is already "woke" or focused on race was already focused on it, but now it's like a phenomenon, everybody is focused on it. Everybody is in this now, and (Predominantly White institution does a great job too on social justice and incorporating diversity and inclusion. Educating people on biases, and you know the first-year curriculum and I think throughout courses as you go through your major anyway (Sage).

Multiracial students at the university realize that much focus is now placed on race and finding new ways to promote social justice and diversity. This emphasis on race education spreads across the campus and Sage discussed that it makes him feel more comfortable:

Like I said, as of July 2020 everyone is invested in race because a lot of people, a lot more people. There are a lot of people at (Predominantly White Institution) who weren't supposed to be involved in social justice before, who are now. Who are taking those race-based courses. I feel, I'm not even on campus and I feel really comfortable about the way people might code switch and try to understand Black or Brown, or even mixed people (Sage).

The institution is, in year 2020, focused on diversity and diversity education. The university's diversity focus impacted all students, but especially multiracial students and their identity development. Racial injustice impacted the exosystem and now people are showing attention to inequity and minoritized individuals at the university.

\section{Macrosystem}


At this university, for multiracial students, macrosystem represents the predominantly White institution's beliefs and attitudes that are shared amongst employees and students. Multiracial students believe that the institution is focused on diversity, by hosting race talks and promoting inclusivity. Bay is a transfer student who has been at this university for one year. Bay announced, "I feel like there is more diversity at (Current Institution). I think they are more in tune with wanting to connect with their other races, other groups if you will. They are just more open about it and they are more welcoming about it" (Bay). Many multiracial students discussed this welcoming feeling that the institution displayed. Multiracial participants shared that although the university was diverse and welcoming, it was segregated. Halle Berry stated her experience with segregation:

I would say that the (Predominantly White institution) is diverse, but it is segregated. So, I think it is an important thing to the school, like everywhere you go. Is it a coincidence that after 6 o'clock at night all the White people are not around? I don't know what that's about. Even if you go to the SAC. A lot of Black people are hanging out with Black people and a lot of White people are hanging out with White people. I'll even mention, if you go to the Tavern on 4th street where everyone goes on Thursday nights, there is literally a section that the Black people hangout and a section that the White people hangout. I feel like it is important at this school. It's something that determines who you hang out with, where you go, who you sit with and all that. I think it is important at this school (Halle Berry).

This exposure to segregation highlights the importance of race, especially for multiracial students in this predominantly White institution.

\section{Time "Chonosystem"}


Time or "chronosystem" was the element that neither multiracial students nor their university could control. Currently, for the multiracial students enrolled in this institution, the chronosystem consists of recent events on racial injustice, in wake of a global pandemic (COVID-19). This racial injustice impacts the multiracial students' identity development and their sense of belonging at the university. Recent events surrounding racial injustice has made change in the chronosystem and has taken place outside and inside the predominantly White institution.

\section{Black Lives Matter (BLM)}

The United States has a history of racial injustice and violence. The extent of this is as deep as the systemic level in society. Currently, Black lives are being murdered at the hands of White individuals with nearly no repercussion. This has occurred throughout history, but now with technology, it is on video for the world to see. Three individuals' lives were lost in the year of this study, that stay in Students of Color's minds. These names are Ahmaud Arbery (02/23/2020), Breonna Taylor (03/13/2020), and George Floyd (05/25/2020). These Black individuals all lost their lives on video by White individuals with no repercussion, at the time of this study. Their tragic deaths reignited the Black Lives Matter (BLM) social movement, because during these murders, the country was making it seem like Black lives didn't matter. Videos of these Black individuals being murdered streamed across social media and news outlets. College students of color were compelled to see these triggering videos repeatedly. Many college students related to these murdered individuals, due to two of them being close to their own age ( $25 \& 26)$. The racial climate in the country, city, and campus was tense. This 
sparked outrage and encouraged individuals and communities to protest for racial justice and fight for humanity.

Police officers shooting unarmed Black individuals is something that was common in the news. These events are detrimental to students of color who were forced to see this racial injustice and think “Am I next?”. Multiracial students at the university who have reached self-actualization, and some that have not, feel the need to fight for racial equity. One way that these students were doing this was by protesting against racial injustice. Sage speaks of his current experience with protesting:

And you know like the times we are in now, especially with protests for Breonna Taylor, which I am involved in, it's becoming less on the academic and more like, it's going to wrap you in whether you want to be in it or not, and that's not a bad thing. It's just, what's important right now (Sage).

Although this multiracial students' focus should be purely on his academics, he is not able to do so because fighting for racial equity is what was most important to him at the moment.

Neither multiracial students nor the university can control the chronosystem, but they are impacted by it. Specifically, the students' sense of belonging is impacted by whether or not they receive support from peers and the institution. The purpose of this study was to understand the sense of belonging for multiracial students in a predominantly White institution. These students' sense of belonging is best understood using Renn's (2004) Ecological Theory of Mixed-Race Identity Development and viewing their experiences through an ecological lens. Multiracial students at this 
university received racism based on their physical appearance, but they do have a sense of belonging. Racism was salient for multiracial students at this university. Peers acknowledging, respecting, and becoming more educated about race, created a positive context at this university. The current context encouraged people to focus on racial identity and this contributes to their sense of belonging. Sense of belonging is formed in their mesosystem with the individuals around them at the university.

\section{Conclusion}

This chapter contained the findings of the research on multiracial students and their sense of belonging at a predominantly White institution. The purpose of this qualitative study was to better understand multiracial students' sense of belonging at a predominantly White institution. Majority of multiracial students I interviewed did feel a sense of belonging at the university, due to close friends of color and diverse organizations. Truly being authentic at all times is difficult, due to other individuals having unreasonable expectations and authenticity being a journey. Multiracial students feel that they cannot be their completely authentic self at all times and constantly feel a need to codeswitch to appease others. This occurred in the curricular and extracurricular settings. Chronic codeswitching is a barrier for multiracial students on their journey towards being more authentic. Although multiracial students at this university encounter barriers, they are also the multiracial bridge. Participants in this study described being able to communicate with both White and Black peers about issues specific to the other race, in a way that they are more receptive. Although multiracial participants felt that they were a bridge, they also felt like they were pawns at the predominantly White institution. Participants brought up a recurring feeling of not mattering to the employees 
and the university as a whole. Being treated as pawns deterred a sense of belonging, but racially diverse close friends and student organizations increased their sense of belonging. This university was the most racially diverse place the multiracial participants had ever been. Multiracial students in this study growing up felt a need to suppress an aspect of their multiracial identity in order to be accepted. When enrolled in this university, they were exposed to more diverse groups, which exacerbated the frequency of suppression to navigate belonging. Chapter 5 includes the implications for practice and the recommendations for future research. 


\section{CHAPTER 5}

\section{DISCUSSION}

\section{Summary of Study}

Sense of belonging is an important factor as it relates to the intention to persist in and graduate from college. In a higher education setting, sense of belonging is emphasized in order to ensure that all students obtain it. Although sense of belonging is an important factor for all students, it is reportedly overlooked in multiracial students (Hausmann et al., 2007). In fact, many reports show that multiracial students experience disapproval, lack of social recognition, and exclusion (Brown, 1995; Kerwin \& Ponterotto, 1995; Museus et al., 2016; Nakashima, 1996). The purpose of this qualitative study was to understand sense of belonging for multiracial students in a predominantly White institution. I sought to research this phenomenology by interviewing 11 multiracial (Black/White) undergraduate students at one predominantly White institution to inquire about their experience. This was done virtually in one 90-minute semi-structured interview with each participant. The interviews were audio recorded, transcribed, and sent to each member for approval. Once approval was received, two cycles of coding followed. Participants' exact words were gained through in vivo coding and similarities were found by using pattern coding. Answers to research questions, as well as emergent themes represent the findings of the research: 
- Central Research Question: How do multiracial students at a predominantly White institution describe their sense of belonging?

- RQ1: In what ways do multiracial college students feel that they can be their completely authentic self at all times while at a predominantly White institution?

○ RQ2: How do multiracial students feel comfortable or uncomfortable at a predominantly White institution?

○ RQ3: How salient is multiracial students' race while at a predominantly White institution?

There are four emergent themes in this study. The emergent themes are chronic codeswitching, multiracial bridge, multiracial students as pawns, and sense of belonging with close friends and student organizations. Chronic codeswitching describes the constant adjustments that multiracial participants had to make to their personality and appearance, depending on the racial identity of the people they were around. Multiracial bridge is what participants identify as when they explain how they advocate for multiple racial groups in a way that others are more receptive. Multiracial students as pawns describes the way that participants have been treated by university employees and the university as a whole. Many participants explain that they are not genuinely cared for by the university. Sense of belonging with close friends and student organizations is what multiracial participants experience. In these spaces, multiracial participants disclose they could be authentic and comfortable.

\section{Implications for Practice}


This study on multiracial students and their sense of belonging in a predominantly White institution can be used to increase sense of belonging for multiracial students. Increase in sense of belonging leads to increase in persistence and graduation rates (Hausmann et al., 2007). Below I provide the implications for practice utilizing the information gained from this study. There are three implications for practice that have emerged from this study. The implications are racial diversity education, courses on the multiracial experience, and the creation of multiracial organizations. These implications will allow predominantly White institutions to increase sense of belonging for multiracial students.

\section{Racial Diversity Education}

Diversity education contributes to diverse learning environments, which support academic and social excellence (Williams, 2013). Diversity education is a topic that came up a multitude of times. None of the interview questions asked about diversity education specifically, yet several multiracial participants insisted that diversity education is needed for the university. Many multiracial participants described it as "racial ignorance" and Bay expressed:

I don't think they are coming at it in the sense to be rude, I think it is lack of knowledge for whatever the topic is whether that be the religion or race, I really think that is what it is. I think lack of representation or just knowledge of the history of these things, of these topics (Bay).

Racial diversity education is needed to educate individuals at the university about race and racial issues, to remove ignorance. The university currently receives occasional diversity education sessions for the general campus population. Diversity dialogues are helpful, if facilitated properly. Conversations, such as these, may comfort multiracial 
students when they see that people are trying to learn and be better. When asked when they felt most comfortable at the institution, Nichole admitted:

I will say that I appreciate the diversity talks that the campus tries to hold. There was one that I had to go to at (Residence Hall). Being an honor student, all of the honor students had to go to this diversity and equity some type of meeting. I can't remember her name, but she was the (Diversity Scholarship) lady in the diversity office (Nichole).

Multiracial students appreciate when talks like these are held because it means that their peers are trying to learn about diverse experiences. Talks like these also mean that the multiracial participants do not always have to be the educators and that burden can be lifted from their shoulders. Hogan and Mallott (2005) explain that when diversity education that focuses on race is taking place at the university, it reduces prejudice and racist remarks from students who completed the training. Multiracial students commonly receive racist remarks in the form of microaggressions, which can be everlasting (Nadal et al., 2011). Racial diversity education would be beneficial for the general campus population at this predominantly White institution, but this study indicates that it is needed for employees at the university generally, and predominantly in White Greek Life.

\section{Racial Diversity Education Targeted for Employees}

Multiracial students at this university felt that they were being used as pawns by employees. These students felt like their identities and success were being exploited instead of honored. Bay was transparent and shared her experience:

Sometimes, this is my moment of honesty, sometimes I wonder if going to (predominantly White institution), if I was just someone to help their statistics. I 
always question that, whether it is at a job or school or whatever it may be, I always question if I am just there for their statistics (Bay).

Bay wondered if she was at the university just to help the institution look better on paper. Currently, Black students have among the highest dropout rates and lowest persistence rates at predominantly White institutions (Espinosa et al., 2019). Multiracial students are different from Black students, but they feel that their success is grouped. Black/White multiracial students feel that they are not looked at as a separate racial group and are categorized as Black by the university. Multiracial participants shared that some employees at this university are not attempting to learn about multiracial students' experiences and only care about their academic success. Sage stated why he mistrusts professors at times and referred to an experience with a professor:

It's those moments where you make a comment on, well I have this lived experience and a person is like "well that's wrong because it doesn't apply to all Black people or all minority people." That's when I'm like okay, you don't get it then. That's where that mistrust comes from. It doesn't happen all the time, but the fact that it happens, it puts you on edge. (Sage).

In this situation, the professor denied multiracial experiences and identities, which contributed to a lack of sense of belonging (Harris, 2017b). Multiracial students have unique identities and experiences. More diversity education is needed for all employees including faculty, so they are more receptive and better understand multiracial students. Minoritized students attending these institutions report experiencing discrimination at least once during their college tenure (Cuyjet, 1998). Hogan and Mallott (2005) found that the denial component of modern racism is "rooted in ignorance and misunderstanding” (p. 123) and can be improved through racial diversity education. 
Using Hogan and Mallot's (2005) findings, employees at the university receiving racial diversity education on multiracial students, will be able to better understand areas of discrimination and become more inclusive. Employees receiving racial diversity education will bring awareness of multiracial students (Hogan and Mallott, 2005), which will promote a welcoming environment for these students throughout campus (Ingram et al., 2014).

\section{Racial Diversity Education Targeted for Predominantly White Greek Life}

Diversity education is important for all, but as found in this study is especially needed for the predominantly White Greek organizations. Most multiracial participants stated that predominantly White Greek life made them feel uncomfortable or out of place. Halle Berry discussed her belongingness at the university and what she noticed, "I saw how prevalent Greek life here is and how, it is very very White, and I don't feel like I belong. I don't think I felt like this was the place for me" (Halle Berry). This lack of representation in Greek life lowered the multiracial students' sense of belonging at the institution. Not only does predominantly White Greek life make students feel out of place, but students in predominantly White Greek life also make racist remarks towards multiracial individuals. Halle Berry goes on to discuss future experiences with a member of predominantly White Greek life:

...basically it was one day, I was in the library with my friend and we were sitting at a table. We have a White friend that was sitting next to us. Someone she knew came up to her and was making conversation, we weren't really listening, we were typing away and doing our homework in the library. She comes over to us and she is telling us what they were talking about, and the White dude she was talking to had said "O why are you working with those ghetto bitches". We were like WHAT!?!?! He said something along those lines like "Why are you working with those ghetto bitches" or something like that and it was frustrating because we started researching who this guy was. He had a history of being a (Honor 
Scholar), was in a (IFC) fraternity, he worked on the student activities board, to this day he just became (Leadership Role) of the student activities board. Working with (Organization), working with the (Specific College), the (Specific College). $\mathrm{He}$ is the (Leadership Position) of the (Specific College), so we were so livid. We were just like how is this happening? (Halle Berry).

When experiences such as this occur, the multiracial students do not feel like they belong at the university. Racial diversity education targeted for predominantly White Greek life is needed to increase sense of belonging for multiracial students at the predominantly White institution. This education will be beneficial to the multiracial students, but also for the Greek organization members. Racial diversity education will help build their organizations and assist with retaining their members of color.

\section{Multiracial Experience Courses}

Courses designed around the multiracial experience are another needed practice. These courses could be used as a general education requirement to educate all students at the university. Multiracial experience courses would fit appropriately in the Pan-African Studies (PAS) department or other various disciplinary perspectives. Multiracial students at the university felt that their experiences were overlooked. Multiracial experience courses will allow individuals at the predominantly White institution to have an opportunity to gain knowledge surrounding multiracial experiences. Multiracial students discussed that their peers inquired about their experiences and point of view at times. At the same time, Sage stated:

I also tend to feel more comfortable when my personal life doesn't have to be used as an example for how I think in the class. I like having other examples that are in books or things that I can relate to but aren't me (Sage). 
Multiracial students want people to receive education on the multiracial experience, but do not want to feel like the experiment. These courses would educate students on multiracial individuals, which could reduce ignorant racial remarks to these individuals, which in turn would increase their sense of belonging. Multiracial experience courses would be beneficial for the general campus population but would be especially beneficial for multiracial students at the institution.

Multiracial students discussed that my interview with them was one of the first times they were able to truly think about their multiracial experience and identity development. Students in this study discussed that they have to educate themselves about being multiracial and their identity development. They desire to learn more about their identity, because learning, reflecting, and writing about their multiracial identity helps them feel comfortable. Leroy discusses his experience writing an essay for his minority academic scholarship. Leroy explained:

...they talked about relating to a quote, and I had a quote by MLK and they said relate it to a difficult time in your life where you had to overcome something and I told you about the bank and growing up biracial and all that. And it's one of those if your story is touching we will give you more money so I had to pour my heart out into that and I talked about my family upbringing and you know that kinda I said this scholarship helped me get more comfortable with campus and also it helped us get more comfortable with being biracial, Arabic, multiracial, the scholarship would always let us know that at the end of the day the world needs minorities (Leroy).

Many multiracial students at the university share Leroy's experience with writing and being comfortable with their multiracial identity. Unfortunately, this student and other multiracial students like him have not been given the opportunity to reflect on their multiracial identity at the university and write about their experience. Multiracial 
experience courses will also give multiracial students the opportunity to learn various strategies to cope with discrimination they face. Coping is an important tool for multiracial students to learn so they can overcome discrimination they may face (Lazarus, 1990). Having Multiracial Experience courses at the institution will allow multiracial students opportunities to learn, write, and reflect on their multiracial experience and multiracial identity development.

\section{Multiracial Organizations}

Predominantly White institutions are just that, predominantly White. Multiracial students can feel extremely uncomfortable when they are the only Person of Color in the academic setting. Yet, sense of belonging is possible in a dyad, clique, or group of like individuals (Strayhorn, 2012). Organizations provide opportunities for student involvement, yet for multiracial students they can provide another obstacle for finding a sense of belonging at the university. The main reason for this is because it can be difficult for multiracial students to find peers that they can connect to and discuss their struggles with. Multiracial students report monoracial support groups do not accept them completely (Jones \& Jones, 2010). From this research, an implication for practice is

developing multiracial organizations at the university. Creating multiracial organizations is an opportunity institutions can develop to support and retain these students (Palmer et al., 2012).

Multiracial students help other multiracial students at the university feel comforted and that they belong. Multiracial students are constantly codeswitching at this predominantly White institution, based on who they are around. Multiracial students 
cannot be their authentic selves at all times and cater to the individuals around them so they will be accepted. Paige announced:

I am always just nervous about being the person that is not following the identity that other people give me. I know it sounds really bad, but it feels like I am always being compared. It's like "you are too this" or "you are too that" and I feel like I can never please people in their own mind about what I should be (Paige)

Being around multiracial individuals will allow multiracial students at this university to let their guards down and finally be their authentic selves. In this organization, multiracial students will not all be the same, but they will be able to share struggles and experiences that everyone can relate to. Multiracial students connecting with each other will find comfort in the multiracial organization, which will increase their sense of belonging. Increased sense of belonging leads to higher academic outcomes and positive adjustments, such as increased self-esteem, self-worth, and overall wellbeing (Van Ryzin et al., 2009).

\section{Recommendations for Future Research}

Beneficial information was yielded from this study on multiracial students and their sense of belonging in a predominantly White institution. Even with this new information, there are several gaps in knowledge surrounding multiracial students. Future research would benefit from exploring the long-term effects of chronic codeswitching for multiracial individuals, looking into sense of belonging for multiracial students who withdrew from the university, studying additional institutional types, and studying multiracial students of ethnicities other than African American (Black) and European American (White). These recommendations for future research will be discussed further below. 


\section{Long-term Effects of Chronic Codeswitching}

The first recommendation for future research builds on a particular finding of this research. Chronic codeswitching was an emerging theme in this study. This theme was expected, but not to this intense degree. Codeswitching constantly and never being authentic can have severe consequences, especially on mental health, for multiracial students (Sanchez et al., 2009). Further research is needed on the long-term effects of chronic codeswitching. This could be researched in a longitudinal study and finding this information will give insight to the impact attending a predominantly White institution has on multiracial students' and their mental health. Multiracial identity development is an ongoing process (Renn, 2004), which will continue long after multiracial students depart from the institution.

\section{Sense of Belonging for Multiracial Students Who Withdrew}

The next recommendation for future research addresses a limitation in this study. This study researched sense of belonging for multiracial students in one predominantly White institution. Participants in this study were undergraduate, multiracial students, enrolled at a predominantly White institution. I recommend that future research examine multiracial students who withdrew from this university. All the participants I interviewed were currently enrolled in the university. Researching participants who withdrew from the institution will augment the data, giving a holistic view on sense of belonging for multiracial students at this university. By interviewing students who left the university, factors that severely harm sense of belonging can be discovered.

\section{Additional Institution Types}


An additional recommendation for future research is to examine multiracial students' sense of belonging at additional institution types. All institution types are different in their racial makeup and opportunities that they offer. Some are made up primarily of marginalized individuals and have programs catered specifically to those students, while other institutions have a larger percentage of White students. Many multiracial students in this study shared that they felt comfort around People of Color and with involvement in diverse organizations. Historically Black Colleges and Universities (HBCU) primarily serve the African American community and better understand minority racial identity (Allen, 1992). This better understanding of minority racial identity could correlate with sense of belonging. Multiracial students' sense of belonging at community colleges should also be examined. At community colleges, nearly all students are commuters and students have minimal involvement opportunities (Astin, 1984). Minimal involvement opportunities could correlate with multiracial students' sense of belonging.

\section{Various Multiracial Combinations}

This study focused on multiracial students with one parent African American (Black) and the other European American (White). There are 56 other multiracial combinations on the United States Census (Saulny, 2011). The sense of belonging for multiracial students in this study do not represent the sense of belonging for all combinations of multiracial students. Each multiracial combination has its own specific racial background and characteristics, which means they encounter their own discrimination. Further research is needed to examine the sense of belonging for all 57 multiracial combinations. 


\section{Conclusion}

By the year 2050, 20\% of the United States' population will identify as multiracial (Garrod et al., 2014; Jackson, 2010; Lee \& Bean, 2004; Shih \& Sanchez, 2009). Multiracial students are the fastest growing population in the world meaning there will be an increase in multiracial students at predominantly White institutions (Saulny, 2011). Multiracial students face an array of challenges such as rejection by own racial groups, assumption of racial identity, and discrimination from both Black and White individuals. These challenges can diminish multiracial student sense of belonging at these institutions. Potential implications and the current racial climate brought the need to examine multiracial students' sense of belonging at these institutions to the forefront. Currently, multiracial students do feel a sense of belonging at this university, but not primarily from institutional climate or initiatives. Multiracial students feel a sense of belonging with their close friends of color and diverse organizations in which they were involved. The phenomenon of multiracial students in a predominantly White institution is described as often feeling uncomfortable throughout their time at the university and they do not feel that they can be their completely authentic self at all times. This leads them to chronic codeswitch in search of acceptance. Employing these implications for practice, based on the findings in this study, will ensure that multiracial students do not feel like pawns at predominantly White institutions and will increase their sense of belonging. Multiracial students are needed at these institutions to provide the multiracial bridge and bridge the gap with racial issues; by facilitating conversations in their peer groups and organizations amongst racially diverse peers. Utilizing this research, we can ensure that

multiracial students have a better chance at predominantly White institutions to not feel 
like "the minority of the minorities" (Leroy), and instead feel like "the best of both worlds" (Taty). 


\section{REFERENCES}

Abes, E. S., Jones, S. R., \& Stewart, D. (2019). Rethinking college student development theory using critical frameworks. Sterling, VA: Stylus Publishing.

Abiola, U. (2017). The monolith myth and myriad manifestations of melanin: Skin tone bias/colorism and Black ivy league undergraduates. (Unpublished doctoral dissertation). University of Pennsylvania, Philadelphia, PN.

Agar, M. H. (1980). The professional stranger: An informal introduction to ethnography. San Diego, CA: Academic Press.

Allen, W. (1992). The color of success: African American college student outcomes at predominantly White and historically Black colleges. Harvard Educational Review, 62, 26-44.

Alpert, J. L. (1970). The origin of slavery in the United States-the Maryland precedent. The American Journal of Legal History, 14(3), 189-221.

AASCU Government Relations and Policy Analysis Division. (2020, February). Top 10 higher education state policy issues for 2020. American Association of State Colleges and Universities. Retrieved from https://www.aascu.org/policy/publications/policy-matters/Top102020.pdf

Ancis, J. R., Sedlacek, W. E., \& Mohr, J. J. (2000). Student perceptions of campus cultural climate by race. Journal of Counseling \& Development, 78, 180-185. 
Angrosino, M. V. (2007). Doing ethnographic and observational research. Thousand Oaks, CA: Sage.

Astin, A. W. (1984). Student involvement: A developmental theory for higher education. Journal of College Student Development, 40(5), 518-529.

Atkinson, D., Morten, G., \& Sue, D. W. (1979). Counseling American minorities: A cross- cultural perspective. Dubuque, IA: Brown Company.

Axtell, J. (1974). The school upon a hill: Education and society in colonial New England. New Haven. CT: Yale University Press.

Bales, K. (2007). Ending slavery: How we free today's slaves. Berkeley, CA: University of California Press.

Baumeister, R. F., \& Leary, M. R. (1995). The need to belong: Desire for interpersonal attachments as a fundamental human motivation. Psychological Bulletin, 117, 497-529.

Baxter Magolda, M. B. (2009). The activity of meaning making: A holistic perspective on college student development. Journal of College Student Development 50(6), 621-639.

Bazeley, P. (2013). Qualitative data analysis: Practical strategies. Thousand Oaks, CA: Sage.

Billings, A. G., \& Moos, R. H. (1984). Coping, stress, and social resources among adults with unipolar depression. Journal of Personality and Social Psychology, 46, 877891. 
Bogdan, R., \& Biklen. S. (1982). Qualitative research for education: An introduction to theory and methods. Boston, MA: Allyn \& Bacon.

Borgatta, E. F., \& Borgatta, M. L. (Eds.). (1992). Encyclopedia of sociology (Vol. 4). New York, NY: Macmillan.

Brackett, K. P., Marcus, A., McKenzie, N. J., Mullins, L. C., Tang, Z., \& Allen, A. M. (2006). The effects of multiracial identification on students ${ }^{\text {ee }}$ perceptions of racism. The Social Science Journal, 43(3), 437-444.

Bronfenbrenner, U. (1993). The ecology of cognitive development: Research models and fugitive findings. In R.H. Wozniak, \& G.H. Elder, Jr. (Eds.) Examining lives in context: Perspectives on the ecology of human development (pp 619-47).

Washington, DC: American Psychological Association.

Brown, U. M. (1995). Black/White interracial young adults: Quest for racial identity. American Journal of Orthopsychiatry, 65, 125-130. doi:10.1037/h0079587

Brown II, C. M., \& Dancy II, E. T. (2010). Predominantly White institutions. In K. Lomotey (Ed.), Encyclopedia of African American education (pp. 524-526). Thousand Oaks, CA: SAGE Publications, Inc. doi: 10.4135/9781412971966.n193

Brunsma, D. L. (2006). Mixed messages: Multiracial identities in the "color-blind" era. Boulder, CO: Lynne Rienner Publishers.

Campbell, M. E., \& Eggerling-Boeck, J. (2006). “What about the children?” The psychological and social well-being of multiracial adolescents. The Sociological Quarterly, 47(1), 147-173. doi: 10.1111/j.1533-8525.2006.00041.x 
Carden, A. (2014). Freedom's delay: America's struggle for emancipation, 1776-1865. Knoxville, TN: University of Tennessee Press.

Carter, R. T. (2007). Racism and psychological and emotional inquiry: Recognizing and assessing race-based traumatic stress. Counseling Psychologist, 35(1), 13-105.

Charles, C. Z., Fischer, M. J., Mooney, M. A., \& Masses, D. S. (2009). AffirmativeAction programs for minority students: Right in theory, wrong in practice. The Chronicle of Higher Education. Retrieved from http://http://www.chronicle.com/article/Affirmative-Action-Programs/35122

Cortes, C. E. (2000, March-April). The diversity within: Intermarriage, identity, and campus community. About Campus, 5-10.

Creswell, J. W., \& Miller, D. L. (2000). Determining validity in qualitative inquiry. Theory Into Practice, 39, 124-130. doi: 10.1207/s15430421tip3903_2

Creswell, J. W., \& Poth, C. N. (2018). Qualitative inquiry \& research design: Choosing among five approaches. Los Angeles, CA: Sage.

Crosling, G., Thomas, L., \& Heagney, M. (2008). Student success and retention. In G. Crosling, L. Thomas, \& M. Heagney (Eds.), Improving student retention in higher education: The role of teaching and learning (pp. 1-13). London: Routledge.

Cross, W. E., Jr. (1995). The Psychology of Nigrescence: Revisiting the Cross Model. In J. G. Ponterotto, J. M. Casas, L. A. Suzuki, and C. M. Alexander (Eds.), Handbook of multi- cultural counseling. Thousand Oaks, CA: Sage. 
Cuyjet, M. J. (1998). Recognizing and addressing marginalization among African American college students. College Student Affairs Journal, 18(1), 64-71.

Daniel, R., G. (2010) More than Black: Multiracial identity \& new racial order. Philadelphia, PA: Temple University Press.

Davidson, W. B., Bromfield, J. M., \& Beck, H. P. (2007). Beneficial academic orientations and self-actualization of college students. Psychological Reports, 100(2), 604-612.

Denzin, N. K., \& Lincoln, Y. S. (2011). The SAGE handbook of qualitative research $\left(4^{\text {th }}\right.$ ed.). Thousand Oaks, CA: Sage.

Ely, M., Anzul, M., Friedman, T., Garner, D., \& Steinmetz, A. M. (1991). Doing qualitative research: Circles within circles. Philadelphia: Falmer.

Erlandson, D. A., Harris, E. L., Skipper, B. L., \& Allen, S. D. (1993) Doing naturalistic enquiry: A guide to methods. Newbury Park, CA: Sage.

Espinosa, L. L., Turk, J. M., Taylor, M., and Chessman, H. M. (2019). Race and ethnicity in higher education: A status report. Washington, DC: American Council on Education.

Feagin, J. (2013). Systemic racism: A theory of oppression. New York, NY: Routledge.

Feagin, J. R., Vera, H., \& Imani, N. (1996). The agony of education: Black students at White colleges and universities. New York, NY: Routledge. 
Ford, K. A. \& Malaney, V. K. (2012). "I now harbor more pride in my race": The educational benefits of inter-and intraracial dialogues on the experiences of Students of Color and multiracial students, Equity \& Excellence in Education, 45(1), 14-35.

Freeman, K. (2005). African Americans and college choice: The influence of family and school. Albany, NY: State University of New York Press.

Fries-Britt, S. L., \& Turner, B. (2001). Facing stereotypes: A case study of Black students on a White campus. Journal of College Student Development, 42, 420-429.

Garrod, A., Kilkenny, R., \& Gómez, C. (2014). Mixed: Multiracial college students tell their life stories. Ithaca, NY: Cornell University Press.

Gasser, H. S. (2002). Portraits of individuality: A qualitative study of multiracial college students. Journal of Student Affairs, 11, 42-53.

Gayles, J. G., \& Kelly, B. T. (2007). Experiences with diversity in the curriculum: Implications for graduate programs and student affairs practice. NASPA Journal 44(1), 193-208. doi: 10.2202/1949-6605.1761

Giorgi, A. (ED.). (1985). Phenomenology and psychological research. Pittsburgh, PA: Duquesne University Press.

Giorgi, A. (2009). The descriptive phenomenological method in psychology: A modified Husserlian approach. Pittsburgh, PA: Duquesne University Press.

Glesne, C. (2016). Becoming qualitative researchers: An introduction (5 $5^{\text {th }}$ ed.). Boston, MA: Pearson. 
Gurin, P., Dey, E. L., Hurtado, S., \& Gurin, G. (2002). Diversity and higher education: Theory and impact on educational outcomes. Harvard Educational Review, 72(3), 330-366. https://doi.org/10.17763/haer.72.3.01151786u134n051

Gurin, P., Lehman, J. S., \& Lewis, E. (2004). Defending diversity: Affirmative action at the University of Michigan. Ann Arbor, MI: University of Michigan Press.

Hammersley, M., \& Atkinson, P. (1995). Ethnography: Principles in practice (2 ${ }^{\text {nd }}$ ed.). New York, NY: Routledge.

Haney Lopez, I. (1996) White by law. New York: New York University Press.

Harper, S. R. (2013). Am I my brother's teacher? Black undergraduates, racial socialization, and peer pedagogies in predominantly White postsecondary contexts. Review of Research in Education, 37(1), 183-211.

Harper, S. R., Davis, R. J., Jones, D. E., McGowan, B. L., Ingram, T. N., \& Platt, C. S. (2011). Race and racism in the experiences of Black male resident assistants at predominantly White universities.” Journal of College Student Development, 52(2), 180-200.

Harper, S. R., \& Hurtado, S. (2007). Nine themes in campus racial climates and implications for institutional transformation. In S. R. Harper \& L. Patton (Eds.), Responding to the realities of race on college campuses, New Directions for Student Services, No. 120 (pp. 7-24). San Francisco, CA: Jossey-Bass. 
Harris, D. R. \& Sim, J. J. (2000). An empirical look at the social construction of race: The case of mixed-race adolescents (Population Studies Center Research Report 00-452).

Harris, D. R., \& Sim, J. J. (2002). Who is multiracial? Assessing the complexity of lived race. American Sociological Review, 67(4), 614-627.

Harris, J. C. (2017a). Multiracial campus professionals' experiences with multiracial microaggressions. Journal of College Student Development 58(7), 1055-1073. doi:10.1353/csd.2017.0083.

Harris, J. C. (2017b). Multiracial college students' experiences with multiracial microaggressions, Race Ethnicity and Education, 20(4), 429-445, doi: $10.1080 / 13613324.2016 .1248836$

Hausmann, L. R., Schofield, J. W. \& Woods, R. L. (2007). Sense of belonging as a predictor of intentions to persist among African American and White first-year college students. Research in Higher Education, 48(7), 803-839.

Helms, J. E. (1995). An update of Helms's White and people of color racial identity development models. In J. G. Ponterotto, J. M. Casas, L. A. Suzuki, and C. M. Alexander (Eds.), Handbook of Multicultural Counseling. Thousand Oaks, CA. Sage.

Hickman, C. B. (1997). The devil and the one drop rule: Racial categories, African Americans, and the U.S. census. Michigan Law Review, 95(5), 1161-1265. doi: $10.2307 / 1290008$ 
Hoffman, M., Richmond, J., Morrow, J., \& Salomone, K. (2003). Investigating “sense of belonging” in first-year college students. Journal of College Student Retention, 4, 227-256.

Hogan, D. E., \& Mallott, M. (2005). Changing racial prejudice through diversity education. Journal of College Student Development, 46(2), 115-125.

Hollinger, D. A. (2005). The one drop rule \& the one hate rule. Daedalus, 134(1), 18-28.

Holloway, S. R., Wright, R., Ellis, M., \& East, M. (2009). Place, scale and the racial claims made for multiracial children in the 1990 US Census. Ethnic and Racial Studies, 32(3), 522-547, doi: 10.1080/01419870802021120

Hubbard, D. (2006). The color of our classroom, the color of our future. Academe, 92(6), 27-29.

Hughes, R. L. (2002). Understanding the context of the "Other" education: Black and White students talk about their experiences at lone star university, a predominantly White institution of higher education in the south. New Orleans, LA: American Educational Research Association.

Hurtado, S. (2007). Linking diversity with the educational and civic missions of higher education. The Review of Higher Education, 30(2), 185-196.

Hurtado, S. \& Carter, D. F. (1997). Effects of college transition and perceptions of the campus racial climate on Latino college students' sense of belonging. Sociology of Education, 70(4), 324-345. 
Ingram, P., Chaudhary, A. K., \& Jones, W. T. (2014). How do biracial students interact with others on the college campus? College Student Journal, 48(2), 297-311.

Jackson, K. F. (2007). Beyond race: Examining the cultural identity of multiracial individuals. Dissertation Abstracts International, Section A: Humanities and Social Sciences, 68(5-A), 2172

Jackson, K. F. (2010). Ethical considerations in social work research with multiracial individuals. Journal of Social Work Values and Ethics, 7(1), 1-10.

Janesick, V. J. (2011). “Stretching” exercises for qualitative researchers ( $3^{\text {rd }}$ ed.). Thousand Oaks, CA: Sage.

Jedlowski, P. (2001). Memory and sociology. Time \& Society, 10(1), 29-44.

Jones, A., \& Crandall, R. (1986). Validation of a short index of self-actualization. Personality and Social Psychology Bulletin, 12(1), 63-73.

Jones, A., \& Jones, J. (2010). Breaking barriers for multiracial students. National Forum of Multicultural Issues Journal, 7(1), 1-6.

Jones, L., Castellanos, J., \& Cole, D. (2002). Examining the ethnic minority student experience at predominantly White institutions: A case study. Journal of Hispanic Higher Education, 1(1), 19-39. doi.org/10.1177/1538192702001001003

Jones, N. A., \& Bullock, J. J. (2013). Understanding who reported multiple races in the U.S. decennial census: Results from census 2000 and the 2010 census. Family Relations, 62(1), 5-16. 
Jordan, W. D. (1974). The White man's burden: Historical origins of racism in the United States. Oxford, London: Oxford University Press.

Kellogg, A. H., \& Liddell, D. L. (2012). "Not half but double": Exploring critical incidents in the racial identity of multiracial college students. Journal of College Student Development 53(4), 524-541. doi:10.1353/csd.2012.0054.

Kerwin, C. \& Ponterotto, J. G. (1995). Biracial identity development: Theory and research. In J. G. Ponterotto, J. M. Casas, L. A. Suzuki, \& C. M. Alexander (Eds.), Handbook of multiracial counseling, 199-217. Thousand Oaks, CA: Sage.

Key, F. S. (1814). The star spangled banner. Garden City, NY: Doubleday, Doran \& company.

Kilson, M. (2001). Claiming place: Biracial young adults of the post-civil rights era. Westport, CT: Bergin \& Garvey.

King, A. R. (2008). Student perspectives on multiracial identity. In K. A. Renn \& P. Shang (Eds.), Biracial and multiracial students: New Direction for Student Services, 123, 33-41. San Francisco, CA: Jossey-Bass.

King, A. R. (2011). Environmental influences on the development of female college students who identify as multiracial/biracial-bisexual/pansexual. Journal of College Student Development 52(4), 440-455. doi:10.1353/csd.2011.0050.

Lazarus, R. S. (1990). Theory-based stress measurement. Psychological Inquiry, 1, 3-13.

Lazarus, R. S., \& Folkman, S. (1984). Stress, appraisal, and coping. New York, NY: Springer. 
Lee, J. \& Bean, F. D. (2004). America’s changing color lines: Immigration, race/ethnicity, and multiracial identification. Annual Review of Sociology, 30, 221-242. doi:10.1146/annurev.soc.30.012703.110519

Lewis, A. E., Chesler, M., \& Forman, T. A. (2000). The impact of "colorblind" ideologies on students of color: Intergroup relations at a predominantly White university. Journal of Negro Education, 69(1/2), 74-91.

Liang, C. T. H., Alvarez, A. N., Juang, L. P., \& Liang, M. X. (2007). The role of coping in the relationship between perceived racism and racism-related stress for Asian Americans: Gender differences. Journal of Counseling Psychology, 54(2), 132141.

Lincoln, Y. S., \& Guba, E. G. (1985). Naturalistic inquiry. Beverly Hills, CA: Sage.

Lincoln, Y. S., \& Guba, E. G. (1986). But is it rigorous? Trust worthiness and authenticity in naturalistic evaluation. In D. Williams (Ed.). Naturalistic evaluation (pp. 73-84). San Francisco: Jossey-Bass.

Literte, P. E. (2010). Revising race: How biracial students are changing and challenging student services. Journal of College Student Development, 51(2), 115-134.

Lombardo, P. A. (1988). Miscegenation, eugenics, and racism: Historical footnotes to Loving v. Virginia. U.C. Davis Law Review, 21(2), 421-452.

Machi, L. A., \& McEvoy, B. T. (2016). The literature review six steps to success $\left(3^{\text {rd }}\right.$ ed.). Thousand Oaks, CA: Corwin. 
Maddox, K. B. \& Gray, S. A. (2002). Cognitive representations of Black Americans: Reexploring the role of skin tone. Personality and Social Psychology Bulletin, $28(2), 250-259$.

Maier, P. (1999). The strange history of all men are created equal. Washington and Lee Law Review, 56(3), 873-890.

Manning, K. (1992). A rationale for using qualitative research in student affairs. Journal of College Student Development 33, 132-136.

Maslow, A. H. (1943). A theory of human motivation. Psychological Review, 50(4), 37096.

Maslow, A. (1954). Motivation and personality. New York, NY: Harper.

Maslow, A. H. (1962). Toward a psychology of being. New York: Van Nostrand Company.

Maslow, A. H. (1987). Motivation and personality (3rd ed.). Delhi, India: Pearson Education.

Meek Mill, Jay-Z, \& Rick Ross (2018). What's free. On Championships [CD].

Merriam, S. B., \& Tisdell, E. J. (2015) Qualitative research: A guide to design and implementation (4th ed.). San Francisco, CA: Jossey-Bass.

Miles, M. B., Huberman, A. M., \& Saldana, J. (2014). Qualitative data analysis: A sourcebook of new methods (3rd ed.). Thousand Oaks, CA: Sage. 
Morning, A. (2005). Multiracial classification on the United States census: Myth, reality, and future impact. Revue Européenne des Migrations Internationales, 21(2), 111134.

Mortenson, T. G. (2005). Measurements of persistence. In A. Seidman (Ed.), College student retention (pp. 31-60). Westport: Praeger Publishers. http://publications.naspa.org/naspajournal/vol38/iss3/art2 28(1), 13-19.

Moustakas, C. (1994). Phenomenological research methods. Thousand Oaks, CA: Sage.

Museus, S. D., Lambe Sariñana, S. A., \& Ryan, T. K. (2015) A qualitative examination of multiracial students' coping responses to experiences with prejudice and discrimination in college. Journal of College Student Development, 56(4), 331348.

Museus, S. D., Lambe Sariñana, S. A., Yee, A. L., \& Robinson, T. E. (2016) A qualitative analysis of multiracial students' experiences with prejudice and discrimination in college. Journal of College Student Development, 57(6), 680697.

Nadal, K. L., Wong, Y., Griffin, K., Sriken, J., Vargas, V., Wideman, M., \& Kolawole, A. (2011). Microaggressions and the multiracial experience. International Journal of Humanities and Social Science, 1(7), 36-44.

Nadal, K. L., Wong, Y., Griffin, K. E., Davidoff, K., \& Sriken, J. (2014). The adverse impact of racial microaggression on college students' self-esteem. Journal of College Student development, 55(5), 461-474. 
Nakashima, C.L. (1996). Voices from the moment: Approaches to multiraciality. In M. P. P. Root (Ed.), The multiracial experience: Racial borders as the new frontier (pp. 79-97). Thousand Oaks, CA: Sage.

National Center for Education Statistics, U.S. Department of Education. (2020). Federal programs for education and related activities. Digest of education statistics 2020. Retrieved October 27, 2020, from the National Center for Education Statistics Web site: https://nces.ed.gov/programs/coe/indicator_cha.asp

National Center for Education Statistics, U.S. Department of Education. (2018). Federal programs for education and related activities. Digest of education statistics 2018. Retrieved October 27, 2020, from the National Center for Education Statistics Web site: https://nces.ed.gov/programs/digest/d18/ch_3.asp

Nieswiadomy, R. M. (1993). Foundations of nursing research (2nd ed.). Norwalk, CT: Appleton \& Lange.

Nora, A., Kramer, B., \& Itzen, R. (1996). Persistence among non-traditional Hispanic college students: A casual model. Paper presented at the annual meeting of the Association for the Study of Higher Education, Albuquerque, NM.

Oiler, C. J. (1986). Phenomenology: The method. In P. L. Munhall \& C. J. Oiler (Eds.)., Nursing research: A qualitative perspective (pp. 69-82). Norwalk, CT: AppletonCentury-Crofts.

O’Keeffe, P. (2013). A sense of belonging: Improving student retention. College Student Journal, 47(4), 605-613. 
Omi, M., \& Winant, H. (1986). Racial formation in the United States. New York: Routledge and Kegan Paul.

Outlaw, F. H. (1993). Stress and coping: The influence of racism on the cognitive appraisal processing of African Americans. Issues in Mental Health Nursing, 14, $399-409$.

Ozaki, C., \& Johnston, M. (2008). The space in between: Issues for multiracial student organizations and advising. In K. A. Renn \& P. Shang (Eds.), Biracial and multiracial college students: Theory, research, and best practices in student affairs. New Directions for Student Services (pp. 53-62). San Francisco, CA: Jossey-Bass.

Palmer, R. T., Maramba, D. C., \& Holmes, S. L. (2012). A contemporary examination of factors promoting the academic success of minority students at a predominantly White university. Journal of College Student Retention: Research, Theory \& Practice, 13(3), 329-349.

Patton, L. D. (2004). From protest to progress? An examination of the relevance, relationship and roles of black culture centers in the undergraduate experiences of Black students at predominantly White institutions (Doctoral dissertation, Indiana University, 2004). Dissertation Abstracts International, 65, 292.

Pérez-Peña, R. (2017, January 27). Woman linked to 1955 Emmett Till murder tells historians her claims were false. The New York Times, p. 13 
Polkinghorne, D. E. (1989). Phenomenological research methods. In R. S. VaUe \& S. Hailing (Eds.), Existential-phenomenological perspectives in psychology, 41-60. New York, NY: Plenum Press.

Porter, K. (2002). The value of a college degree. ERIC Digest. Retrieved from ERIC database (ED470038).

Poston, W. C. (1990). The biracial identity development model: A needed addition. Journal of Counseling \& Development, 69(2), 152-155. doi.org/10.1002/j.15566676.1990.tb01477.x

Princes, C. D. W. (1994). The precarious question of Black cultural centers versus multicultural centers. (Report No HE 028386) Harrisburg, PA: Annual Conference of the Pennsylvania Black Conference on Higher Education. (ERIC Document Reproduction Service No. ED383273)

Renn, K. (2000). Patterns of situational identity among biracial and multiracial college students. The Review of Higher Education. 23(4), 399-420.

Renn, K. (2003). Understanding the identities of mixed-race college students through a developmental ecology lens. Journal of College Student Development. 44(3), 383403.

Renn, K. (2004). Mixed race students in college: The ecology of race, identity, \& community. New York: SUNY Press.

Renn, K. (2008). Research on biracial and multiracial identity development: Overview and synthesis. New Directions for Student Services, 123, 13-21. 
Reynolds, A. L., Sneva, J. N., \& Beehler, G. P. (2010). The influence of racism-related stress on the academic motivation of Black and Latino/a students. Journal of College Student Development, 51(2), 135-149.

Ritchie, J., Lewis, J., \& Elam, G. (2003). Designing and selecting samples. In J. Ritchie \& J. Lewis (Eds.), Qualitative research practice: A guide for social science students and researchers, 77-108. Thousand Oaks, CA: Sage.

Rockquemore, K. A. \& Brunsma, D. L. (2002). Socially embedded identities: Theories, typologies, and processes of racial identity among Black/White biracials. The Sociological Quarterly, 43(3), 335-356.

Root, M. P. P. (1990). Resolving “other" status: Identity development of biracial individuals. Women \& Therapy, 9, 185-205.

Root, M. P. P. (1992). A bill of rights for racially mixed people. The Multiracial experience: Racial borders as the new frontier, 3-14

Root, M. P. P. (1996). The multiracial experience: Racial borders as the new frontier. Thousand Oaks, CA: Sage.

Roth, W. D. (2005) The end of the one drop rule? Labeling of multiracial children in Black intermarriages. Sociological Forum, 20, 35-67.

Saldana, J. (2016). The coding manual for qualitative researchers (3rd ed.). Thousand Oaks, CA: Sage. 
Sanchez, D. T., Shih, M., \& Garcia, J. A. (2009). Juggling multiple racial identities: Malleable racial identification and psychological well-being. Cultural Diversity and Ethnic Minority Psychology, 15(3), 243-254. doi.org/10.1037/a0014373

Sanders Thompson, V. L. (2006). Coping responses and the experience of discrimination. Journal of Applied Social Psychology, 36, 1198-1214.

Saulny, S. (2011, March 24). Census data presents rise in multiracial population of youths. New York Times. p. 1-2. Retrieved from https://www.nytimes.com/2011/03/25/us/25race.html?_r=1\&nl=todaysheadlines\& emc $=$ tha23\&pagewanted $=$ print

Shah, K., \& Adolphe, J. (2019, August 16). 400 years since slavery: A timeline of American history. Retrieved from https://www.theguardian.com/news/2019/aug/15/400-years-since-slaverytimeline.

Shih, M. \& Sanchez, D. (2009). When race becomes even more complex: Toward understanding the landscape of multiracial identity and experiences. Journal of Social Issues, 65(1), 1-11. doi:10.1111/j.1540-4560.2008.01584.x

Solórzano, D. G., Ceja, M., \& Yosso, T. (2000). Critical race theory, racial microaggressions, and campus racial climate: The experiences of African American college students. Journal of Negro Education, 69(1), 60-73.

Stage, F. K., \& Manning, K. (1992). Enhancing the multicultural campus environmental: A cultural brokering approach. New Directions for Student Services, 60. 
Stake, R. E. (1995). The art of case study research. Thousand Oaks, CA: Sage.

Standen, B. C. (1996). Without a template: The biracial Korean/White experience. In M. P. P. Root (Ed.), The multiracial experience: Racial borders as the new frontier (pp. 245-262). Newbury Park, CA: Sage.

Stephan, C. W. (1992). Mixed-heritage individuals: Ethnic identity and trait characteristics. In M. P. P. Root (Ed.), Racially mixed people in America (pp.5063). Newbury Park, CA: Sage.

Strayhorn, T. L. (2012). College student sense of belonging. New York, NY: Routledge.

Study Group on the Conditions of Excellence in Higher Education. (1984). Involvement in college: Realizing the potential of American higher education. A report of the National Institute of Education, U.S. Department of Education, Washington, DC: U.S. Government Printing Office.

Swingewood, A. (1991). A short history of sociological thought. New York, NY: St. Martin's Press.

Talbot, D. M. (2008). Exploring the experiences and self- labeling of mixed-race individuals with two minority parents. In K. A. Renn \& P. Shang (Eds.), Biracial and multiracial students: New Direction for Student Services, 123, 23-31. San Francisco, CA: Jossey-Bass.

Texas. Convention. (1861). Declaration of the causes which impel the state of Texas to secede from the Federal Union: Also the ordinance of secession. Austin, TX: 
Herald Office. Retrieved from the Library of Congress, https://www.loc.gov/item/95139713/.

Thelin, J. R., \& Gasman, M. (2011). Historical overview of American higher education. In Schuh, J., Jones, S., Harper, S., \& Komives, S. (eds), Student services: A handbook for the profession. San Francisco, CA: Jossey-Bass.

Thomas, J. (1993). Doing critical ethnography. Newbury Park, CA: Sage

Thomas, R. M. (1992). Comparing Theories of Child Development, $3^{\text {rd }}(\mathrm{ed}$.$) , Belmont,$ CA: Wadsworth Publishing.

Tinto, V. (1975). Dropout from higher education: A theoretical synthesis of recent research. Review of Educational Research, 45, 89-125.

Tinto, V. (1993). Leaving college: Rethinking the causes and cures of student attrition, 2nd(ed.), Chicago, IL: University of Chicago Press.

Truong, K. A., \& Museus, S. D. (2012). Responding to racism and racial trauma in doctoral study: An inventory for coping and mediating relationships. Harvard Educational Review, 82, 226-254.

Utsey, W. O., Ponterotto, J. G., Reynolds, A. L., \& Cancelli, A. A. (2000). Racial discrimination, coping, life satisfaction, and self-esteem among African Americans. Journal of Counseling and Development, 78, 72-80.

Velásquez, P. (1999). The relationship between cultural development, sense of belonging, and persistence among chicanos in higher education: An exploratory study. Paper 
presented at the annual meeting of the Association for the Study of Higher Education, San Antonio, TX.

Van Manen, M. (1990). Researching lived experience: Human science for an action sensitive pedagogy. Albany: State University of New York Press.

Van Manen, M. (2014). Phenomenology of practice: Meaning-giving methods in phenomenological research and writing. Walnut Creek, CA: Left Coast Press.

Van Ryzin, M. J., Gravely, A. A., \& Roseth, C. J. (2009). Autonomy, belongingness, and engagement in school as contributors to adolescent psychological well-being. Journal of Youth and Adolescence, 38(1), 1-12.

Wallace, K. R. (2001). Relative/Outsider: The art and politics of identity among mixed heritage students. Westport, CT: Ablex.

Wallace, K. R. (2003). Contextual factors affecting identity among mixed heritage college students. In M.P.P. Root and M. Kelley (eds.), Multiracial child resource book: Living complex identities. Seattle, WA: MAVIN Foundation.

Waters, M. (1990). Ethnic options. Berkeley, CA: University of California Press.

Wertz, F. J. (2005). Phenomenological research methods for counseling psychology. Journal of Counseling Psychology, 52, 167-177. doi: 10.1037/00220167.52.2.167

Whitfield, S. J. (1991). A death in the delta: The story of Emmett Till. Baltimore, MD: The Johns Hopkins University Press. 
Wijeyesinghe, C. L. (2001). Racial identity in multiracial people: An alternative paradigm. In C. L. Wijeyesinghe and B. W. Jackson III (eds.), New perspectives on racial identity development: A theoretical and practical anthology. New York: NY: University Press.

Williams, D. A. (2013). Strategic diversity leadership: Activating change and transformation in higher education. Sterling, VA: Stylus Publishing, LLC.

Willie, S. S. (2003). Acting Black: College, identity, and the performance of race. New York, NY: Routledge.

Winkle-Wagner, R., Johnson, S.D., Morelon-Quainoo, C., \& Santiague, L. (2010). A sense of belonging: Socialization factors that influence the transitions of students of color into advanced-degree programs. In S. K. Gardner, \& P. Mendoza (Eds) On becoming a scholar (pp.179- 199). Sterling, VA: Stylus.

Wong, M. P., \& Buckner, J. (2008). Multiracial student services come of age: The state of multiracial student services in higher education in the United States. In K. A. Renn \& P. Shang (Eds.), Biracial and multiracial students (pp. 43-51). San Francisco, CA: Jossey-Bass. 


\section{Appendix A}

\section{Semi-Structured Interview Protocol}

- Central Research Question: How do multiracial students at a predominantly White institution describe their sense of belonging?

- In what ways do you feel connected to the predominantly White institution you are enrolled in?

- Can you tell me a story or give me examples of how you feel connected to this institution?

○ To what extent do you feel that you belong at this predominantly White institution?

- Can you describe your connection with this predominantly White institution?

- Can you describe a place or group on campus where you easily found your sense of belonging?

- Can you describe any people on campus with whom you easily found your sense of belonging?

- RQ1: In what ways do multiracial college students feel that they can be their completely authentic self at all times while at a predominantly White institution?

- Do you feel you can be your completely authentic self at all times while at the predominantly White institution you are enrolled? If so, in what ways? If not, why?

- Can you tell me a story or give me an example of a time you were your completely authentic self while at this institution?

What does authenticity mean for you?

o Have you ever felt that you were not being your true self while at this predominantly White institution?

- Can you tell me a story or give me an example of a time you felt that you were not being your true self at this institution? 
- RQ2: How do multiracial students feel comfortable or uncomfortable at a predominantly White institution?

○ To what extent do you feel comfortable at the predominantly White institution you are enrolled?

○ To what extent do you trust or mistrust professors, administrators, or resources at the predominantly White institution you are enrolled?

- What makes you feel comfortable at this predominantly White institution?

- Can you tell me a story or give me an example of a time you felt most comfortable at this institution?

- Do you ever feel uncomfortable at this predominantly White institution? If so, what makes you feel this way?

- Can you tell me a story or give me an example of a time you felt uncomfortable or excluded while at this institution?

- How did you navigate being uncomfortable or excluded at this predominantly White institution?

- RQ3: How salient is multiracial students' race while at a predominantly White institution?

○ How important is your race while at this predominantly White institution?

- What does being multiracial mean to you?

$\circ$ What does being multiracial at a predominantly White institution mean to you? 


\title{
CURRICULUM VITAE
}

\author{
Nicholas Wright \\ nicholas.wright@stcloudstate.edu (270) 498-9542 550 3 ${ }^{\text {rd }}$ Avenue South, St. Cloud, MN 56301 \\ EDUCATION \\ University of Louisville, Louisville, KY \\ Doctor of Philosophy in Counseling and Personnel Services \\ May 2021 \\ Specialization: College Student Personnel \\ GPA: 3.97 \\ Master of Education in Counseling and Personnel Services \\ August 2018 \\ Concentration: College Student Personnel \\ GPA: 3.98 \\ Bachelor of Science \\ May 2016 \\ Justice Administration/Criminal Justice \\ GPA: 3.51

\section{TEACHING EXPERIENCE} \\ University of Louisville, Co-taught \\ - ECPY 664-College Student Populations \\ Fall 2018 \\ - ECPY 623-Helping Skills for Student Affairs Professionals \\ Spring 2019 \\ - ECPY 660-Introduction to College Student Personnel \\ Fall 2020
}

\section{RESEARCH EXPERIENCE}

- Research Associate conducting research with a team which includes two faculty members, Dr. Amy Hirschy and Dr. Susan Longerbeam. We conducted research on the Contribution of Student Affairs Preparation Programs to Undergraduate Student Success: Influences of Mentoring on Campus Racial Climate and Sense of Belonging.

- Principle Investigator on dissertation research focusing on multiracial students and their sense of belonging in a predominantly White institution.

\section{PROFESSIONAL EXPERIENCE}

Student Accessibility Services, Director

April 2021 - Current

St. Cloud State University, St. Cloud, Minnesota

- Accessed and restructured the Student Accessibility Service office by updating software programs/systems to be more efficient and user friendly for the population we serve, students with disabilities.

- Evaluate documentation of disabilities and provide accommodations to over 775 students from a broad range of disabilities (e.g. autism spectrum, deaf, blind, learning disabilities, depression, attention deficit hyperactivity disorder, traumatic brain injury, dyslexia). 
- Direct the Student Accessibility Services office and supervise a staff consisting of 10 individuals from 2 different labor unions: 4 full-time American Sign Language Interpreters (MAPE); 1 fulltime Office Manager (AFSCME); 1 Contracted Disability Coordinator (AFSCME); 2 Graduate Assistants; 2 Student Workers; 1 Graduate Intern.

- Develop and present trainings to educate students, faculty, staff, and community members on the Americans with Disabilities Act (ADA) and accommodations in higher education.

- Budgetary responsibilities and control of Student Accessibility Services, which has a budget of over $\$ 65,000$.

- Serve as the chair of the Americans with Disabilities Act (ADA) committee at St. Cloud State University and an active member working with the Convention on the Rights of Persons with Disabilities (CRPD), which is an international human rights treaty of the United Nations intended to protect the rights and dignity of people with disabilities.

\section{College of Education and Human Development, Doctoral Fellow}

August 2018 - April 2021

University of Louisville, Louisville, Kentucky

- Acted as a coordinator for the management of projects regarding the M.Ed. and Ph.D. College Student Personnel programs.

- Actively informed students of the requirements, curriculum, and the process of applying for the College Student Personnel graduate program.

- Conducted interviews and defined themes for qualitative studies on Intergenerational Mentoring.

- Met individually with current students of the M.Ed. in College Student Personnel program to ensure they felt a sense of belonging and to answer any questions they had.

- Co-taught courses titled ECPY 664-Subcultures, ECPY 660-Introduction to Student Personnel Work, and ECPY 623-Helping Skills with my supervisor, Dr. Susan Longerbeam. While doing this I used a variety of teaching methods to ensure that all students grasped the concepts in person or through virtual learning.

Disability Resource Center, Disability Resources Coordinator July 2017 — August 2018

University of Louisville, Louisville, Kentucky

- Recruited, trained, and supervised the Disability Resource Center graduate assistant and intern.

- Served on search committees where I interviewed and effectively assisted in the hiring of employees at the Disability Resource Center and the University of Louisville.

- Established an advocacy program to instill confidence in students with disabilities through mentoring and various speaking opportunities to promote diversity and inclusivity on the campus of the University of Louisville.

- Coordinated direct support services for students with physical disabilities, psychological disorders, sensory disabilities, learning disabilities, and other health impairments in the director's absence.

- Directed the supplemental note taking program for students with disabilities to utilize this accommodation.

- $\quad$ Planned the programming of the annual iCOUNT event, which raises awareness for students with disabilities, through marketing, advertising, and recruiting presenters. While in this program I helped increase our overall attendance at the event by over $280 \%$.

- Coordinated accommodations for students with Attention Deficit Hyperactivity Disorder, learning disabilities, and other comorbid disabilities.

Disability Resource Center, Note Taker Coordinator August 2016 - July 2017

University of Louisville, Louisville, Kentucky

- Recruited supplemental note takers through soliciting via email to provide notes for students with disabilities. 
- Assisted with various programs that the Disability Resource Center offered by welcoming, presenting, and engaging students to educate them on their accommodations and the resources that were available to them.

- $\quad$ Proctored exams for students with disabilities.

- Delivered completed examinations to various departments on campus.

- Assisted with the organization of the annual iCOUNT event, which raises awareness for students with disabilities, by applying my networking skills to accumulate over $\$ 500.00$ in donations from numerous restaurants.

J.B. Speed School of Engineering, Student Success Coordinator January 2017 — August 2017

University of Louisville, Louisville, Kentucky

- Developed recruitment strategies to attract "at risk" students to attend the academic preparation bridge program known as the Brown-Forman Engineering Academy.

- Supervised a team of four mentors for the Brown-Forman Engineering Academy.

- Designed and implemented assessments to critique previous programs to enhance them in the upcoming years.

- Active member of the Diversity Week team where we discussed and executed several events to showcase diversity within engineering.

- Shadowed advising appointments under seven Academic Counselors where different methods and theories were applied to assist various students.

- Advised incoming J.B. Speed School of Engineering students during their freshmen orientation.

\section{Housing and Residence Life, Community Manager}

May 2015 - May 2016

University of Louisville, Louisville, Kentucky

- Maintained high standards of customer service during high-volume, fast-paced operations.

- Communicated clearly and positively with employees as well as residents.

- Ensured that residents lived in a safe environment and were prepared for any emergency.

- Supervised ten community hall assistants in the residence hall.

- Trained Community Hall Assistants on the proper way to handle procedures and duties while on duty.

Office of Admissions, Student Orientation Staff

October

2013 - July 2015

University of Louisville, Louisville, Kentucky

- Welcomed all incoming students as well as family members to the University of Louisville and showcased the campus.

- Hosted tours through campus while answering all questions that students and parents had while providing excellent customer service.

- Connected with each individual student on a personal level and gave insight on how to be successful in college.

- Gave personal experience on problems I encountered and on those that they may potentially face while in college. Advised students on the various academic and social support resources located on campus that could help combat these conflicts.

Arts \& Science, CONECT Mentor

October 2012 - July 2015

University of Louisville, Louisville, Kentucky

- Mentored African-American students during their first year of college to prepare them to graduate in four years. 
- Informed students of resources on campus that they can go to assist them with their specific situation.

- Responsible for One-on-One Peer Mentoring, as well as hosting monthly programs \& workshops (African American Recognition Reception, Making the Connection, Keeping the Connection, etc.).

- Hosted an event titled “A Sistah's Voice” monthly which held open conversations on the problems facing the African-American community, specifically females.

\section{PRESENTATIONS}

Wright, N. L., Oliner, N., Snow, A., \& McClendon, M. (2020, March). Near Peer Mentoring in Student Affairs Preparation Programs (SAPP). Research presentation explaining findings regarding student affairs preparation programs and their impact on campus racial climate during the 2020 American College Personnel Association (ACPA) annual conference in Nashville, Tennessee.

Wright, N. L. \& Thompson, C. (2020, January). Do I Really Belong? 1-hour presentation taking a look into sense of belonging for students and professionals utilizing the seven dimensions of wellness during the 2020 College Personnel Association of Kentucky (CPAK) annual conference at Northern Kentucky University, Highland Heights, KY.

Wright, N. L. (2019, September). Diversity Dialogues: Conversation Rotation. Facilitated 90-Minute Discussion with 22 Student Affairs Professionals on how the University can Support Undocumented, LGBTQ+, Military, and Non-Traditional Students, Louisville, KY.

Wright, N. L. \& LaMarche, E. (2019, May). Diversity Den. 1-hour workshop with 31 Student Affairs Professionals During the Student Affairs Diversity Retreat, Louisville, KY.

Wright, N. L. (2018, May). Disability Advocacy 101. Trained Peer Advisors and the Student Orientation Staff Members on how to Advocate for Students with Disabilities, Louisville, KY.

Wright, N. L. (2018, February). The Impact of Micro-aggressions. 90-minute Workshop with 27 Student Affairs Professionals, Louisville, KY.

Wright, N. L., Brandewie, H., Ross, A., McKoy, C., \& Pendelton, A. (2018, January). Careers in Student Affairs. Graduate Panel in College Personnel Association of Kentucky (CPAK) 2018 Conference at Transylvania University, Lexington, KY.

Wright, N. L. (2017, February). Dealing with Disabilities as Diversity. 1-hour presentation during the 2017 Kentucky Engage Symposium, Louisville, KY.

Wright, N. L. (2016, October). Cultural Exploration, 15-minute talk during 2016 Diversity Week at the University of Louisville to approximately 75 students, Louisville, KY.

\section{PUBLICATIONS}

Wright, N. L. (2021). Chronic Codeswitching: A phenomenological study examining multiracial student sense of belonging in a predominantly White institution. Journal of College Student Development. (Submitted for Initial Review).

Longerbeam, S., Wright, N. L., Hirschy, A., Oliner, N., Johnson, V., Snow, A., \& McClendon, M. (2021). Student affairs in higher education preparation program influence on campus racial climate through near peer mentoring. Journal of College Student Development. (Submitted for Initial Review). 


\section{RESEARCH INTERESTS}

- Multiracial Students

- Sense of Belonging

- Inclusivity

- Mentoring

- Accessibility

\section{TEACHING PHILOSOPHY}

- As a professor, I have the goal of reaching every student. I believe that the "unmotivated student" is nonexistent and it is my duty to find a way to motivate them. I have the goal of continuing conversations outside of the classroom. Debates, conversations, and knowledge should not stop when students leave the classroom door. It is important that students bring the knowledge with them and continue these talks to challenge preconceived notions and ideas.

\section{PROFESSIONAL AFFILIATIONS}

\section{National}

- ACPA (American College Personnel Association) 2019-Current

- AHEAD (Association on Higher Education And Disability) 2018

- IMPACT-Service, Action, Advocacy 2017

- $\quad$ Phi Beta Sigma Fraternity, Incorporated 2015-Current

\section{Minnesota}

- MN AHEAD (Minnesota Association on Higher Education And Disability) 2021

\section{Kentucky}

- CPAK (College Personnel Association of Kentucky) 2018-Current

- KY AHEAD (Kentucky Association on Higher Education And Disability)

$$
2018
$$

\section{CAMPUS LEADERSHIP AND SERVICE Americans with Disabilities Act (ADA) Committee, Chair} 2021

St. Cloud State University

- In accordance with Section 504 of the Rehabilitation Act of 1973 and the Americans with Disabilities Act of 1990 (ADA), St. Cloud State University is committed to providing access to the programs, activities, services, and benefits of the university. As chair, I lead the institution in providing equal access with a committee of faculty and staff across campus.

\section{Convention on the Rights of Persons with Disabilities (CRPD)}

2021

St. Cloud State University 
- The Convention on the Rights of Persons with Disabilities is an international human rights treaty of the United Nations intended to protect the rights and dignity of persons with disabilities. This committee advocates for persons with disabilities, promotes change on the global level, and provides educational sessions to increase awareness.

\section{Disability Resource Center Program Review Committee}

2020

University of Louisville

- Evaluated the effectiveness and quality of the Disability Resource Center programs and services through systematic, focused, and reflective evaluations. Program review has been designed to follow CAS Professional Standards for Higher Education.

\section{Student Affairs Diversity Committee 2018-Current}

University of Louisville

- Strives to support the Division of Student Affairs in its efforts to promote inclusiveness, embrace diversity, and foster an environment for student success.

\section{Disability Resource Center Hiring Committee 2018}

University of Louisville

- Served on two hiring committees for the Disability Resource Center to hire two Disability

Resources Coordinators while I was working for the College of Education and Human

Development.

\section{HONORS AND AWARDS \\ Faculty Favorite Nomination \\ 2019 \& 2020}

- Nominated by students as the University of Louisville faculty member they would like to recognize for making a significant impact on their learning and intellectual development.

\section{Outstanding ACPA Chapter Award}

$$
2019
$$

- CPAK, the College Personnel Association of Kentucky, was selected as the Outstanding ACPA chapter of 2019 due to the accomplishments in fundraising, involvement, and leadership that our chapter achieved.

\section{Outstanding Student in College Student Personnel, University of Louisville 2018}

- Selected as an Outstanding Student by the faculty members in the College of Education and Human Development.

\section{Dean's Citation, University of Louisville 2018}

- In recognition of superior accomplishments in my graduate studies beyond the achievement of a high grade point average.

\section{Cum Laude, University of Louisville \\ 2016}


- Graduated from the University of Louisville with honors by obtaining a GPA of 3.51 on a 4.0 scale.

\section{C.O.N.E.C.T. Mentor of the Year} 2015

- Voted as the most impactful mentor of the year by the C.O.N.E.C.T. mentor staff for building strong relationships through adversity.

\section{Woodford R. Porter Scholar}

2012-2016

- $\quad$ Received the Woodford R. Porter Scholarship as an incoming first year student for having a high GPA and involvement while in secondary education. Met requirements to maintain this scholarship throughout my time as an undergraduate student. 